Aus der Klinik für Allgemein-, Viszeral- und Kinderchirurgie

(Prof. Dr. med. B. M. Ghadimi)

der Medizinischen Fakultät der Universität Göttingen

\title{
Das Antihelminthikum Niclosamid inhibiert das Wachstum kolorektaler Karzinomzelllinien durch Modulation des kanonischen und des nicht-kanonischen Wnt-Signalweges
}

\author{
INAUGURAL-DISSERTATION \\ zur Erlangung des Doktorgrades \\ der Medizinischen Fakultät der \\ Georg-August-Universität zu Göttingen
}

vorgelegt von

Malte Benedikt Monin

aus

Detmold

Göttingen 2015 


\section{Dekan:}

I. Berichterstatter:

II. Berichterstatter:

III. Berichterstatter:
Prof. Dr. rer. nat. H. K. Kroemer

Prof. Dr. med. S. König

Prof. Dr. med. G. Wulf

Tag der mündlichen Prüfung: 10. Februar 2016 


\section{Inhaltsverzeichnis}

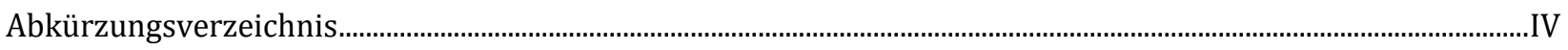

Abbildungsverzeichnis .................................................................................................................................................... VII

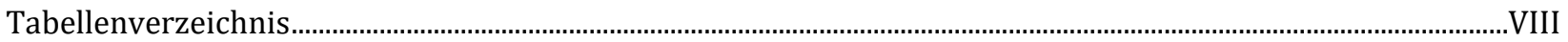

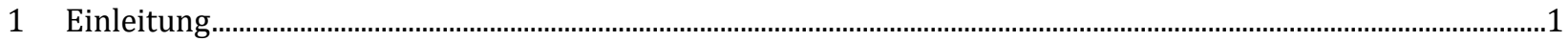

1.1 Das kolorektale Karzinom des Menschen................................................................................................................

1.2 Genetisches Stufenmodell der kolorektalen Karzinogenese...................................................................................2

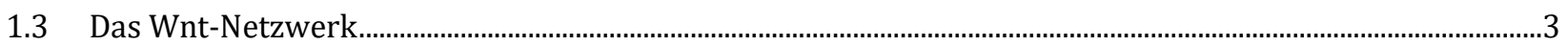

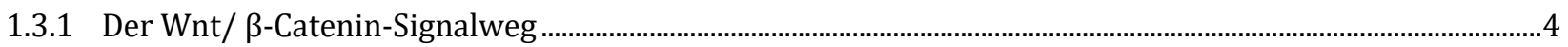

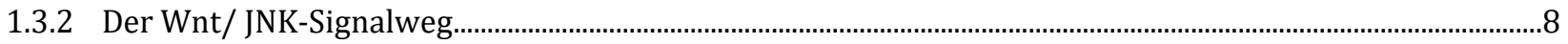

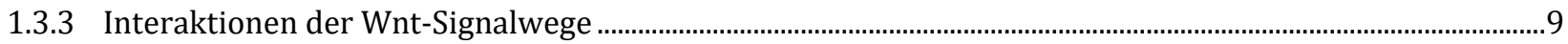

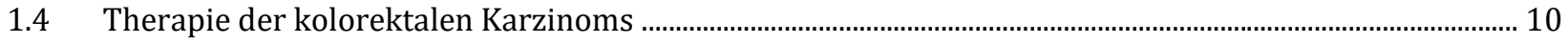

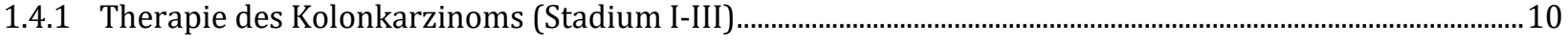

1.4.2 Therapie des Rektumkarzinoms (Stadium I-III) ............................................................................................

1.4.3 Therapie des metastasierten kolorektalen Karzinoms (Stadium IV) ................................................................11

1.4.4 Experimentelle molekulare Therapieansätze zur Modulation des Wnt-Netzwerkes im kolorektalen

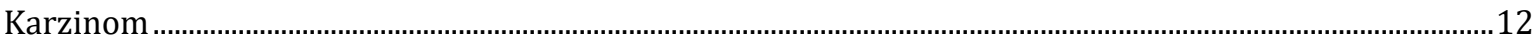

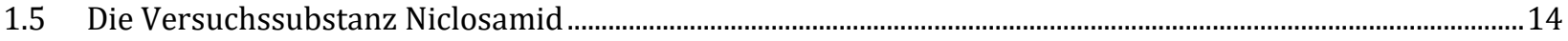

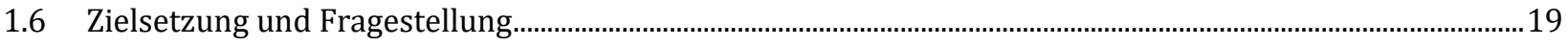

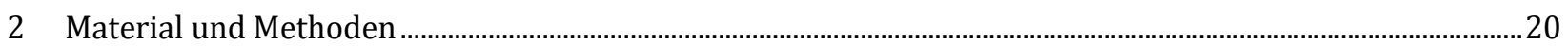

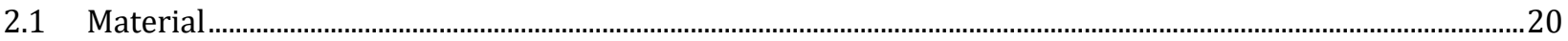

2.1 .1 Geräte

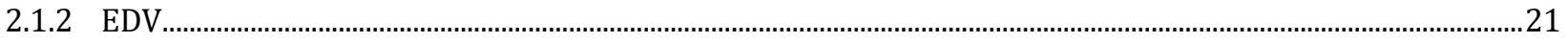

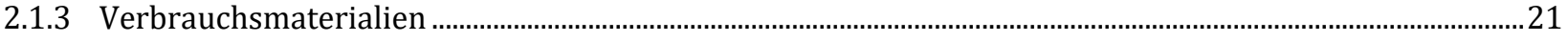

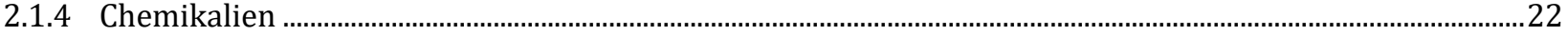

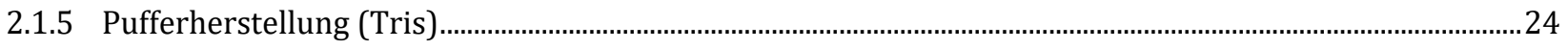

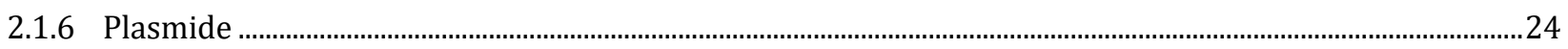

2.1 .7 Enzyme

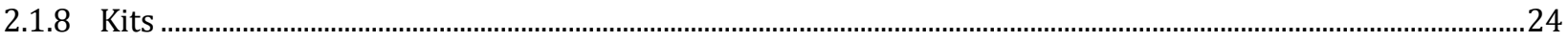

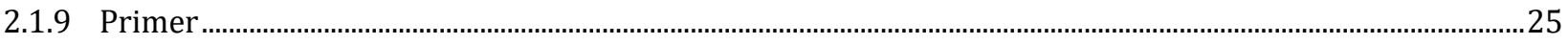

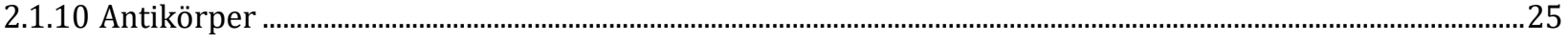

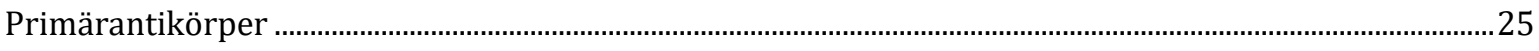

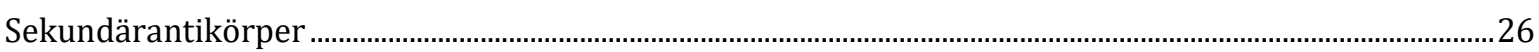

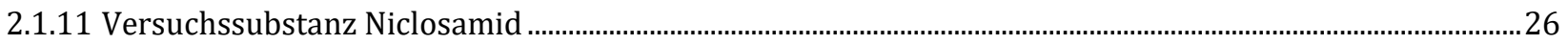

2.1.12 Kolorektale Karzinomzelllinien ..........................................................................................................................27

2.1.13 Medien für die Zellkultur ...............................................................................................................................2

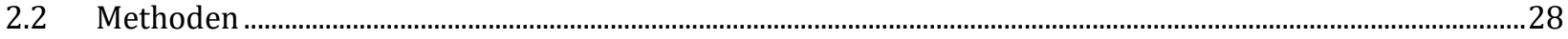




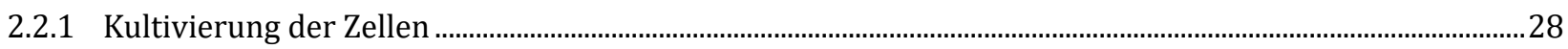

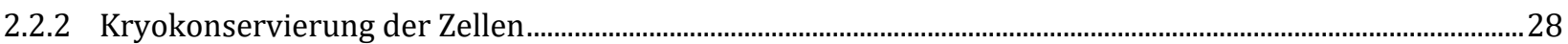

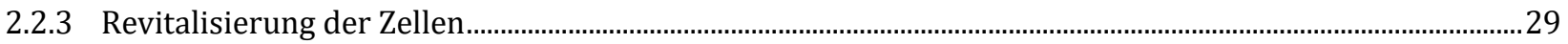

2.2.4 Isolation von Fibroblasten..............................................................................................................................29

2.2.5 Immunhistochemischer Nachweis von Fibroblasten .......................................................................................29

Kultivierung und Fixation auf Chamber Slides..........................................................................................................29

Immunhistochemischer Nachweis von Vimentin in primären Zellen ..............................................................30

2.2.6 Wachstum und Zytotoxizität nach Inkubation mit Niclosamid ............................................................................ 30

Kultivierung für 24 Stunden und 12 Stunden........................................................................................................30

Zellzahlbestimmung mit Neubauer-Zählkammer .................................................................................................... 31

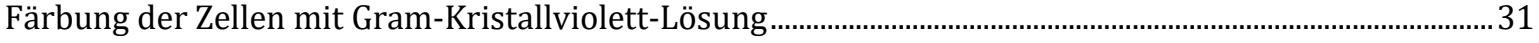

Durchflusszytometrische Analyse nach Annexin-V-Fluos - / Propidiumiodid - Doppelfärbung ............... 32

2.2.7 TOPflash/ FOPflash Dual-Luciferase ${ }^{\circledR}$ Reporter Assay.............................................................................................33

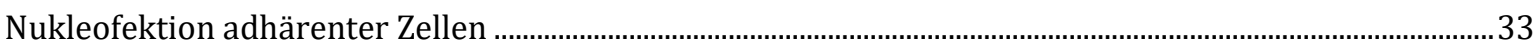

Dual-Luciferase ${ }^{\circledR}$ Reporter Assay ........................................................................................................................... 34

2.2.8 Real-time Reverse Transcription-Polymerase Chain Reaction (RT-PCR) .......................................................35

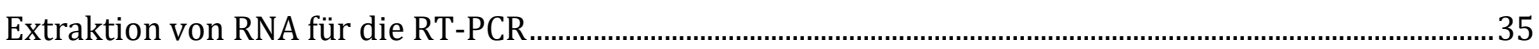

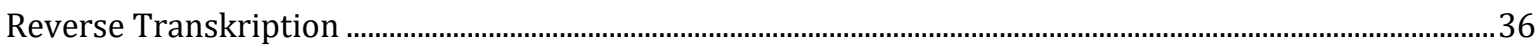

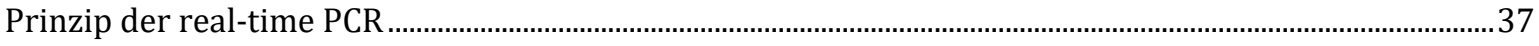

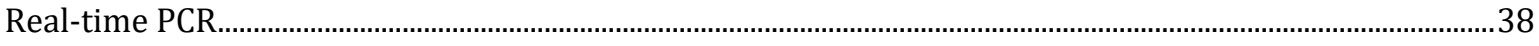

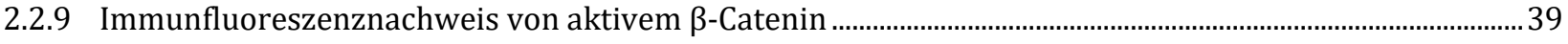

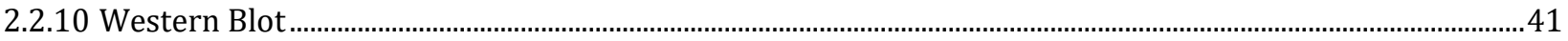

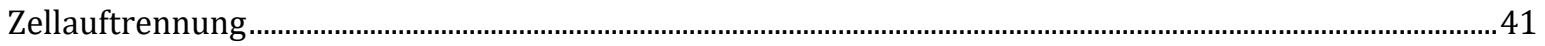

SDS-Polyacrylamidgel-Elektrophorese

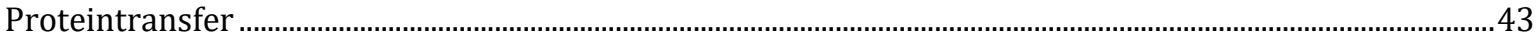

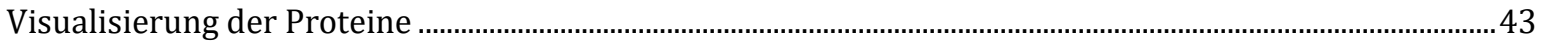

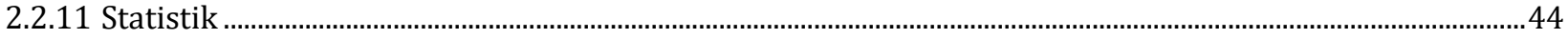

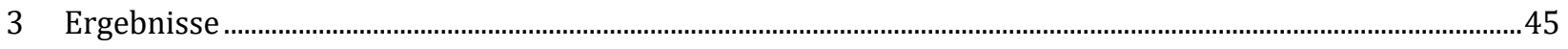

3.1 Wachstum und Zytotoxizität nach Inkubation mit Niclosamid ........................................................................... 45

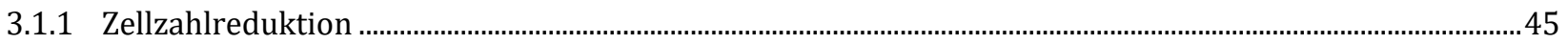

3.1.2 Effektivität des Niclosamids unter Betrachtung des APC- respektive $\beta$-Catenin-Mutationsstatus ............ 48

3.1.3 Morphologische Veränderungen der Zellen ...........................................................................................................49

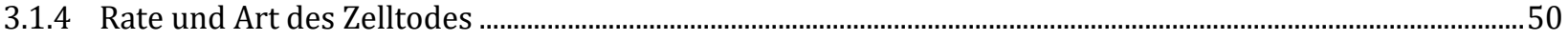

3.2 Wirkung von Niclosamid auf das Wnt-Netzwerk ..................................................................................................54

3.2.1 Effekt des Niclosamids auf den kanonischen Wnt-Signalweg ............................................................................ 54

Aktivität des kanonischen Wnt-Signalweges (TOPflash/ FOPflash) ………......................................................5 54

Analyse kanonischer Wnt-Komponenten auf Transkriptionsebene ....................................................................5 
Analyse von aktivem $\beta$-Catenin fluoreszenzmikroskopisch und auf Proteinebene . .60

3.2.2 Effekt des Niclosamids auf den nicht-kanonischen Wnt/ JNK-Signalweg

3.3 Immunhistochemischer Nachweis von Fibroblasten........................................................................................... 64

4 Diskussion ..........................................................................................................................................................65

4.1 Therapeutischer Bereich des Niclosamids nach 24 und 12 Stunden Inkubation..........................................65

4.2 Unabhängigkeit der Niclosamid-Effektivität vom Mutationsstatus kolorektaler Karzinomzellen................67

4.3 Apoptose- und Nekroseinduktion in kolorektalen Karzinomzellen nach Inkubation mit Niclosamid ........68

4.4 Interaktion von Niclosamid mit dem Wnt-Netzwerk .............................................................................................70

4.4.1 Inhibierung des kanonischen Wnt-Signalweges durch Niclosamid.................................................................. 70

Reduktion der relativen Wnt-Aktivität nach Inkubation mit Niclosamid ............................................................. 70

Reduzierte Transkription kanonischer Wnt-Zielgene nach Inkubation mit Niclosamid .............................. 71

Unabhängigkeit des Niclosamid-Wirkmechanismus vom zytosolischen $\beta$-Catenin-

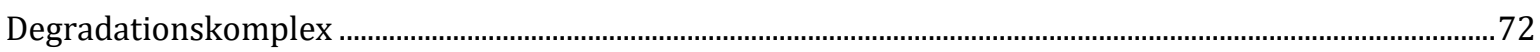

Unabhängigkeit des Niclosamid-Wirkmechanismus vom aktiven unphosphorylierten $\beta$-Catenin ........... 72

Blockierung kanonischer Wnt-Koaktivatoren und Aktivierung kanonischer Wnt-Inihibitoren durch

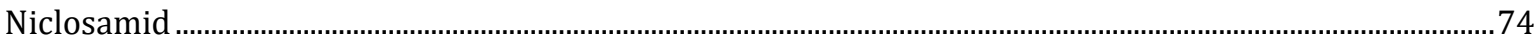

4.4.2 Aktivierung des nicht-kanonischen Wnt/ JNK-Signalweges ............................................................................. 76

4.5 Ausblick ............................................................................................................................................................78

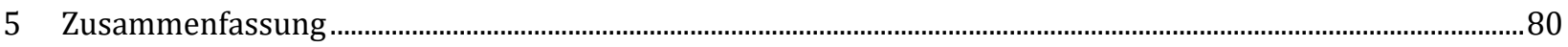

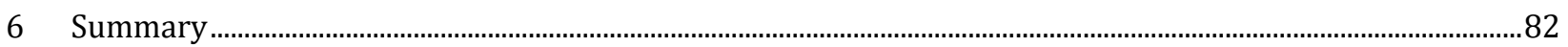

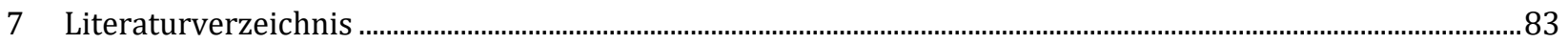

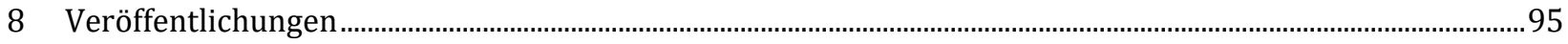




\section{Abkürzungsverzeichnis}

\begin{tabular}{|c|c|}
\hline$\mu \mathrm{l}$ & Mikroliter \\
\hline$\mu \mathrm{M}$ & mikromolar \\
\hline 5 -FU & 5-Fluoruracil (Chemotherapeutikum) \\
\hline A & Ampere \\
\hline Abb. & Abbildung \\
\hline $\mathrm{ABC}$ & active $\beta$-catenin (aktives $\beta$-Catenin) \\
\hline AEC & 2-Amino-9-Ethylcarbazol \\
\hline AML & akute myeloische Leukämie \\
\hline AP-1 & activator protein 1 (AP-1-Transkirptionsfaktor) \\
\hline APC & adenomatöses-Polyposis-coli-Protein \\
\hline APS & Adenosinphosphosulfat \\
\hline \multirow[t]{2}{*}{ AWMF } & Arbeitsgemeinschaft der Wissenschaftlichen Medizinischen \\
\hline & Fachgesellschaften e.V. \\
\hline $\mathrm{Bcl}$ & B-cell-lymphoma (Bcl-Protein) \\
\hline bidest. & bidestilliert \\
\hline BSA & bovines Serumalbumin \\
\hline cDNA & $\begin{array}{l}\text { complementary deoxyribonucleic acid (komplementäre Desoxyribonuklein- } \\
\text { säure) }\end{array}$ \\
\hline $\mathrm{CK}$ & Casein-Kinase \\
\hline CML & chronisch myeloische Leukämie \\
\hline CtBP & C terminal binding protein (CtBP-Protein) \\
\hline DAAM & dishevelled associated activator of morphogenesis (DAAM-Protein) \\
\hline DAPI & 4',6-Diamidin-2-phenylindol \\
\hline DMEM & Dulbecco's modified eagle medium (DMEM-Zellkulturmedium) \\
\hline DMSO & Dimethylsulfoxid \\
\hline DNA & deoxyribonucleic acid (Desoxyribonukleinsäure) \\
\hline DTT & Dithiothreitol \\
\hline Dvl & Dishevelled-Protein \\
\hline EDTA & Ethylendiamintetraessigsäure \\
\hline EGFR & $\begin{array}{l}\text { endothelial growth factor receptor (Rezeptor des endothelialen Wachstums- } \\
\text { faktors) }\end{array}$ \\
\hline FACS & fluorescence-activated cell sorting (Durchflusszytometrie) \\
\hline FAP & familiäre adenomatöse Polyposis coli \\
\hline FCS & fetal calf serum (fetales Kälberserum) \\
\hline $\mathrm{Fz}$ & Frizzled-Protein \\
\hline gDNA & genomic deoxyribonucleic acid (genomische Desoxyribonukleinsäure) \\
\hline
\end{tabular}




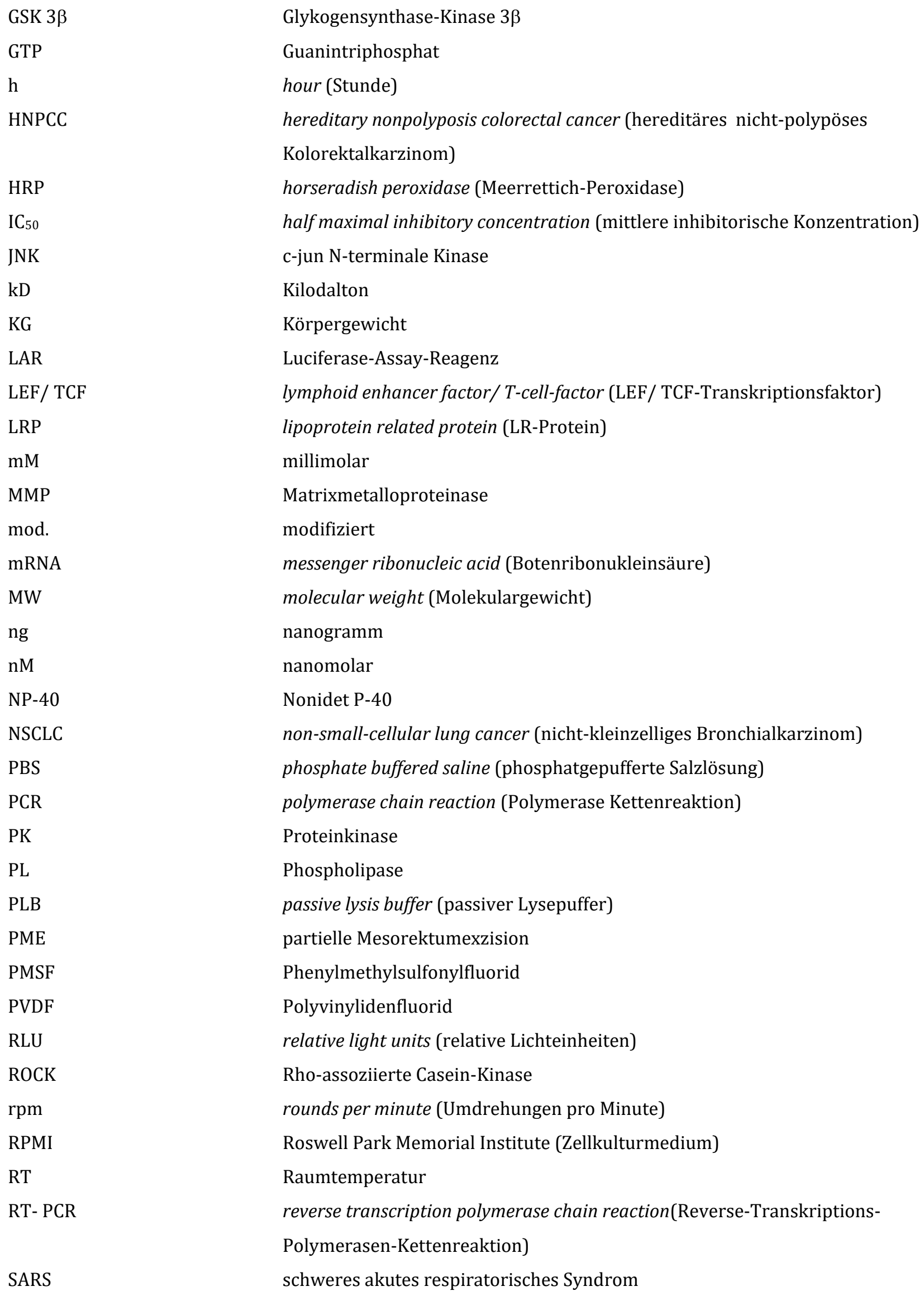

Guanintriphosphat

hour (Stunde)

hereditary nonpolyposis colorectal cancer (hereditäres nicht-polypöses

Kolorektalkarzinom)

horseradish peroxidase (Meerrettich-Peroxidase)

half maximal inhibitory concentration (mittlere inhibitorische Konzentration)

c-jun N-terminale Kinase

Kilodalton

Körpergewicht

Luciferase-Assay-Reagenz

lymphoid enhancer factor/ T-cell-factor (LEF/ TCF-Transkriptionsfaktor)

lipoprotein related protein (LR-Protein)

millimolar

Matrixmetalloproteinase

modifiziert

messenger ribonucleic acid (Botenribonukleinsäure)

molecular weight (Molekulargewicht)

nanogramm

nanomolar

Nonidet P-40

non-small-cellular lung cancer (nicht-kleinzelliges Bronchialkarzinom)

phosphate buffered saline (phosphatgepufferte Salzlösung)

polymerase chain reaction (Polymerase Kettenreaktion)

Proteinkinase

Phospholipase

passive lysis buffer (passiver Lysepuffer)

partielle Mesorektumexzision

Phenylmethylsulfonylfluorid

Polyvinylidenfluorid

relative light units (relative Lichteinheiten)

Rho-assoziierte Casein-Kinase

rounds per minute (Umdrehungen pro Minute)

Roswell Park Memorial Institute (Zellkulturmedium)

Raumtemperatur

reverse transcription polymerase chain reaction(Reverse-Transkriptions-

Polymerasen-Kettenreaktion)

schweres akutes respiratorisches Syndrom 
SCCHN

SDS

Ser

SFRP

TRS

TBST

TGEV

Thr

TME

TMED

UICC

VEGF

Wif

$\mathrm{xg}$ squamous cell carcinoma of the head and neck (Kopf- und Halstumoren)

sodium dodecyl sulfate (Natriumdodecylsulfat)

Serin (Aminosäure)

secreted Frizzled-related proteins (SFR-Proteine)

target retrieval solution

Tris-buffered saline + Tween (Tris-gepufferte Base + Tween)

transmissibler-Gastroenteritis-Virus

Threonin (Aminosäure)

totale Mesorektumexzision

Tetramethylethylendiamin

Union internationale contre le cancer (Internationale Vereinigung gegen

Krebs)

Vascular Endothelial Grwoth Factor (vaskulär-endothelialer

Wachstumsfaktor)

Wnt-inhibitory factors (WI-Faktoren)

multipliziert mit Gravidität (Erdanziehungskraft) 


\section{Abbildungsverzeichnis}

Abbildung 1: Genetisches Stufenmodell der kolorektalen Karzinogenese ............................................................... 2

Abbildung 2: $\quad$ Der kanonische Wnt/ $\beta$-Catenin-Signalweg …...................................................................................... 4

Abbildung 3: Der nicht-kanonische Wnt/ JNK-Signalweg ………......................................................................... 8

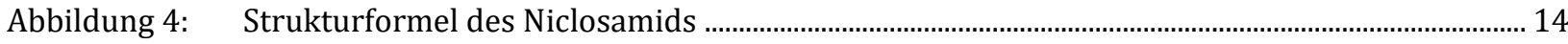

Abbildung 5: $\quad$ Relative Zellzahlreduktion nach Inkubation mit Niclosamid ......................................................... 45

Abbildung 6: Zelldichte und -morphologie nach Inkubation mit Niclosamid ....................................................... 49

Abbildung 7: $\quad$ Apoptose- und Nekroseraten nach Inkubation mit Niclosamid .......................................................... 51

Abbildung 8: $\quad$ Relative Wnt-Aktivität nach Inkubation mit Niclosamid ......................................................................... 54

Abbildung 9: Relative transkriptionelle Expression kanonischer Wnt-Komponenten nach Inkubation mit

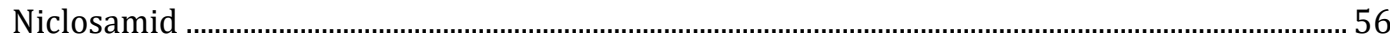

Abbildung 10: Analyse der Expression von aktivem $\beta$-Catenin (ABC) nach Inkubation mit Niclosamid ........ 60

Abbildung 11: Analyse der Expression von c-jun nach Inkubation mit Niclosamid ................................................ 62

Abbildung 12: Vimentin-Expression in primären Fibroblasten .................................................................................. 63

Abbildung 13: Inhibierung des kanonischen Wnt-Signalweges durch Niclosamid ................................................ 73

Abbildung 14: Aktivierung des nicht-kanonischen Wnt/ JNK-Signalweges durch Niclosamid ........................... 75 


\section{Tabellenverzeichnis}

Tabelle 1: $\quad$ Stadieneinteilung kolorektaler Karzinome nach UICC …………......................................................... 10

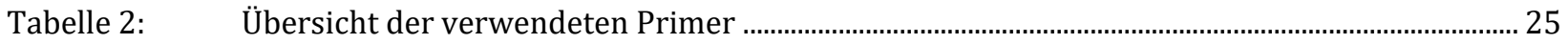

Tabelle 3: $\quad$ Übersicht der verwendeten Primärantikörper ......................................................................................... 25

Tabelle 4: $\quad$ Übersicht der verwendeten Sekundärantikörper .......................................................................... 26

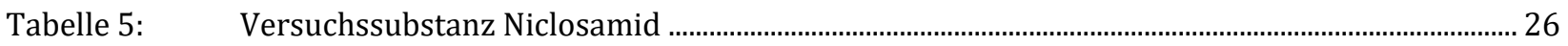

Tabelle 6: $\quad$ Übersicht der verwendeten Zelllinien ....................................................................................................... 27

Tabelle 7: $\quad$ Färbeprotokoll zum Nachweis von Vimentin ...................................................................................... 30

Tabelle 8: $\quad$ Pipettierschema für Niclosamid-Inkubation …………………………………………………….... 31

Tabelle 9: $\quad$ Färbeprotokoll nativer Zellen mit Kristallviolett-Lösung ………....................................................... 32

Tabelle 10: Pipettierschema zur Herstellung der Annexin-V-Fluos-Markierungslösung ................................. 32

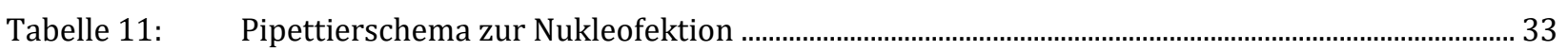

Tabelle 12: $\quad$ Pipettierschema zum Dual-Luciferase ${ }^{\circledR}$ Reporter Assay .................................................................. 34

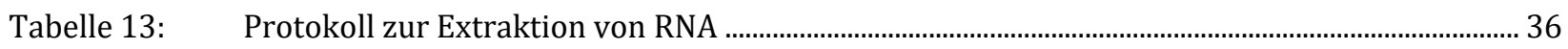

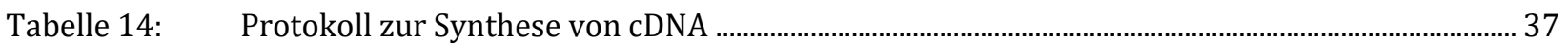

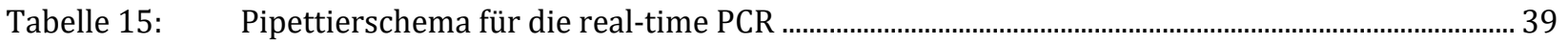

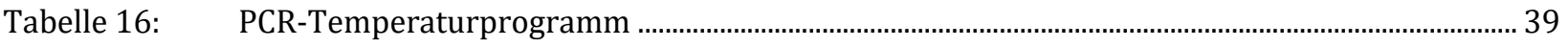

Tabelle 17: $\quad$ Färbeprotokoll zum Nachweis von aktivem $\beta$-Catenin .......................................................................... 40

Tabelle 18: Pipettierschema zur Zellauftrennung für Western Blot ................................................................... 40

Tabelle 19: $\quad$ Protokoll zur Zelllyse für Western Blot .................................................................................................. 41

Tabelle 20: $\quad$ Pipettierschema zur Herstellung der Western Blot-Gele .................................................................... 41

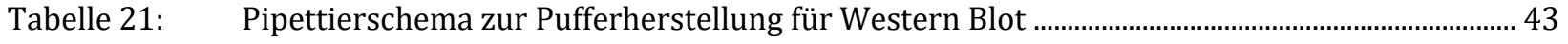

Tabelle 22: $\quad$ Vergleich des Mutationsstatus mit der Proliferationshemmung durch Niclosamid ................... 48 


\section{$1 \quad$ Einleitung}

\subsection{Das kolorektale Karzinom des Menschen}

Das kolorektale Karzinom hat geschlechtsunabhängig hinter dem Prostatakarzinom des Mannes und dem Mammakarzinom der Frau die zweithäufigste Inzidenz unter den malignen Tumorerkrankungen in Deutschland. Dabei nimmt das Erkrankungsrisiko mit zunehmendem Alter erheblich zu. Als Risikofaktoren wurden neben dem Alter, wobei Personen ab 50 Jahre als gefährdet gelten, ballaststoffarme ( $<30$ g Ballaststoffe pro Tag) fettreiche Ernährung mit übermäßigem Anteil an rotem beziehungsweise verarbeitetem Fleisch, körperliche Inaktivität, Übergewicht (ab einem BMI von $>25 \mathrm{~kg} / \mathrm{m}^{2}$ ) sowie chronischer Tabak- und Alkoholkonsum identifiziert. Außerdem erkranken Verwandte ersten Grades eines Patienten mit kolorektalem Karzinom überdurchschnittlich häufiger (Robert KOCH-Institut 2012, American Cancer Society 2011, Leitlinie Kolorektales Karzinom 2014).

Im Jahr 2008 waren 11,8 respektive 13 \% der Krebstodesursachen des Mannes respektive der Frau auf kolorektale Karzinome zurückzuführen. Damit sind beim Mann nur die Karzinome der Lunge und bei der Frau die Karzinome der Mamma für prozentual mehr Krebstodesfälle verantwortlich (Robert KOCH-Institut 2012). Für die Prognose und das Überleben der Patienten ist vor allem die hämatogene Metastasierung über die Pfortader in die Leber entscheidend. Die Zahl der Patienten, die bei Diagnosestellung synchrone Metastasen aufweisen, liegt zwischen 15 und $20 \%$. Innerhalb von 2 Jahren nach Diagnosestellung entwickeln weitere $25 \%$ hepatische Metastasen (LEPORRIER et al. 2006). Zusammengenommen werden also etwa $40 \%$ aller Patienten mit einer Lebermetastasierung konfrontiert. Ist die operative Entfernung der Lebermetastasen möglich, liegt die 5-Jahres-Überlebensrate lediglich zwischen 30 und 45 \% (FONG et al. 1997, LEPORRIER et al. 2006, CUMMINGS et al. 2007, ANDRES et al. 2012, CARDONA et al. 2013).

Zu 85 \% entsteht der überwiegende Teil der kolorektalen Karzinome sporadisch. Weitere $10 \%$ sind mit vererbbaren Syndromen wie dem hereditären nicht-polypösen Kolorektalkarzinom (HNPCC) oder der familiären adenomatösen Polyposis coli (FAP) assoziiert. Schließlich entwickeln sich $5 \%$ der Karzinome auf dem Boden chronischentzündlicher Darmerkrankungen wie dem Morbus Crohn oder der Colitis ulcerosa (WEITZ 
et al. 2003). Unabhängig von der Pathogenese geht das kolorektale Karzinom annäherungsweise immer aus benignen Adenomen hervor. Aufgrund dieser Beobachtung prägten JACKMAN und MAYO (1951) den Begriff der Adenom-Karzinom-Sequenz. Der Entwicklungsprozess vom normalen Epithel über dysplastisches Epithel und dem Adenom zum malignen Karzinom erstreckt sich im Mittel über einen Zeitraum von zehn Jahren (MUTO et al. 1975).

\subsection{Genetisches Stufenmodell der kolorektalen Karzinogenese}

Im Einklang zur Adenom-Karzinom-Sequenz entwickelten FEARON und VOGELSTEIN ein genetisches Stufenmodell der kolorektalen Karzinogenese (VOGELSTEIN et al. 1988, FEARON \& VOGELSTEIN 1990, FEARON 2011). Verschiedene Aktivierungen von Protoonkogenen und Inaktivierungen von Tumorsuppressorgenen sind hierbei obligat (vgl. Abbildung 1).

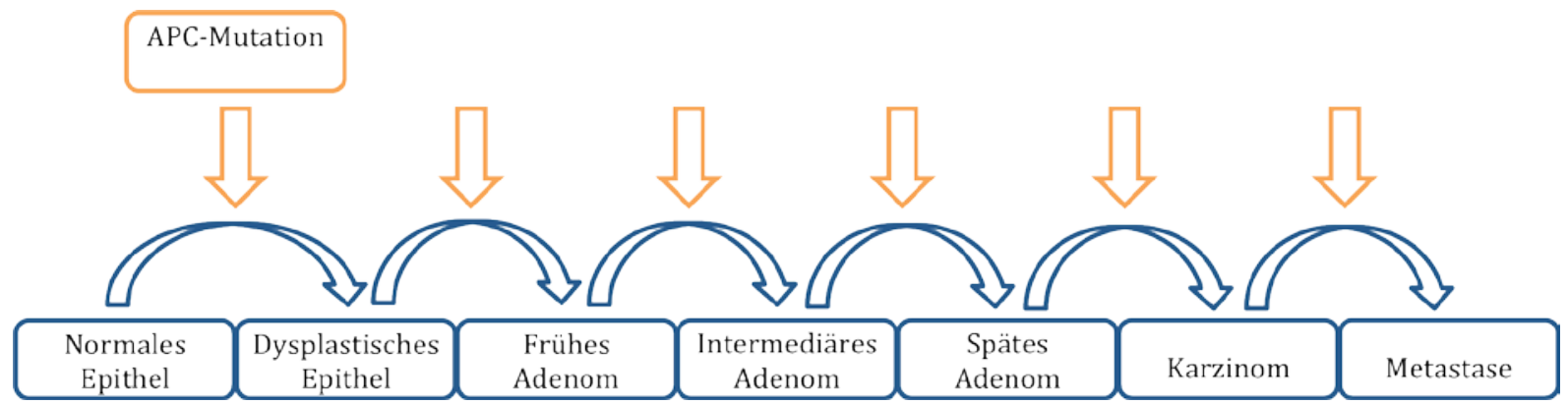

Abbildung 1: Genetisches Stufenmodell der kolorektalen Karzinogenese (mod. nach KINZLER \& VOGELSTEIN 1996). Neoplastischer Prozess im Kolon und Rektum durch konstitutiv aktivierende Mutationen von APC initiiert. Progression von dysplastischem Epithel über das Adenom zum Karzinom ggf. mit Metastasierung durch weitere variable Mutationen.

Mutationen des Tumorsupressorgens APC (adenomatöses-Polyposis-coli-Protein) sind bereits in 70 bis $85 \%$ der ersten dysplastischen Läsionen des kolorektalen Epithels und kleinsten Adenomen mit einem Durchmesser von 0,5 cm nachweisbar (POWELL et al. 1992, JEN et al. 1994, FEARON 2011). Auf Basis dieser Erkenntnis wurde das APC-Gen zum gatekeeper des Kolonepithels erhoben (KINZLER \& VOGELSTEIN 1996). Durch Mutationen dieses gatekeepers kommt es zur übermäßig stimulierten Proliferation des Epithels, wodurch der neoplastische Entwicklungsprozess initiiert wird. Zumindest sechs weitere variable 
Aktivierungen von Protoonkogenen und Inaktivierungen von Tumorsuppressorgenen tragen dann zur Tumorprogression bei (KINZLER \& VOGELSTEIN 1996).

Ursprünglich wurden Mutationen des auf Chromosom 5q21 lokalisierten APC-Gens als ursächlich für die dominant vererbbare FAP identifiziert (KINZLER et al. 1991, NISHISHO et al. 1991). Es konnte gezeigt werden, dass mehr als 85 \% der Patienten, die an FAP erkrankt sind, Keimbahnmutationen im APC-Gen aufweisen (POWELL et al. 1993). Bei Untersuchungen, die Gemeinsamkeiten zwischen den heriditär-bedingten und den sporadischen kolorektalen Karzinomen aufdecken sollten, konnte belegt werden, dass somatische Mutationen im APC-Gen in mehr als $80 \%$ der sporadischen kolorektalen Adenome und Karzinome nachweisbar sind (SMITH et al. 1992, JEN et al. 1994).

Für das kolorektale Karzinom ist vor allem die Funktion des APC-Proteins innerhalb des kanonischen Wnt-Signalweges von zentraler Bedeutung. Posttranslational reguliert APC hier die Menge des aktiven $\beta$-Catenins (RUBINFELD et al. 1993, SU et al. 1993, MUNEMITSU et al. 1995, KORINEK et al. 1997). Kolorektale Karzinome, die keine APC-Mutation tragen, weisen zu über $50 \%$ eine aktivierende Mutation des Protoonkogens und Schlüsselproteins des kanonischen Wnt-Signalweges $\beta$-Catenin auf (MORIN et al. 1997). Außerdem wurden bei etwa einem Viertel der betroffenen Patienten ohne APC-Mutation eine Mutation des Tumorsuppressors Axin2 beschrieben (LIU et al. 2000, LAMMI et al. 2004). Der kanonische WntSignalweg wird durch die beschriebenen Mutationen jeweils konstitutiv aktiviert und nimmt somit eine exponierte Stellung für die kolorektale Karzinogenese ein (CANCER GENOME ATLAS NETWORK 2012).

\subsection{Das Wnt-Netzwerk}

Die Wnt-Signalwege sind speziesunabhängig hochgradig konserviert. Sie sind sowohl in physiologische Prozesse wie die Embryonalentwicklung und die Gewebe- und Stammzellhomöostase als auch in Prozesse der Pathogenese karzinomatöser und degenerativer Erkrankungen involviert. Mittlerweile sind 19 humane Wnt-Gene identifiziert worden, die für unterschiedliche hydrophobe palmitolierte Cystein-reiche WntGlykoproteine kodieren (The Wnt Homepage http://web.stanford.edu/group/nusselab/cgibin/wnt/human). Über die 10 humanen Rezeptoren der Frizzled-Familie wird das Wnt-Signal nach intrazellulär weitergeleitet (The Wnt Homepage http://web.stanford.edu/group/nusselab/cgi- 
bin/wnt/Frizzled vertebrate). Klassischerweise wird zwischen dem kanonischen $\beta$-Cateninabhängigen Wnt-Signalweg (Wnt/ $\beta$-Catenin-Signalweg) und den nicht-kanonischen $\beta$-Catenin-unabhängigen Wnt-Signalwegen (Wnt/ JNK-Signalweg und Wnt/ $\mathrm{Ca}^{2+}$ Signalweg) unterschieden. Sowohl der kanonische Wnt/ $\beta$-Catenin-Signalweg als auch der nicht-kanonische Wnt/ JNK-Signalweg sind Gegenstand dieser Arbeit. Die beiden Signalkaskaden werden im Folgenden erläutert.

\subsubsection{Der Wnt/ $\beta$-Catenin-Signalweg}

Das sogenannte kanonische Wnt-Signal schützt $\beta$-Catenin vor der Phosphorylierung. Dadurch verbleibt $\beta$-Catenin in seinem aktiven Zustand, entgeht dem proteasomalen Abbau, wird in den Zellkern transloziert und initiiert dort die Transkription kanonischer WntZielgene. Viele molekulare Details der kanonischen Wnt-Signalkaskade sind bislang noch nicht vollständig aufgeschlüsselt. Die gesicherten Erkenntnisse sind in Abbildung 2 dargestellt und werden im Folgenden zusammengefasst (LOGAN \& NUSSE 2004, TOLWINSKI \& WIESCHAUS 2004, NUSSE 2005, CLEVERS 2006).

\section{a) Inaktiver Zustand}

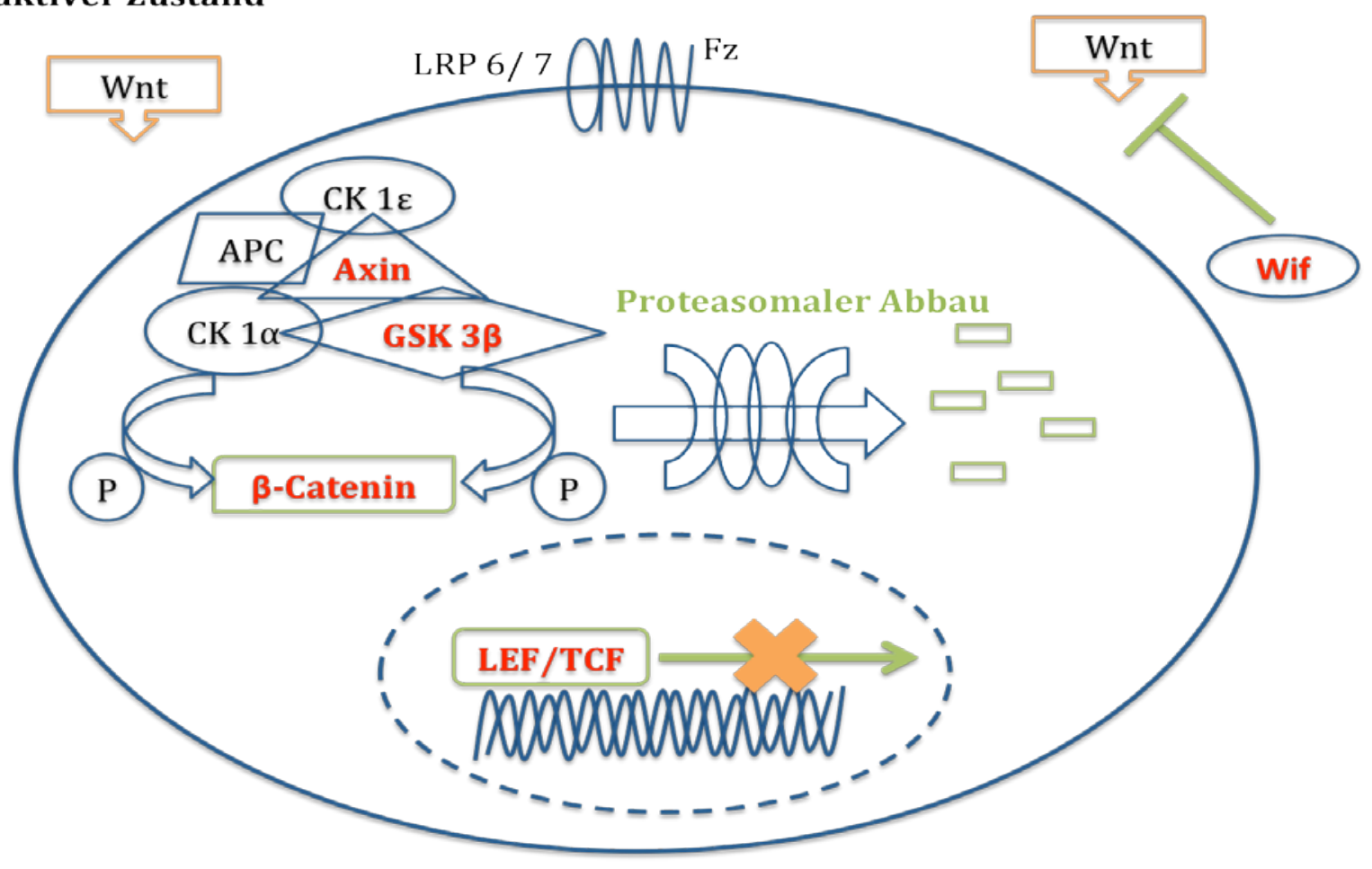




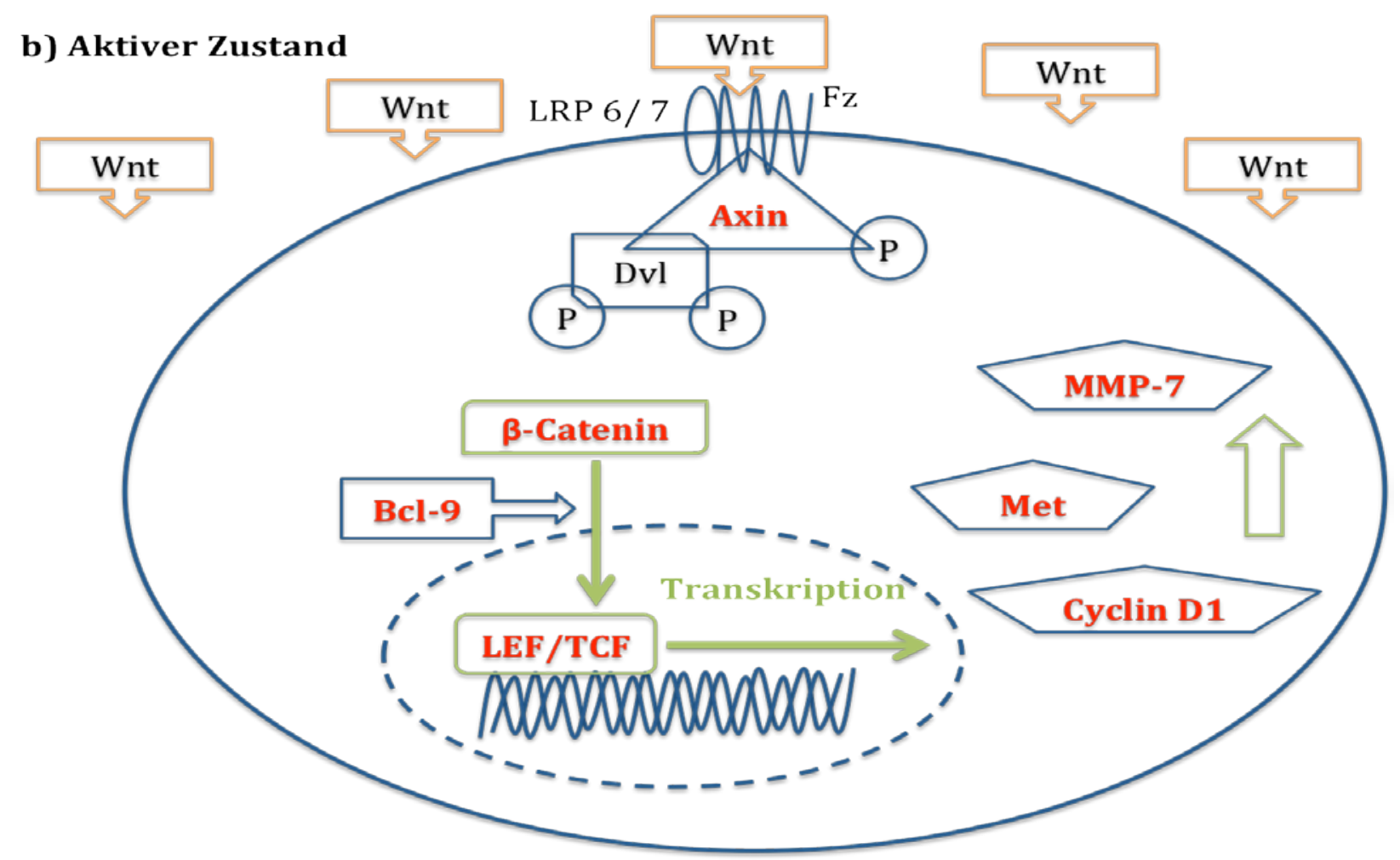

Abbildung 2: Der kanonische Wnt/ $\beta$-Catenin-Signalweg. a) Inaktiver Zustand: Durch Ausbleiben der Wnt-Stimulation wird $\beta$-Catenin durch den Degradationskomplex phosphoryliert, dadurch inaktiviert und schlussendlich proteasomal degradiert. b) Aktiver Zustand: Das Wnt-Protein bindet an seine Rezeptoren und hemmt intrazellulär den zytosolischen Degradationskomplex. $\beta$-Catenin verbleibt in seinem aktiven Zustand und bildet einen nukleären Triple-Komplex mit LEF/ TCF und Bcl-9. Dadurch wird die Transkription kanonischer Wnt-Zielgene initiiert. Die rot hervorgehobenen Komponenten sind Gegenstand der vorliegenden Arbeit.

Im physiologischen Ruhezustand wird durch geringe Spiegel an Wnt-Proteinen das kontinuierlich translatierte $\beta$-Catenin umgehend durch Phosphorylierung degradiert und anschließend proteasomal abgebaut. Die Phosphorylierung erfolgt durch den zytosolischen Degradationskomplex (KIMELMAN \& XU 2006, STAMOS \& WEIS 2012). Das Protein Axin bildet das Gerüst des Degradationskomplexes (IKEDA et al. 1998). Genau wie Axin hat auch der Tumorsuppressor adenomatöses-Polyposis-coli-Protein (APC) Bindungsstellen für $\beta$ Catenin (EKLOF SPINK et al. 2001). Die exakte Funktion von APC ist bisher nicht geklärt. Bekannt ist aber, dass APC nach Bindung von $\beta$-Catenin an den Degradationskomplex durch die Casein-Kinase $1 \varepsilon$ (CK $1 \varepsilon$ ) und die Glykogensynthase-Kinase $3 \beta$ (GSK $3 \beta$ ) phosphoryliert 
wird. Hierdurch wird die Affinität für $\beta$-Catenin gesteigert (HA et al. 2004, XING et al. 2004). Gebundenes $\beta$-Catenin wird initial durch die Casein-Kinase $1 \alpha$ (CK $1 \alpha)$ an einem Serin-Rest (Ser45) seines N-terminalen Endes phosphoryliert. Dieser erste Schritt wird als Priming für die GSK $3 \beta$ angenommen, damit diese $\beta$-Catenin an weiteren $\mathrm{N}$-terminalen Serin- und Threonin-Resten (Ser22, Ser37 und Thr41) phosphorylieren kann (YOST et al. 1996, AMIT et al. 2002, LIU et al. 2002, YANAGAWA et al. 2002). Axin wiederum hat einen stimulierenden Effekt auf die GSK $3 \beta$, wodurch die Phosphorylierung des $\beta$-Catenins um mehr als das 20.000-Fache gesteigert wird (DAJANI et al. 2003). Durch die sequentielle N-terminale Phosphorylierung wird die Polyubiquitinierung des $\beta$-Catenins durch die SCF${ }^{\beta}$-TrCP1-Ubiquitin-Ligase ermöglicht; dadurch kann $\beta$-Catenin in den Proteasomen schlussendlich abgebaut werden (ABERLE et al. 1997, HART et al. 1999, KITAGAWA et al. 1999, LATRES et al. 1999, WINSTON et al. 1999, WU et al. 2003).

Verschiedene Wnt-Inhibitoren und -Aktivatoren konnten identifiziert werden, die in die Feinregulation der Wnt-Aktivität eingebunden sind. Durch ihre morphologische Verwandtschaft zu den Wnt-Rezeptoren komplexieren sowohl die verschiedenen secreted Frizzled-related proteins (SFRP) als auch die Wnt-inhibitory factors (Wif) freie Wnt-Proteine. Hierdurch werden die Wnt-Proteine inaktiviert (LIN et al. 1997, RATTNER et al. 1997, HSIEH 1999). Sowohl während der Embryonalentwicklung als auch während der Entstehung und Progression von Karzinomen ist der Abbauprozess des $\beta$-Catenins durch eine gesteigerte Expression der verschiedenen Wnt-Proteine gehemmt (NUSSE 2005, CLEVERS 2006). Die extrazellulär lokalisierten Wnt-Proteine binden an den Cystein-reichen N-Terminus der verschiedenen 7-Transmembran-Rezeptoren der Frizzled-Familie (Fz) (BHANOT et al. 1996). Zur Initiierung der intrazellulären Wnt-Signalkaskade ist zusätzlich eine Bindung an den 1-Transmembran-Korezeptor Lipoprotein Related Protein 6/7 (LRP 6/7) notwendig (PINSON et al. 2000, TAMAI et al. 2000, WEHRLI et al. 2000). Intrazellulär bindet nachfolgend das Protein Dishevelled (Dvl) an den C-Terminus des Fz-Rezeptors (UMBAUER et al. 2000, WONG et al. 2003), wodurch es zur Hyperphosphorylierung von Dvl kommt (YANAGAWA et al. 1995). Parallel bewirkt das Wnt-Protein eine Aktivierung seines Korezeptors LRP 6/7 durch Phosphorylierung an dessen intrazellulärem Anteil durch die Casein-Kinase $1 \gamma$ (CK $1 \gamma$ ) und die GSK 3ß; somit wird eine Bindungsstelle für Axin geschaffen (MAO J et al. 2001, TAMAI et al. 2004, DAVIDSON et al. 2005, ZENG et al. 2005). Die Translokation von Axin an die Zellmembran 
erfolgt im Verbund des gesamten Degradationskomplexes und ist Dvl-abhängig (CLIFFE et al. 2003) ebenso wie die nachfolgende Internalisierung des Fz-Rezeptors (SATO et al. 2010). Durch die räumliche Nähe nach Bindung an den beiden Wnt-Rezeptoren kommt es zur Heterodimerisierung des Dvl mit dem Axin über die sogenannten DIX-Domänen (KISHIDA et al. 1999, ITOH et al. 2000).

Axin scheint durch die Translokation an die Zellmembran destabilisiert zu werden, wodurch der Degradationskomplex dissoziiert (MAO B et al. 2001). Darüber hinaus gibt es Hinweise, dass hyperphosphoryliertes aktiviertes Dvl die GSK $3 \beta \mathrm{zu}$ inhibieren vermag (LEE et al. 2003). Zusammengenommen führen diese Vorgänge dazu, dass $\beta$-Catenin in seinem unphosphorylierten (= aktiven) Zustand verbleibt (van NOORT et al. 2002). Aktives $\beta$-Catenin wird in den Zellkern transloziert, wo es die Endstrecke des kanonischen Wnt-Signalweges auf DNA-Ebene initiiert.

Im Nukleus interagiert $\beta$-Catenin mit dem Transkriptionsfaktor lymphoid enhancer factor/ T-cell-factor (LEF/ TCF), was zur Transkription der Wnt-Zielgene führt (BEHRENS et al. 1996, HUBER et al. 1996, MOLENAR et al. 1996, van de WETERING et al. 1997). Im physiologischen Ruhezustand (ohne Aktivierung des Wnt-Signalweges) fungiert LEF/ TCF als Repressor der Wnt-assoziierten Transkription (BRANNON et al. 1997). Unphosphoryliertes $\beta$-Catenin verdrängt identifizierte Korepressoren aus ihrem Komplex mit LEF/ TCF (CAVALLO et al. 1998, CHIANNADURAI 2002, DANIELS et al. 2005, ROOSE et al. 1998). Durch die Bindung von $\beta$-Catenin an LEF/ TCF wird der Transkriptionsfaktor aktiviert. Dies wird durch Bildung eines nukleären Triple-Komplexes mit dem Koaktivator B-cell-lymphoma-9 (Bcl-9) (KRAMPS et al. 2002, THOMPSON et al. 2002, BREMBECK et al. 2004, SAMPIETRO et al. 2006) verstärkt.

Durch die beschriebenen Vorgänge im Nukleus wird die Expression der Wnt-Zielgene gesteigert. Tabellarisch sind die bisher identifizierten Gene auf der WntHomepage der Universität Stanford zusammengestellt (The Wnt Homepage http://web.stanford.edu/group/nusselab/cgi-bin/wnt/target genes). Die Gene sind größtenteils zelltypspezifisch und repräsentieren zum Teil verschiedene Komponenten des kanonischen Wnt-Signalweges im Sinne einer Autoregulation. Beim kolorektalen Karzinom spielen die Matrixmetalloproteinase Matrilysin (= MMP7) (BRABLETZ et al. 1999, CRAWFORD et al. 1999), das Zellzyklusprotein Cyclin D1 (SHTUTMAN et al. 1999, TETSU \& McCORMICK 1999, SANSOM et al. 2005) 
und die Rezeptor-Tyrosinkinase Met (BOON et al. 2002) als kanonische Wnt-Zielgene eine besondere Rolle.

\subsubsection{Der Wnt/ JNK-Signalweg}

Der humane Wnt/ JNK-Signalweg wurde ursprünglich als planar cell polarity-Signalweg in Drosophilia melanogaster beschrieben (STRUTT 2003). Nach Bindung eines Wnt-Proteins an einen der Rezeptoren aus der Fz-Familie wird das Signal intrazellulär über Dvl weitergeleitet. Im Vordergrund stehen hierbei die Wnt-Proteine Wnt-5A und Wnt-11 sowie die Fz-Rezeptoren Fz3, Fz5 und Fz6 (SEIFERT \& MLODZIK 2007). Intrazellulär werden verschiedene GTPasen aktiviert (vgl. Abbildung 3).

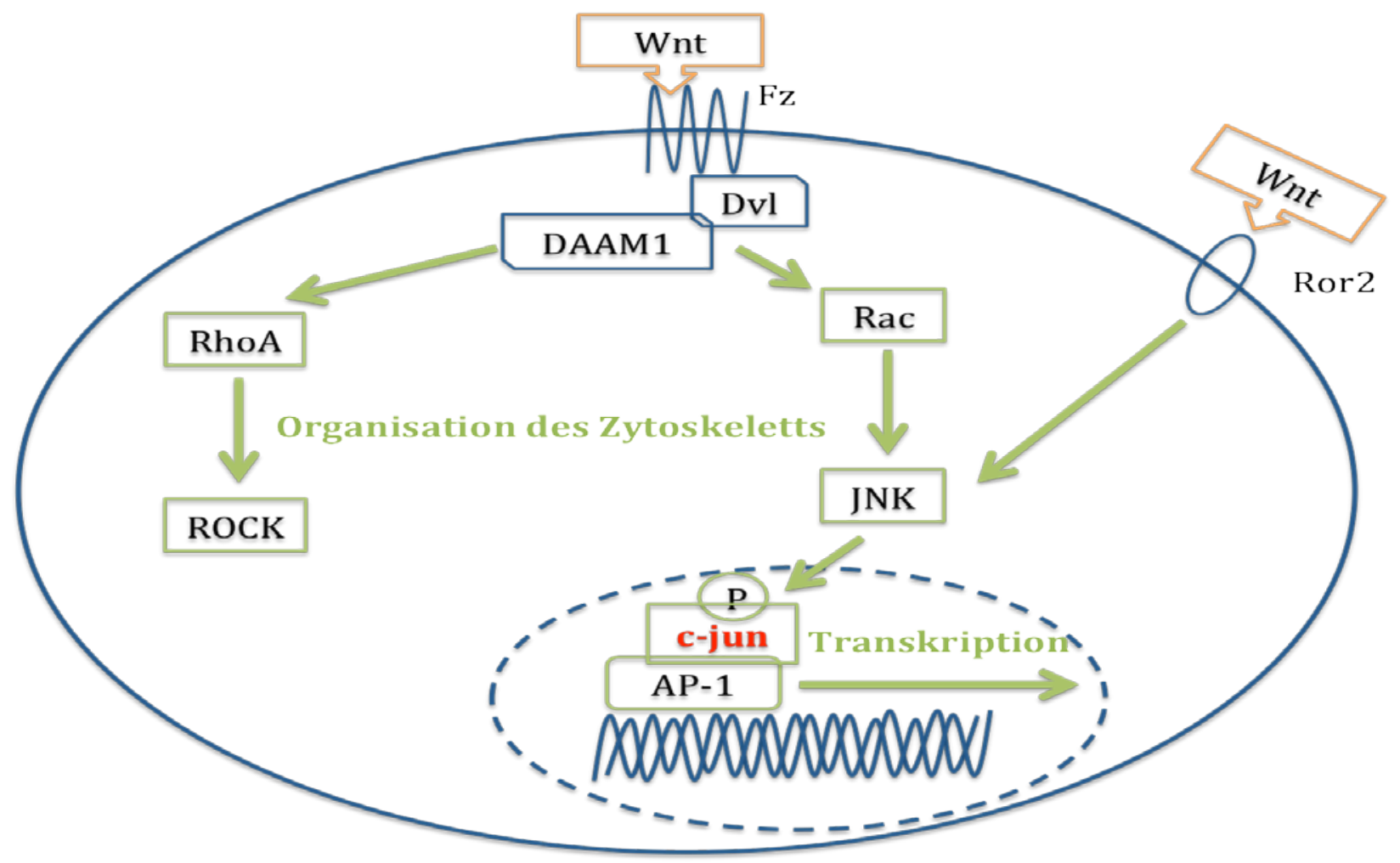

Abbildung 3: Der nicht-kanonische Wnt/ JNK-Signalweg. Nach Bindung von Wnt an seine Rezeptoren werden intrazelluläre Signalkaskaden aktiviert, die die GTPasen ROCK und JNK aktivieren. Dies führt nachfolgend zur Organisation des Zytoskeletts und nach Phosphorylierung des c-jun-Proteins zur gesteigerten Transkription der Zielgene von AP-1. Die rot hervorgehobenen Komponenten sind Gegenstand der vorliegenden Arbeit. 
Über die DEP-Domäne des Dvl kommt es einerseits zur Aktivierung der GTPase Rac (BOUTROS \& PARICIO 1998, MORIGUCHI et al. 1999). Das aktivierte Rac-Protein stimuliert nachfolgend die c-jun N-terminale Kinase (JNK) (LI et al. 1999). Darüber hinaus kann das Wnt-Signal die Aktivität der JNK auch über die Tyrosinrezeptorkinase Ror2 steigern (OISHI et al. 2003). Schlussendlich aktiviert die JNK das Protein c-jun durch Phosphorylierung. Der Transkriptionsfaktor activator protein 1 (AP-1) wird durch aktives c-jun stimuliert (WEBER et al. 2000). Aufgrund seiner exponierten Funktion ist c-jun - analog zum $\beta$-Catenin im kanonischen Wnt-Signalweg - das Schlüsselprotein des nicht-kanonischen Wnt/ JNKSignalweges. Die c-jun-Expression stellt somit ein Maß für die Aktivität des nicht-kanonischen Wnt/ JNK-Signalweges dar.

Parallel bindet das DAAM1-Protein (dishevelled associated activator of morphogenesis 1) an das Dvl-Protein. Nachfolgend aktiviert Dvl die GTPase RhoA (HABAS et al. 2001). Die aktivierte RhoA aktiviert wiederum die Rho-assoziierte Casein-Kinase (ROCK) (WINTER et al. 2001).

Sowohl die aktivierte JNK als auch die aktivierte ROCK beeinflussen synergistisch die Organisation des Zytoskeletts (WATANABE et al. 2005, WEHRLE-HALLER \& IMHOF 2003).

\subsubsection{Interaktionen der Wnt-Signalwege}

Lange Zeit wurde zwischen dem kanonischen Wnt-Pfad auf der einen Seite und den nichtkanonischen Wnt-Pfaden auf der anderen Seite unterschieden (WONG et al. 1994, DU et al. 1995, TORRES et al. 1996, OLSON et al. 1998). Durch intensive Forschung auf dem Gebiet der WntSignaltransduktion konnten in den letzten Jahren jedoch vielseitige Wechselwirkungen zwischen den Wnt-Pfaden beschrieben werden. Potenzierende und inhibierende Effekte stehen sich in Abhängigkeit vom jeweiligen Rezeptorstatus, von nachgeschalteten Effektoren sowie von extrazellulären regulierenden Proteinen gegenüber (MIKELS \& NUSSE 2006). Die daraus resultierende Vorstellung eines Wnt-Netzwerkes anstatt mehrerer unabhängiger Wnt-Signalwege ist Grundlage der vorliegenden Arbeit (KESTLER \& KÜHL 2008, PUKROP \& BINDER 2008, RAO \& KÜHL 2011). 


\subsection{Therapie des kolorektalen Karzinoms}

Das Kolon- und das Rektumkarzinom sind sich aufgrund der gemeinsamen Ätiologie und Pathologie sehr ähnlich (vgl. Kapitel 1.1). Sie werden daher meist unter dem Begriff des kolorektalen Karzinoms zusammengefasst. Gemäß der Klassifikation der Union internationale contre le cancer (UICC) wird eine Neoplasie als Rektumkarzinom definiert, wenn sie maximal $16 \mathrm{~cm}$ gemessen von der Anokutanlinie auftritt. Weiter proximal lokalisierte Karzinome werden bis einschließlich der Bauhinschen Klappe als Kolonkarzinome definiert (WITTEKIND 2010). Die Therapieregime der beiden Karzinomtypen unterscheiden sich jedoch und richten sich jeweils nach dem gemeinsamen durch die UICC definierten Stadium (vgl. Tabelle 1).

\begin{tabular}{|c|c|c|c|}
\hline Stadium & Tiefeninvasion & Lymphknotenmetastasen & Fernmetastasen \\
\hline Ia & $\mathrm{T} 1$ & N0 & M0 \\
\hline Ib & $\mathrm{T} 2$ & N0 & M0 \\
\hline II & $\mathrm{T} 3, \mathrm{~T} 4$ & No & M0 \\
\hline III & Alle T-Stadien & $\mathrm{N} 1, \mathrm{~N} 2$ & M0 \\
\hline IV & Alle T-Stadien & Alle N-Stadien & M1 \\
\hline Tabelle 1: & \multicolumn{3}{|c|}{$\begin{array}{l}\text { Stadieneinteilung kolorektaler Karzinome nach UICC (mod. nach WITTEKIND et al. 2010). T1 } \\
\text { Infiltration der Submukosa. T2 Infiltration der Muscularis propria. T3 Infiltration der } \\
\text { Subserosa oder des nicht-peritonealisierten perikolischen oder perirektalen Gewebes. T4 } \\
\text { Infiltration von Nachbarorganen/ -strukturen und/ oder Perforation des viszeralen } \\
\text { Peritoneums. N0 keine Lymphknotenmetastasen. N1 weniger als } 3 \text { Lymphknotenmetastasen. } \\
\text { N2 mehr als } 3 \text { Lymphknotenmetastasen. M0 keine Fernmetastasen. M1 Fernmetastasen. }\end{array}$} \\
\hline
\end{tabular}

\subsubsection{Therapie des Kolonkarzinoms (Stadium I-III)}

In den Stadien I-III wird beim Kolonkarzinom ein primär operatives Therapieregime mit kurativer Zielsetzung verfolgt. Die Operation umfasst die en-bloc-Resektion des Primärtumors samt infiltrierter Nachbarstrukturen und -organe sowie die Entfernung von mindestens 12 Lymphknoten. Ziel ist die R0-Resektion, das heißt, dass auch histopathologisch kein Tumorgewebe mehr nachweisbar ist. Eine adjuvante Monochemotherapie nach R0-Resektion mit 5-Fluoruracil (5-FU) wird bereits für Patienten mit erhöhtem Rezidivrisiko im Stadium II empfohlen. Ein erhöhtes Risiko liegt vor, wenn 
der Primärtumor als T4 klassifiziert wurde, der Tumor bereits perforiert war oder es während der Operation zu einer Perforation kam, die Operation unter Notfallbedingungen ablief oder weniger als 12 Lymphknoten analysiert werden konnten. Im Stadium III wird die adjuvante Chemotherapie bestehend aus 5-FU und Folinsäure kombiniert mit Oxaliplatin oder Irinotecan allen Patienten angeraten, da die postoperative Chemotherapie die Prognose signifikant verbessert und einen Überlebensvorteil im Vergleich zur alleinigen Operation bietet (Leitlinie Kolorektales Karzinom 2014, Onkopedia Leitlinie Kolonkarzinom 2012).

\subsubsection{Therapie des Rektumkarzinoms (Stadium I-III)}

Beim Rektumkarzinom wird im Stadium I auch die primäre chirurgische Resektion im Sinne einer totalen oder partiellen Mesorektumexzision (TME/ PME) empfohlen. In diesem Stadium schließt sich weder eine prä- noch eine postoperative Strahlen- oder Chemotherapie an. Für die Stadien II und III ist in den Therapieregimen eine neoadjuvante Radiotherapie kombiniert mit einer Chemotherapie (5-FU mit Folinsäure) vorgesehen. Durch diese präoperative Therapie treten Lokalrezidive seltener auf und die Überlebensrate wird insgesamt signifikant erhöht. Nach erfolgter Operation mit R0-Resektion und Entfernung von mindestens 12 Lymphknoten schließt sich in beiden Stadien eine adjuvante Chemotherapie (5-FU mit oder ohne Folinsäure) an (Leitlinie Kolorektales Karzinom 2014, Onkopedia Leitlinie Rektumkarzinom 2012).

\subsubsection{Therapie des metastasierten kolorektalen Karzinoms (Stadium IV)}

In der metastasierten Situation (UICC-Stadium IV) ist das Therapieregime für Kolon- und Rektumkarzinome identisch. Primär resektable Leber- und Lungenmetastasen sollen unter der Voraussetzung, dass nach der Resektion noch ausreichend Organparenchym vorhanden ist, operativ entfernt werden. Potentiell resektable Leber- und Lungenmetastasen werden einer neoadjuvanten Chemotherapie zugeführt. Dadurch sollen die Metastasen gezielt verkleinert und ihre Resektabilität erreicht werden. An die Operation mit R0-Resektion schließt sich jeweils eine adjuvante Chemotherapie an. In beiden Fällen wird eine kurative Strategie verfolgt. Bei Inoperabilität des Primärtumors und/ oder der Metastasen ist die Situation palliativ. Sowohl für die kurative als auch die palliative Versorgung existieren verschiedene Chemotherapieprotokolle, über deren Anwendung individuell beraten wird. 
Neben Chemotherapeutika (5-FU, Folinsäure, Oxaliplatin, Irinotecan) kommen zusätzlich die monoklonalen Antikörper Cetuximab und Panitumumab, die beide gegen den Rezeptor des endothelialen Wachstumsfaktors (EGFR) gerichtet sind, oder Bevacizumab, der antiangiogenetisch über den vaskulären endothelialen Wachstumsfaktor (VEGF) wirkt, zum Einsatz (Leitlinie Kolorektales Karzinom 2014, Onkopedia Leitlinie Kolonkarzinom 2012, Onkopedia Leitlinie Rektumkarzinom 2012).

Die 5-Jahres-Überlebensrate von Patienten mit kolorektalem Karzinom nimmt mit fortschreitendem UICC-Stadium dramatisch ab. In der metastasierten Situation leben nach diesem Zeitraum trotz Behandlung noch etwa 10 \% der Patienten (O'NEIL \& GOLDBERG 2008, CIDÓN 2010). Hieraus ergibt sich die Notwendigkeit, das Wissen über die molekularen Veränderungen beim kolorektalen Karzinom zu nutzen, um neue Therapieansätze zu entwickeln respektive etablierte Therapieregime zu erweitern.

\subsubsection{Experimentelle molekulare Therapieansätze zur Modulation des Wnt- Netzwerkes im kolorektalen Karzinom}

Die Attraktivität einer gezielten therapeutischen Modulation des Wnt-Netzwerkes ist durch dessen exponierte Stellung in der kolorektalen Karzinogenese begründet (vgl. Kapitel 1.2). Vor allem die erforderliche selektive Wirkung auf neoplastische Zellen mit möglichst geringer Beeinflussung des Wnt-Netzwerkes im normalen Gewebe birgt Schwierigkeiten bei der Evaluierung verschiedener Substanzen.

Als potentielle Angriffspunkte werden im Allgemeinen vier Ebenen diskutiert. Zunächst scheint es sinnvoll, die Interaktion der Wnt-Proteine mit deren Rezeptoren und damit die Aktivierung der nachgeschalteten intrazellulären Signaltransduktionskaskade $\mathrm{zu}$ blockieren. Das Peptid Foxy-5 soll den Effekt des Proteins Wnt-5a imitieren. Wnt-5a vermag den kanonischen Wnt-Signalweg zu blockieren (TOPOL et al. 2003). Mittlerweile wird die Toxizität von Foxy-5 als auch von monoklonalen Antikörpern gegen Fz-Rezeptoren (OMP-18R3, OTSA-101) und Wnt-Proteine (OMP-54F28) in einer klinischen Phase-I-Studie untersucht (SEBIO et al. 2014). Auch eine Aktivierung des zytosolischen Degradationskomplexes mit dem Ziel, die Akkumulation von aktivem $\beta$-Catenin zu verhindern, gilt als vielversprechender Ansatz. So steigert das Phytoöstrogen Genistein die 
Genexpression der GSK 3 $\beta$, was nachfolgend die Wnt-Aktivität hemmt (SU \& SIMMEN 2009). Zurzeit wird Genistein in Kombination mit 5-FU, Folinsäure, Oxaliplatin und Bevacizumab in Phase II klinisch bei Patienten mit kolorektalem Karzinom im metastasierten Zustand evaluiert (SEBIO et al. 2014). Auf nukleärer Ebene wird ergänzend eine Blockierung der aktivierenden Interaktion von $\beta$-Catenin mit dem LEF/ TCF-Transkriptionsfaktor als zielführend diskutiert. Einerseits wurde dies beispielsweise für die aktive Form von Vitamin $\mathrm{D}\left(1,25(\mathrm{OH})_{2} \mathrm{D}_{3}\right)$ beschrieben, welches $\beta$-Catenin durch Komplexierung am Vitamin D-Rezeptor inaktiviert (PALMER et al. 2001). Ebenso wurde den Vitamin-A-Säuren ein kompetitiver Antagonismus mit $\beta$-Catenin um die Bindung an LEF/ TCF zugeschrieben (XIAO et al. 2003). Schließlich gibt es Bemühungen, Proteine, die durch die aberrante Aktivität des Wnt-Netzwerkes gesteigert translatiert werden, therapeutisch zu inaktivieren. Dies ist sinnvoll, wenn die Proteine mit der Karzinomformation und -progression assoziiert sind. Das small molecule CWP232291 wird aktuell in Phase I klinisch für hämatologische Tumoren im Hinblick auf dessen Toxizität evaluiert. Es soll das antiapoptotische WntZielgen Survivin hemmen und dadurch den Zelltod der Karzinomzellen ermöglichen (SEBIO et al. 2014). Neben den jeweils exemplarisch genannten Inhibitoren sind zahlreiche weitere Substanzen beschrieben worden, die das Wnt-Netzwerk auf den vier genannten Ebenen beeinflussen; an dieser Stelle sei auf weiterführende Reviews verwiesen (van ES \& CLEVERS 2005, BARKER \& CLEVERS 2006, DAHMANI et al. 2011, McDONALD \& SILVER 2011, YAO et al. 2011, KIESSLICH et al. 2012, SEBIO et al. 2014). Darüber hinaus werden einigen Wirkstoffen - wie dem in dieser Arbeit im Fokus stehenden Niclosamid - Wnt-modulierende Effekte zugeschrieben (vgl. Kapitel 1.5), ohne dass der exakte Wirkmechanismus bisher geklärt werden konnte.

Zurzeit werden in der klinischen Anwendung keine Wnt-modulierenden Wirkstoffe routinemäßig bei der Therapie des kolorektalen Karzinoms eingesetzt (vgl. Kapitel 1.4.1 1.4.3). Einigkeit herrscht aber über die Sinnhaftigkeit einer selektiven Blockade des WntNetzwerkes (van ES \& CLEVERS 2005, BARKER \& CLEVERS 2006, DAHMANI et al. 2011, McDONALD \& SILVER 2011, YAO et al. 2011, KIESSLICH et al. 2012, SEBIO et al. 2014). Insbesondere scheint die Hemmung der $\beta$-Catenin-abhängigen LEF/ TCF-Transkriptionsrate erfolgsversprechend zu sein, um eine verhältnismäßig selektive Wirkung auf Karzinomzellen zu erzielen. Unerwünschte Arzneimittelwirkungen - beispielsweise durch Störung der LEF/ TCFunabhängigen $\beta$-Catenin-vermittelten Zelladhäsion - dürften hierdurch minimiert werden 
(BARKER \& CLEVERS 2006). Gerade die Formation des nukleären Triple-Komplexes aus $\beta$-Catenin, Bcl-9 und LEF/ TCF (vgl. Kapitel 1.3.1) ist weitgehend unabhängig von anderen $\beta$-Catenin-Proteininteraktionen. Auf dieser Ebene der Wnt-Signaltransduktion besteht ein hohes Potential für eine selektive therapeutische Intervention, ohne die $\beta$-Cateninvermittelte Zelladhäsion zu stören (HE \& AXELROD 2006, SAMPIETRO et al. 2006). Ein zukünftiges

Ziel könnte darin bestehen, Wirkstoffe zu evaluieren, die das Wnt-Netzwerk genau an dieser Stelle beeinflussen.

\subsection{Die Versuchssubstanz Niclosamid}<smiles>O=C(Nc1ccc([N+](=O)[O-])cc1Cl)c1cc(Cl)ccc1O</smiles>

Abbildung 4: Strukturformel des Niclosamids (PAN et al. 2012)

Niclosamid (5-Chlor-N-(2-chlor-4-nitrophenyl)-2-hydroxybenzamid) ist ein halogeniertes Salicylanilid, bei dem über eine Amidbindung ein Derivat der Salicylsäure mit einem Derivat des Anilins konjugiert ist (vgl. Abbildung 4). Ursprünglich wurde der Wirkstoff unter dem Handelsnamen Yomesan ${ }^{\circledR}$ von Bayer als Molluskizid zur effizienten Eradikation von Schnecken eingeführt. Außerdem vermag es in Form des 2-HydroxyethylammoniumSalzes (Clonitralid) die Parasitenlast von Schistosoma in Gewässern zu reduzieren. Dadurch kann nachfolgend die Gefahr gesenkt werden, an Bilharziose zu erkranken (RÖMPP https://roempp.thieme.de/roempp4.0/do/data/RD-14-01132).

Im human- und veterinärmedizinischen Bereich ist Yomesan ${ }^{\circledR}$ bei Infektionen mit Bandwürmern (Taenia saginata, Tania solium, Diphyllobothrium, Hymenolepsis, Dipylidium) indiziert. Nach oraler Anwendung wird der Bandwurm durch körpereigene Proteasen aufgelöst (GROSS 2009, RÖMPP https://roempp.thieme.de/roempp4.0/do/data/RD-14-01132). Der genaue Wirkmechanismus ist bisher nicht vollständig geklärt. Die Glucoseaufnahme und der Zitratzyklus der Würmer scheinen gehemmt und die Glykolyse getriggert zu werden 
(BARTH 2009). Entscheidend ist aber, dass sich Niclosamid als potenter Entkoppler der oxidativen Phosphorylierung in den Mitochondrien erwiesen hat (WEINBACH \& GARBUS 1969). Dabei ist die systemische Wirkung auf den Wirt des Bandwurmes bei einer oralen Bioverfügbarkeit von gerade einmal $10 \%$ sehr gering; die Plasmakonzentration ist nach 24 Stunden bereits nicht mehr quantifizierbar $(<0,5 \mathrm{ng} / \mathrm{ml}$ ) (CHANG et al. 2006). Das Nebenwirkungsprofil ist aufgrund der geringen oralen Bioverfügbarkeit vor allem auf gastrointestinale Beschwerden wie Übelkeit, Erbrechen, abdominelle Schmerzen und Reizung der Magenschleimhaut beschränkt (BARTH 2009).

Mit dem Ansatz des drug repositioning werden neue Anwendungsgebiete für etablierte Arzneimittelwirkstoffe eruiert (ASHBURN et al. 2004, CHONG \& SULLIVAN 2007). In diesem Kontext mehrten sich die Hinweise, dass Niclosamid auch außerhalb seiner klassischen Indikation als Antihelminthikum eingesetzt werden kann. Der Substanz wurden bereits antivirale, antiparasitäre, antibiotische, immunmodulatorische und chemotherapeutische Wirksamkeit zugeschrieben: Niclosamid kann die Replikation des SARS (schweres akutes respiratorisches Syndrom)-assoziierten Coronavirus und des strukturell verwandten transmissiblen-Gastroenteritis-Virus (TGEV) inhibieren (WU et al. 2004, CHANG et al. 2006). Die Wachstumsrate und Vitalität von Trypanosoma brucei brucei und Trypanosoma congolense, den Erregern der afrikanischen Schlafkrankheit, konnte in vitro nach Inkubation mit Niclosamid signifikant gesenkt werden (MERSCHJOHANN et al. 2008). In vivo konnte in einem Infektionsmodell an Insekten (Galleria mellonella) die Infektion mit dem häufig Antibiotikaresistenten gramnegativen Erreger Pseudomonas aeruginosa durch Behandlung mit Niclosamid verhindert werden (IMPERI et al. 2013). Unlängst wurde auch der Einsatz von Niclosamid bei chronisch-entzündlichen sowie autoimmunen Erkrankungen in Aussicht gestellt. Nach Inkubation mit Niclosamid wurde eine reduzierte Reifung dendritischer Zellen sowie eine reduzierte Antwort reaktiver T-Zellen auf Fremdantigene beobachtet (WU et al. 2014).

Unabhängig konnten verschiedene Arbeitsgruppen dem Niclosamid chemotherapeutische Wirksamkeit bei verschiedenen malignen soliden Tumoren wie dem kolorektalen Karzinom (OSADA et al. 2011, SACK et al. 2011), dem Osteosarkom (CHEN et al. 2009), dem Mamma- und Prostatakarzinom (LU et al. 2011, KETOLA et al. 2012, WANG et al. 2013, YE et al. 2014, LONDONO-JOSHI et al. 2014, LIU et al. 2014), dem Zervixkarzinom und dem Adenokarzinom der Lunge (REN et al. 
2010), dem Ovarialkarzinom (Y0 et al. 2012, AREND et al. 2014), dem Glioblastoma multiforme (WIELAND et al. 2013), den Kopf- und Halstumoren (LI et al. 2013a) sowie den nichtkleinzelligen bronchialen Karzinomen (LI et al. 2013b, LEE et al. 2014) und anderen Lungentumoren (YOU et al. 2013) zuschreiben. Für hämatologische Tumoren wie der akuten myeloischen Leukämie (AML) (JIN et al. 2010), der chronischen myeloischen Leukämie (CML) (WANG et al. 2009) und dem Multiplen Myelom (KHANIM et al. 2011) konnte diese antiproliferative Wirkung bestätigt werden. Zusätzlich konnte die Toxizität des Niclosamids sowohl auf Ebene der Tumorstammzellen bei der AML (JIN et al. 2010) als auch bei Stammzell-ähnlichen Vorläuferzellen des Ovarialkarzinoms (YO et al. 2012) und des Mammakarzinoms (WANG et al. 2013) nachgewiesen werden. Die mittlere inhibitorische Konzentration ( $\mathrm{IC}_{50}$ ) des Niclosamids lag dabei für verschiedene neoplastische Zelllinien zwischen 0,05 und 4,17 $\mu \mathrm{M}$ (LI et al. 2014, AREND et al. 2014, LONDONO-JOSHI et al. 2014). Für die verschiedenen Tumorentitäten wurden potenzielle Wirkmechanismen detailliert analysiert. Bei der CML konnte der erythrozytäre Differenzierungsblock überwunden (WANG et al. 2009) und beim Multiplen Myelom die prognostisch relevante, zur Niereninsuffizienz führende Produktion der freien Leichtketten durch Inkubation mit Niclosamid inhibiert werden (KHANIM et al. 2011). Für das Multiple Myelom konnte eine äquivalente Sensitivität der Myelomzellen gegenüber Niclosamid im Vergleich zur Standardtherapie, bestehend aus Melphalan, Prednisolon und Thalidomid oder Cyclophosphamid, Thalidomid und Dexamethason, dokumentiert werden (KHANIM et al. 2011). In Kombination mit anderen Chemotherapeutika wie dem Oxaliplatin (OSADA et al. 2011), dem Cytarabin, dem Etoposid oder dem Daunorubicin (JIN et al. 2010), dem Temozolomid (WIELAND et al. 2013), dem Erlotinib (LI et al. 2013a) und dem Carboplatin (AREND et al. 2014) wurden augmentierende Effekte beobachtet. Ein synergistischer Wirkmechanismus konnte auch für den monoklonalen Anitkörper TRA-8 belegt werden, der nach Bindung an den Fas-Rezeptor Apoptose induziert (LONDONO-JOSHI et al. 2014). Bei dem gegen den EGF-Rezeptor gerichteten Tyrosinkinase-Inhibitor Erlotinib entwickelt sich häufig nach Einsatz über 6 bis 12 Monate eine Resistenz der neoplastischen Zellen. Niclosamid konnte einen ursächlichen Pathoresistenzmechanismus über den STAT3-Signalweg überwinden (LI et al. 2013a, LI et al. 2013b). Zusätzlich konnte durch Behandlung mit Niclosamid die Radiosensitivität bronchialer Karzinomzellen gesteigert (LEE et al. 2014) und eine erworbene Radioresistenz 
durch Blockierung des STAT3-Signalweges überwunden werden (YOU et al. 2013). Mutierte Splicevarianten des Androgenrezeptors wurden nach Inkubation mit Niclosamid auf der Oberfläche von Prostatakarzinomzellen weniger stark exprimiert, was $\mathrm{zu}$ deren Sensitivierung führte (LIU et al. 2014).

Weiterführende Experimente zur Evaluation der Interaktion mit multiplen Signalwegen der Karzinogenese konnten die Inhibition des Wnt-Signalweges (CHEN et al. 2009, LU et al. 2011, OSADA et al. 2011, SACK et al. 2011, WIELAND et al. 2013, WANG et al. 2013, ONO et al. 2014, LONDONOJOSHI et al. 2014), des NF-KB-Signalweges (JIN et al. 2010, KHANIM et al. 2011, WIELAND et al. 2013), des STAT3-Signalweges (REN et al. 2010, KHANIM et al. 2011, KIM et al. 2013, YOU et al. 2013, YE et al. 2014, LONDONO-JOSHI et al. 2014), des mTOR-Signalweges (BALGI et al. 2009, WIELAND et al. 2013, YOU et al. 2013), des Notch-Signalweges (WANG et al. 2009, WANG et al. 2013, WIELAND et al. 2013) sowie des Hedgehog-Signalweges (WANG et al. 2013) nach Exposition von Niclosamid belegen. Analog zur Vorstellung des Wirkmechanismus bei Wurmerkrankungen wurden auch die Mitochondrien als Wirkungsort untersucht. Niclosamid entkoppelte die oxidative Phosphorylierung (KHANIM et al. 2011) und hemmte die Genexpression von Proteinkomplexen der oxidativen Phosphorylierung (YO et al. 2012). Parallel wurde die Produktion reaktiver Sauerstoffspezies, insbesondere des Superoxids, getriggert (JIN et al. 2010, KHANIM et al. 2011). Außerdem konnten die Induktion von Apoptose (JIN et al. 2010, OSADA et al. 2011, LU et al. 2011, KHANIM et al. 2011, YO et al. 2012, YE et al 2014, LEE et al. 2014, LIU et al. 2014) und von Autophagozytose (BALGI et al. 2009) sowie die Induktion eines transienten G1-Arrestes während des Zellzyklus (WIELAND et al. 2013) durch Inkubation mit Niclosamid belegt werden. Zudem wurden die Zellmigration und -invasion durch den Wirkstoff effektiv inhibiert (SACK et al. 2011, WIELAND et. al. 2013, YE et al. 2014). Im Vergleich wurden die genannten Effekte bei physiologischen Körperzellen und deren Vorläuferzellen im Knochenmark (JIN et al. 2010, ODSADA et al. 2011, WIELAND et al. 2013) erst bei höheren Konzentrationen des Niclosamids beobachtet.

In vivo konnte nach Xenoimplantation von Karzinomzellen in immundefiziente Mäuse und nachfolgender Therapie mit Niclosamid reduziertes Tumorwachstum (JIN et al. 2010, ODSADA et al. 2011, WIELAND et al. 2013, WANG et al. 2013, LI et al 2013a, LI et al. 2013b, YE et al. 2014, LONDONOJOSHI et al. 2014, LIU et al. 2014) und Metastasierungsverhalten (SACK et al. 2011, YE et al. 2014) beobachtet werden. Im Mausmodell zum Mammakarzinom reduzierte Niclosamid die Zahl 
immunsuppressiver Zellen (YE et al. 2014). Augmentiernde Effekte konnten in vivo bei einer kombinierten Applikation von Niclosamid mit dem monoklonalen Antikörper TRA-8 nachgewiesen werden (LONDONO-JOSHI et al. 2014). Außerdem wurde in immundefizienten Mäusen reduziertes Tumorwachstum festgestellt, wenn Glioblastom-Zellen vor Implantation mit Niclosamid kultiviert wurden (WIELAND et al. 2013). In den genannten Untersuchungen zum Einsatz von Niclosamid in vivo wurde die Therapie von den Tieren ohne limitierende unerwünschte Arzneimittelwirkungen gut toleriert (LI et al. 2013a, LI et al. 2013b, YOU et al. 2013, YE et al. 2014, LONDONO-JOSHI et al. 2014).

In Zusammenschau der Literatur weist das als Antihelminthikum zugelassene Niclosamid zusätzlich chemotherapeutische und antiproliferative Eigenschaften auf. Es ist davon auszugehen, dass die Substanz über verschiedene Mechanismen auf neoplastische Zellen und mikrobielle Erreger wirkt (MOOK Jr. et al. 2013). 


\subsection{Zielsetzung und Fragestellung}

Dem antihelminthischen Niclosamid, einem Derivat der Salicylsäure, werden zunehmend chemotherapeutische Eigenschaften bei malignen Tumoren zugeschrieben. Zahlreiche Studien belegen eine Hemmung multipler, in neoplastischen Erkrankungen (re)aktivierter Signalwege (vgl. Kapitel 1.5).

In der vorliegenden Arbeit wurde die Wirkung von Niclosamid auf kolorektale Karzinomzellen untersucht. Dabei richtete sich der Fokus auf die Interaktion der Substanz mit dem Wnt-Netzwerk, welches eine exponierte Stellung in der Karzinogenese des kolorektalen Karzinoms einnimmt (vgl. Kapitel 1.2). Ziel war die Evaluation einer Substanz, die chemotherapeutische Eigenschaften durch die Beeinflussung des molekular relevanten Wnt-Netzwerkes ausübt und damit einen potentiellen therapeutischen Ansatz zur Behandlung fortgeschrittener kolorektaler Karzinome bietet. Die Untersuchungen der vorliegenden Arbeit wurden in Zellkultur durchgeführt. Dabei wurden folgende Fragestellungen adressiert:

1. Inhibiert Niclosamid das Wachstum kolorektaler Karzinomzellen in Abhängigkeit von der eingesetzten Konzentration und dem zellulären Mutationsstatus?

2. Wirkt Niclosamid zytotoxisch durch Induktion des Zelltodes (Apoptose vs. Nekrose)?

3. Welche Auswirkungen hat eine Inkubation kolorektaler Karzinomzellen mit Niclosamid auf den kanonischen Wnt-Signalweg und den nicht-kanonischen Wnt/ JNK-Signalweg? 


\section{Material und Methoden}

\section{$2.1 \quad$ Material}

\subsubsection{Geräte}

2030 Multilable Reader VICTOR ${ }^{\mathrm{TM}}$

Begasungsbrutschrank BB 6060, BB6220

Block Thermomixer (HLC - HTM 130, 24 Fach)

Dampfsterilisator

Durchlichtmikroskop (DM IRBE)

Einfachpipetten $(10 \mu \mathrm{l}, 100 \mu \mathrm{l}, 1000 \mu \mathrm{l})$

Eismaschine

Elektrophoresekammer

FACSCanto II Flow Cytometer

Feinwaage

Fluoreszenzmikroskop DMIRE 2

ImageQuant LAS 400 mini

Kamera IXUS 1000 HS

Kryobox

Kühl-/ Gefrierschränke:

- $\quad 4^{\circ} \mathrm{C}$

- $-20^{\circ} \mathrm{C}$

- $-80^{\circ} \mathrm{C}$

Kühlzentrifuge (Fresco 17)

Magnetischer Rührer

Mithras Multimode Reader LB 940

Multilable Reader VICTOR TM X4

Nucleofector ${ }^{\circledR}$ II

pH-Meter

Pipettierhilfe accu-jet
PerkinElmer, Waltham (USA)

Heraus, Hanau

Heap Labor Consult, Bovenden

Zirbus Technology GmbH, Bad Grund

(Harz)

Leica, Solms

Eppendorf, Hamburg

Ziegra, Isernhagen

Bio-Rad, München

BD Biosciences, Heidelberg

Sartorius, Göttingen

Leica, Wetzlar

GE Healthcare, Freiburg

Canon Deutschland, Krefeld

Nalge Company, Rochester (USA)

Robert-Bosch Hausgeräte GmbH, Gerlingen

Liebherr, Biberach

Sanyo, Wiesloch

Heraeus, Hanau

Heidolph, Schwabach

Berthold Technologies, Oak Ridge (USA)

PerkinElmer, Waltham (USA)

Lonza, Basel (Schweiz)

Sartorius, Göttingen

Brand, Wertheim 
Power Supply

Spectrophotometer (Nano Drop ND 1000)

Steamer Multi Gourmet

Sterilbank HERAsafe

Stickstoff-Tank

Tischzentrifuge (Labofuge $400 \mathrm{R}$ )

Thermal Cycler (CFX 96, Real Time System)

Thermocycler

Thermomixer compact

Vakuum-Sicherheits-Absaugsystem

Vortex Mixer (REAX 2000)

Wasserbad 1012

Zählkammer nach Neubauer $\left(0,0025 \mathrm{~m}^{2}\right)$

\subsubsection{EDV}

BD FACSDiva ${ }^{\mathrm{TM}}$ Software Version 6.1.3

CFX-Manager Software Version 1.5

Image Quant LAS 400 Software Version 1.2

Mirko Winn 2000

Nano Drop 1000 Version 3.5.2

Perkin Elmer 2030 Software Version 4.00
Bio-Rad, München

peqlab, Erlangen

Braun, Kronberg/ Taunus

Heraeus, Hanau

Schütt-biotec, Göttingen

Heraeus, Hanau

Bio-Rad, München

Biometra, Göttingen

Eppendorf, Hamburg

WISA, Wuppertal

Heidolph, Schwabach

GFL - Gesellschaft für Labortechnik mbH, Burgwedel

Optik Labor, Görlitz

\subsubsection{Verbrauchsmaterialien}

$\begin{array}{ll}\text { Auslaufpipetten }(2 \mu \mathrm{l}, 5 \mu \mathrm{l}, 10 \mu \mathrm{l}, 25 \mu \mathrm{l}) & \text { Starlab, Hamburg } \\ \text { Einmalinjektionskanülen } & \text { Braun, Melsungen } \\ \text { Einmalspritzen }(1 \mathrm{ml}) & \text { BD Biosciences, Heidelberg } \\ \text { Falcon Tubes }(15 \mathrm{ml}, 50 \mathrm{ml}) & \text { Sarstedt, Nümbrecht } \\ \text { Filter Tips } & \text { Biozym, Oldenburg } \\ \text { Gewebekulturflachen }\left(25 \mathrm{~cm}^{2}, 75 \mathrm{~cm}^{2}\right) & \text { Starlab, Hamburg } \\ \text { PCR-Platte (96-Well Clear) } & \text { Bio-Rad, München }\end{array}$


PCR Tube Strips

Pipettenspitzen $(10 \mu \mathrm{l}, 100 \mu \mathrm{l}, 1000 \mu \mathrm{l})$

PVDF-Membran

Rektionsgefäße:

- $1,5 \mathrm{ml}$

- $0,6 \mathrm{ml}$

Zellkulturplatten:

- 6 er Well

- 96 er Well

Whatman-Papier

Zellkulturschalen

Zellschaber

\subsubsection{Chemikalien}

4',6-Diamidino-2-phenylindol (DAPI)

Aceton

Acrylamid Mix

Annexin-V-Fluos

Antibody Diluent

APS

BSA

Chloroform

DMEM (3,7 g/l NaHCO 3 , 4,5 g/l D-Glucose,

L-Glutamin, Na-Pyruvat)

DMSO

DTT

ECL-Advance ${ }^{\mathrm{TM}}$ Western blotting detection kit

EDTA

Ethanol

FCS

Fishblock
Bio-Rad, München

Sarstedt, Nümbrecht

Millipore, Schwalbach

Eppendorf, Hamburg

Biozym, Oldenburg

Greiner Bio-one, Frickenhausen

Nunc, Roskilde (Dänemark)

Whatman, Buckinghamshire (UK)

Sarstedt, Nümbrecht

Greiner Bio-one, Frickenhausen
Sigma, Steinheim

Roth, Karlsruhe

Sigma, Steinheim

Roche, Mannheim

Dako Deutschland, Hamburg

Gibco, New York (USA)

AppliChem, Darmstadt

Merck, Hohenbrunn

Biochroma, Berlin

AppliChem, Darmstadt

Qiagen, Hilden

Healthcare, Freiburg

Paesel und Lorei, Duisburg

Frohn GmbH, München; Roth, Karlsruhe

PAN-Biotech, Aidenbach

SurModics BioFx, Eden Prairie (USA) 


\begin{tabular}{|c|c|}
\hline Glycerol & Serva, Heidelberg \\
\hline Glycin & Serva, Heidelberg \\
\hline Gram-Kristallviolettlösung & Merck, Darmstadt \\
\hline Hämatoxylin & Millipore, Schwalbach \\
\hline Hepes & Sigma, Steinheim \\
\hline $\mathrm{H}_{2} \mathrm{O}$ (DNase-/ RNase-frei) & Sigma, Steinheim \\
\hline Isopropanol & Merck, Hohenbrunn \\
\hline Kaliumchlorid & Merck, Darmstadt \\
\hline Kaliumhydroxid & Merck, Darmstadt \\
\hline L-Glutamin $(200 \mathrm{mM})$ & Biochrom, Berlin \\
\hline Magermilchpulver & Merck, Darmstadt \\
\hline MagicMark ${ }^{\mathrm{TM}}$ XF Western Protein Standard & Invitrogen, Darmstadt \\
\hline Mayers Hämalaunlösung & Merck, Darmstadt \\
\hline Magnesiumchlorid & Merck, Darmstadt \\
\hline Natriumchlorid & Roth, Karlsruhe \\
\hline Natriumchloridlösung (isoton 0,9\%) & Braun, Melsungen \\
\hline Natriumhydroxid & Sigma, Steinheim \\
\hline Natriumdesoxycholat & Sigma, Steinheim \\
\hline NP-40 & Sigma, Steinheim \\
\hline $\operatorname{PBS}(10 \mathrm{x})$ & Invitrogen, Darmstadt \\
\hline Penicillin -Streptomycin & Invitrogen, Paisley (UK) \\
\hline Pierce ${ }^{\circledR}$ BCA Protein Assay Kit & Therma Scientific, Rockford (USA) \\
\hline PhosSTOP & Roche, Mannheim \\
\hline PMSF & Qiagen, Hilden \\
\hline Propidiumiodid & AppliChem, Darmstadt \\
\hline Protease Inhibitor Cocktail & Sigma, Steinheim \\
\hline Rainbow Molecular Weight Markers & GE Healthcare Amersham, Freiburg \\
\hline Roti $^{\circledR}$-Load 1 & Carl Roth GmbH und Co. KG, Karlsruhe \\
\hline RPMI 1640 (L-Glutamin, $\mathrm{NaHCO}_{3}$ ) & Sigma, Steinheim \\
\hline Salzsäure & Merck, Darmstadt \\
\hline SDS & pulsone, Uppsala (Schweden) \\
\hline
\end{tabular}


Target Retrieval Solution (TRS)

TEMED

Trypanblau

Trypsin-EDTA (10x)

Tris ultrapure

Tween

Vectashield
Dako, Glostrup (Dänemark)

Merck, Darmstadt

Sigma, Steinheim

PAA Laboratories, Pasching (Österreich)

AppliChem, Darmstadt

AppliChem, Darmstadt

Vector, Burlingame (USA)

\subsubsection{Pufferherstellung (Tris)}

1,0 l Aqua bidest.

6,1 g Tris ultrapure

AppliChem, Darmstadt

9,0 g Natriumchlorid

Roth, Karlsruhe

Einstellung des ph-Wertes auf 7,6 mit 5N Salzsäure

\subsubsection{Plasmide}

FOP-Flash

Renilla-Luciferase (pRL-CMV)

TOP-Flash

\subsubsection{Enzyme}

DNase

\subsubsection{Kits}

Cell Line Nucleofector ${ }^{\circledR}$ Kit V

Dual-Luciferase ${ }^{\circledR}$ Reporter Assay System

iQ SYBR Green Supermix

peqGold TriFast

QuantiTect Reverse Transcription Kit
Millipore, Schwalbach

Promega, Mannheim

Millipore, Schwalbach

Roche, Mannheim

Lonza, Basel (Schweiz)

Promega, Mannheim

Bio-Rad, München

peqlab, Erlangen

Qiagen, Hilden 


\subsubsection{Primer}

\begin{tabular}{|c|c|c|c|c|}
\hline Gen & Primer & $\begin{array}{l}\text { Annealing } \\
\text { Temperature } \\
{\left[{ }^{\circ} \mathrm{C}\right]}\end{array}$ & $\begin{array}{l}\text { Accession } \\
\text { Number }\end{array}$ & $\begin{array}{l}\text { Produktgröße } \\
{[\mathrm{BP}]}\end{array}$ \\
\hline Axin2 & $\begin{array}{l}\text { Reference Position: } 2580 \\
\text { Qiagen, Hilden }\end{array}$ & 60,0 & NM_024355 & 124 \\
\hline Bcl-9 & $\begin{array}{l}\text { Reference Position: } 2375 \\
\text { Qiagen, Hilden }\end{array}$ & 60,0 & NM_001107703 & 103 \\
\hline$\beta_{2}$-Microglobulin & $\begin{array}{l}\text { GGTGACCGTGATCTTTCTGG } \\
\text { TGGGTGGAACTGAGACACG }\end{array}$ & 55,0 & NM_012512 & 145 \\
\hline c-jun & $\begin{array}{l}\text { Reference Position: } 881 \\
\text { Qiagen, Hilden }\end{array}$ & 60,0 & NM_021835.3 & 186 \\
\hline Cyclin D1 & $\begin{array}{l}\text { GACACСAATCTCCTCAACG } \\
\text { GCTCCAGAGACAAGAAACG }\end{array}$ & 54,5 & NM_171992 & 224 \\
\hline GSK $3 \beta$ & $\begin{array}{l}\text { Reference Position: } 1209 \\
\text { Qiagen, Hilden }\end{array}$ & 60,0 & NM_032080.1 & 170 \\
\hline HPRT & $\begin{array}{l}\text { CTGGTGAAAAGGACCTCTCG } \\
\text { ACTTGCCGCTGTCTTTTAGG }\end{array}$ & 58,3 & NM_012583 & 183 \\
\hline Met & $\begin{array}{l}\text { GGACTTTGTTGGACAGTGACG } \\
\text { GATTCCCTCAGTCAGAAACTGG }\end{array}$ & 60,0 & NM_031517 & 104 \\
\hline MMP7 & $\begin{array}{l}\text { TCATAATTGGCTTCGCAAGG } \\
\text { GCATGGCCTAGAGTGTTTCC }\end{array}$ & 60,0 & NM_012864 & 76 \\
\hline Wif1 & $\begin{array}{l}\text { Reference Position: } 684 \\
\text { Qiagen, Hilden }\end{array}$ & 60,0 & NM_053738 & 94 \\
\hline
\end{tabular}

Tabelle 2: $\quad$ Übersicht der verwendeten Primer

\subsubsection{Antikörper}

\section{Primärantikörper}

\begin{tabular}{lllll}
\hline Antigen & Spezies & Verdünnung & Katalogname & Herkunft \\
Active- $\beta$-Catenin (ABC) & Maus & $1: 2000 / 1: 50$ & $05-665$ & Millipore, Darmstadt \\
c-jun & Kaninchen & $1: 1000$ & 9165 & Cell Signaling, \\
& & & & Danvers (USA)
\end{tabular}


Histone Deacetylase $1 \quad$ Kaninchen 1:10000 $2062 \quad$ Cell Signaling, (HDAC)

Vimentin

Ziege

$1: 100$

sc- 7557

Danvers (USA)

Tabelle 3: $\quad$ Übersicht der verwendeten Primärantikörper

\section{Sekundärantikörper}

\begin{tabular}{|c|c|c|c|c|}
\hline Antigen & Spezies & Verdünnung & Katalogname & Herkunft \\
\hline Anti-goat hoseradish peroxidase & Kaninchen & $1: 200$ & P0160 & $\begin{array}{l}\text { DakoCytomation, } \\
\text { Glostrup (DK) }\end{array}$ \\
\hline Anti-mouse Alexa Fluor 568 & Ziege & $1: 400$ & A21134 & $\begin{array}{l}\text { Millipore, } \\
\text { Darmstadt }\end{array}$ \\
\hline Anti-mouse horseradish peroxidase & Ziege & $1: 6000$ & Sc-2055 & Santa Cruz (USA) \\
\hline Anti-rabbit horseradish peroxidase & Ziege & 1:3000 & \#7074 & $\begin{array}{l}\text { Cell Signaling, } \\
\text { Danvers (USA) }\end{array}$ \\
\hline
\end{tabular}

Tabelle 4: $\quad$ Übersicht der verwendeten Sekundärantikörper

\subsubsection{Versuchssubstanz Niclosamid}

\begin{tabular}{lll}
\hline Substanz & Stammlösung & Herkunft \\
Niclosamid $(\mathbf{3 2 7 , 1 2} \mathbf{g} / \mathbf{m o l})$ & $1,0 \mu \mathrm{M}$ (in DMSO) & Sigma, Steinheim \\
& $10,0 \mu \mathrm{M}$ (in DMSO) & \\
\hline
\end{tabular}

Tabelle 5: $\quad$ Versuchssubstanz Niclosamid

Aufgrund der schlechten Wasserlöslichkeit des Niclosamids wurde die Substanz in Dimethylsulfoxid (DMSO) gelöst. Die Stammlösungen wurden jeweils nach 4 Wochen neu angesetzt und lichtgeschützt bei Raumtemperatur (RT) gelagert. 


\subsubsection{Kolorektale Karzinomzelllinien}

\begin{tabular}{llccl}
\hline Zelllinie & Spezies & APC-Mutation & $\beta$-Catenin-Mutation & Referenz \\
CC531 & Ratte & & $\mathrm{x}$ & CLS 500387 \\
SW480 & Mensch & $\mathrm{x}$ & ATCC ${ }^{\circledR}$ CCL-228 \\
SW620 & Mensch & $\mathrm{x}$ & ATCC $^{\circledR}$ CCL-227 \\
\hline
\end{tabular}

Tabelle 6: $\quad$ Übersicht der verwendeten Zelllinien

Zellen der Linie CC531 stammen aus einem im Bereich des sigmoidalen Kolons chemisch induzierten Adenokarzinoms aus WAG/Rij Ratten und weisen eine gain-of-functionMutation des Protoonkogens $\beta$-Catenin auf (GERMANN et al. 2003). Die Zelllinie SW620 wurde aus einer Lymphknotenmetastase der koloreaktalen Adenokarzinomzelllinie SW480 eines 51 jährigen kaukasischen Mannes isoliert. Bei diesen beiden Zelllinien wurden loss-of-function-Mutationen des Tumorsuppressorgens APC nachgewiesen (YANG et al. 2006; DIHLMANN et al. 1999). Damit zeigen die verwendeten Zelllinien bei heterogenen Mutationen alle einen aberrant aktivierten Wnt-Signalweg.

Für Kontrollversuche wurden Fibroblasten aus dem subkutanen Fettgewebe einer nicht behandelten Fischer-Ratte (Charles River, Sulzfeld) isoliert.

\subsubsection{Medien für die Zellkultur}

Die kolorektalen Tumorzelllinien (CC531, SW480, SW620) wurden in RPMI 1640 als Grundmedium supplementiert mit $5 \%$ hitzeinaktiviertem FCS, $1 \%$ L-Glutamin und $1 \%$ Penicillin / Streptomycin kultiviert. Für die Kultivierung der Fibroblasten wurde DMEM als Medium mit zusätzlich 10 \% FCS, 1 \% L-Glutamin und 1 \% Penicillin/ Streptomycin verwendet.

Das FCS wurde zunächst im Wasserbad bei $56^{\circ} \mathrm{C}$ für 30 Minuten hitzeinaktiviert und anschließend steril filtriert. 


\subsection{Methoden}

\subsubsection{Kultivierung der Zellen}

Die verwendeten Zelllinien wurden in wasserdampfgesättigter Atmosphäre und $5 \% \mathrm{CO}_{2}$ bei $37{ }^{\circ} \mathrm{C}$ im Brutschrank kultiviert. Alle Zellkulturversuche wurden unter sterilen Bedingungen durchgeführt. Die Zellen wurden täglich lichtmikroskopisch auf Verunreinigungen und Zellwachstum beurteilt und alle 3 Tage mit frischem, vorgewärmtem Kulturmedium versorgt. Alle Zelllinien wuchsen adhärent als Monoschicht in $75 \mathrm{~cm}^{2}$ großen Zellkulturflaschen. Vor Erreichen der Konfluenz wurden die Zellen ein- bis zweimal pro Woche unter der Sterilbank passagiert. Dazu wurden die adhärenten Zellen nach Entfernung des Kulturmediums zunächst zweimal mit $5 \mathrm{ml}$ PBS gewaschen, um FCS-Rückstände zu entfernen. Anschließend wurden die Zellen mit 1,5 ml Trypsin-EDTA (10x) für 5 bis 15 Minuten im Brutschrank inkubiert, wodurch sie sich vom Gefäßboden ablösten. Durch Zugabe von $7 \mathrm{ml}$ frischem Kulturmedium wurde die Trypsinreaktion gestoppt. Abschließend wurden die Zellen nach Zentrifugation (900 rpm, 7 Min., RT) und Resuspension in frischem Kulturmedium im Verhältnis 1:5 in 20 ml Kulturmedium ausgedünnt.

\subsubsection{Kryokonservierung der Zellen}

Alle verwendeten Zelllinien wurden vor Beginn der Experimente expandiert und in einheitlichen Passagen aliquotiert eingefroren. Vor Erreichen der Konfluenz wurden die adhärenten Zellen hierfür wie unter 2.2.1 beschrieben abgelöst, zentrifugiert, anschließend in Einfriermedium (900 $\mu \mathrm{l}$ FCS, $100 \mu \mathrm{l}$ DMSO) resuspendiert und in beschriftete Kryoröhrchen gefüllt. Über Nacht wurden die Zellen zunächst in einer mit Isopropanol gefüllten Kryobox bei $-80{ }^{\circ} \mathrm{C}$ schrittweise (-1 ${ }^{\circ} \mathrm{C} / \mathrm{Min}$.) eingefroren. Am nächsten Morgen wurden die Aliquots zur dauerhaften Aufbewahrung in Tanks mit flüssigem Stickstoff überführt. 


\subsubsection{Revitalisierung der Zellen}

Für die im Folgenden beschriebenen Zellkulturversuche wurden maximal zehn Passagen der verschiedenen Zelllinien genutzt. Bei Erreichen der zehnten Passage wurden neue Zellen aus der ursprünglichen Passage revitalisiert. Zum Entfernen von DMSO-Rückständen des Einfriermediums wurden die Zellen in $10 \mathrm{ml}$ Kulturmedium resuspendiert und im Anschluss zentrifugiert (900 rpm, 7 Min., RT). Das entstandene Zellpellet wurde in frischem Kulturmedium erneut resuspendiert und anschließend in eine mit $20 \mathrm{ml}$ Kulturmedium gefüllte Zellkulturflasche überführt.

\subsubsection{Isolation von Fibroblasten}

Zum Vergleich der Wirkung des Niclosamids auf gesunde Zellen wurden Fibroblasten aus dem subkutanen Fettgewebe einer unbehandelten Fischer-Ratte isoliert. Sechs Gewebestücke wurden aus dem Unterhautfettgewebe herauspräpariert und in $25 \mathrm{~cm}^{2}$ große Zellkulturflaschen gefüllt mit $10 \mathrm{ml}$ DMEM-Medium in Kultur genommen. Täglich wurde die Emigration von Zellen aus den Gewebestücken optisch beurteilt und das Kulturmedium bei Farbumschlag von rot-violett nach gelb gewechselt, da dies den Verbrauch der Nährstoffe im Medium anzeigt. Nach zwei Wochen war eine ausreichende Menge an Zellen aus dem Gewebeverband ausgewandert, sodass die Fettgewebestücke entfernt und die Fibroblasten expandiert werden konnten (vgl. Kapitel 2.2.2).

\subsubsection{Immunhistochemischer Nachweis von Fibroblasten}

\section{Kultivierung und Fixation auf Chamber Slides}

Zum Identitätsnachweis der isolierten Zellen (vgl. Kapitel 2.2.4) wurden $2 \times 10^{4}$ dieser Zellen auf Chamber Slides in 2 ml DMEM-Medium kultiviert. Nach 24 Stunden wurde das Medium verworfen und mögliche FCS-Rückstände durch zweimaliges Waschen mit $3 \mathrm{ml}$ PBS entfernt. Anschließend wurden die Zellen für 10 Minuten bei $4{ }^{\circ} \mathrm{C}$ in Aceton fixiert. 


\section{Immunhistochemischer Nachweis von Vimentin in primären Zellen}

Das zytoskeletale Intermediärfilament Vimentin ist hochgradig gewebsspezifisch für Zellen mesenchymaler Herkunft. Daher eignet sich eine immunhistochemische Färbung dieses Proteins zum Nachweis der Identität von Fibroblasten. Entsprechend wurde die Expression von Vimentin in den Zellen auf den Chamber Slides gemäß des nachfolgenden Protokolls (vgl. Tabelle 7) analysiert.

1. Inkubation in 0,3 \% $\mathrm{H}_{2} \mathrm{O}_{2}$-haltigem Methanol für 20 Min. bei RT zur Eliminierung der endogenen Peroxidaseaktivität

2. Entfernen von $\mathrm{H}_{2} \mathrm{O}_{2}$ - und Methanol-Rückständen durch zweimaliges Waschen in Tris-Puffer für 5 Min.

3. Inkubation mit polyklonalem Vimentin-Antikörper, verdünnt in Antikörperdiluent im Verhältnis 1:50 bei $4{ }^{\circ} \mathrm{C}$ über Nacht

4. Entfernen von Antikörper-Rückständen durch zweimaliges Waschen in Tris-Puffer für 5 Min.

5. Inkubation mit einem polyklonalen Rabbit-Anti-Goat-Antikörper gekoppelt an eine HRP, verdünnt in Tris-Puffer im Verhältnis 1:200 für 30 Min. bei RT

6. Entfernen von Antikörper-Rückständen durch zweimaliges Waschen in Tris-Puffer für 5 Min.

7. Nachweis der HRP-Aktivität durch Inkubation mit $\mathrm{H}_{2} \mathrm{O}_{2}$-haltigem AEC-Substrat für $30 \mathrm{Min}$. bei RT unter Bildung eines rotbraunen Farbproduktes

8. Entfernen von $\mathrm{H}_{2} \mathrm{O}_{2}$ - und AEC-Rückständen durch zweimaliges Waschen in Aqua bidest. für 5 Min.

9. Kernfärbung mit Hämatoxylin für 30 Min.

Tabelle 7: Färbeprotokoll zum Nachweis von Vimentin

\subsubsection{Wachstum und Zytotoxizität nach Inkubation mit Niclosamid}

\section{Kultivierung für 24 Stunden und 12 Stunden}

Der wachtumsinhibitorische Effekt des Niclosamids wurde zunächst in Zellkultur nach einer Inkubationszeit von 24 und 12 Stunden untersucht. 240.000 (CC531, SW480, SW620) respektive 100.000 (Fibroblasten) Zellen wurden pro Schale einer 6er Well Platte in $3 \mathrm{ml}$ des entsprechenden Kulturmediums ausplattiert. Nach 24 Stunden initialer Inkubationszeit 
wurden aufsteigende Konzentrationen des Niclosamids $(1 \mu \mathrm{M}, 3 \mu \mathrm{M}, 10 \mu \mathrm{M}, 50 \mu \mathrm{M})$ oder Volumina der Trägersubstanz DMSO als Kontrolle $(0,9 \mu \mathrm{l}, 3 \mu \mathrm{l}, 15 \mu \mathrm{l})$ in frisches Kulturmedium hinzugefügt (vgl. Tabelle 8). DMSO wurde somit in einer maximalen Konzentration von 0,5\% eingesetzt. Außerdem wurden Zellen im Sinne einer Mediumkontrolle unbehandelt belassen. Nach weiteren 24 respektive 12 Stunden wurde die Zellzahl der adhärent am Boden angewachsenen Zellen nach Ablösung durch TrypsinEDTA in der Neubauer-Zählkammer bestimmt.

\begin{tabular}{lll}
\hline $\begin{array}{l}\text { Zielkonzentration des Niclosamids } \\
{[\boldsymbol{\mu M}]}\end{array}$ & $\begin{array}{l}\text { Stammlösung } \\
{[\boldsymbol{\mu M}]}\end{array}$ & Ansatz \\
1 & 1 & $3 \mu \mathrm{l}$ Stammlösung $+3 \mathrm{ml}$ Medium \\
3 & 10 & $0,9 \mu \mathrm{l}$ Stammlösung $+3 \mathrm{ml}$ Medium \\
10 & 10 & $3 \mu \mathrm{l}$ Stammlösung $+3000 \mathrm{ml}$ Medium \\
50 & 10 & $15 \mu \mathrm{l}$ Stammlösung $+3000 \mathrm{ml}$ Medium
\end{tabular}

Tabelle 8: $\quad$ Pipettierschema für Niclosamid-Inkubation

\section{Zellzahlbestimmung mit Neubauer-Zählkammer}

Die Zellen wurden in 100 bis $1000 \mu \mathrm{l}$ Medium in Abhängigkeit von der eingesetzten Niclosamid-Konzentration resuspendiert und mit Trypan-Blau im Verhältnis 1:100 versetzt. Trypan-Blau reichert sich ausschließlich in avitalen Zellen an, sodass diese lichtmikroskopisch identifiziert werden können. Zur Zellzahlbestimmung wurden die Zellen in den vier Großquadranten einer Neubauer-Zählkammer ausgezählt. Der Suspension wurde jeweils $\quad 1 \%$ DNase hinzugefügt zur effektiven Vereinzelung der Zellen. Die Gesamtzellzahl wurde mit der nachstehenden Formel berechnet:

Zellzahl $/ \mathrm{ml}=($ Mittelwert der vier Großquadranten $) \times 10^{4} \times$ Verdünnungsfaktor $\times$ Ausgangsvolumen

\section{Färbung der Zellen mit Gram-Kristallviolett-Lösung}

Die Zellen wurden nach 12 Stunden Inkubation mit Niclosamid mit einer KristallviolettLösung (Merck, Darmstadt) gefärbt, um Veränderungen der Zelldichte sowie morphologische Veränderungen der Zellen lichtmikroskopisch zu dokumentieren. Dabei wurde nach dem Protokoll in Tabelle 9 vorgegangen. Die 6 Well Zellkulturplatten wurden 
nach Fixierung und Färbung bei $4{ }^{\circ} \mathrm{C}$ dunkel gelagert. Abschließend erfolgte die lichtmikroskopische Beurteilung.

1. Entfernung des Mediumüberstandes und von FCS-Rückständen durch zweimaliges Waschen mit $3 \mathrm{ml}$ PBS

2. Fixierung in $70 \%$ Ethanol bei RT für 30 Min.

3. Entfernung von Ethanol-Überständen durch dreimaliges Waschen mit Aqua bidest.

4. Inkubation in Gram-Kristallviolett-Lösung bei RT für 45 Min.

5. Entfernung von Färberückständen durch viermaliges Waschen mit Aqua bidest.

6. Weitere Kontrastierung durch Entfärbung unter laufendem Leitungswasser

7. Über Nacht trocknen

Tabelle 9: $\quad$ Färbeprotokoll nativer Zellen mit Kristallviolett-Lösung

Durchflusszytometrische Analyse nach Annexin-V-Fluos - / Propidiumiodid Doppelfärbung

\begin{tabular}{ll}
\hline Inkubationspuffer & $10 \mathrm{mM} \mathrm{Hepes/} \mathrm{NaOH,} \mathrm{pH} \mathrm{7,4}$ \\
& $140 \mathrm{mM} \mathrm{NaCl}$ \\
& $5 \mathrm{mM} \mathrm{CaCl}_{2}$
\end{tabular}

Propidiumiodid-Lösung $\quad 50 \mu \mathrm{g} / \mathrm{ml}$ PBS

Markierungslösung $\quad 1000 \mu \mathrm{l}$ Inkubationspuffer

$20 \mu \mathrm{l}$ Annexin-V-Fluos

$20 \mu$ Propidiumiodid

Tabelle 10: Pipettierschema zur Herstellung der Annexin-V-Fluos-Markierungslösung

Während der Apoptose eukaryotischer Zellen wird die asymmetrische Verteilung der Phospholipide innerhalb der Zellmembran aufgehoben. Dabei wird Phosphatidylserin charakteristischerweise auf die Außenseite der Lipiddoppelmembran transloziert (FADOK et al. 1992a, FADOK et al. 1992b). Das Fluorescein-konjugierte Antikoagulans Annexin-V-Fluos hat eine spezifische, $\mathrm{Ca}^{2+}$-abhängige Affinität für Phosphatidylserin. Eine Doppelfärbung mit Propidiumiodid zur weiteren Unterscheidung von apoptotischen und nekrotischen Zellen ist notwendig, da auch nekrotische Membranüberreste Phosphatidylserin exprimieren. 
Propidiumiodid penetriert nur die permeabilisierte Membran nekrotischer Zellen, nicht aber die intakte Membran apoptotischer Zellen (VERMES et al. 1995).

Nach 24 Stunden Inkubation mit aufsteigenden Niclosamid-Konzentrationen $(1 \mu \mathrm{M}, 3 \mu \mathrm{M}$, $10 \mu \mathrm{M}, 50 \mu \mathrm{M}$ ) oder $15 \mu \mathrm{l}$ des Lösungsmittels DMSO wurden pro Bedingung $10^{6}$ Zellen der Linie CC531 mit PBS gewaschen, durch Zugabe von Trypsin-EDTA vereinzelt, in Medium resuspendiert und zentrifugiert. In der Suspension wurden die am Boden angehefteten Zellen und die Zellen des Überstandes vereinigt. Zur Kontrolle wurden unbehandelte Zellen mitgeführt. Das Zellpellet wurde in $100 \mu \mathrm{l}$ Markierungslösung (vgl. Tabelle 10) resuspendiert und in einem FACS-Röhrchen für 15 Minuten im Dunkeln inkubiert. Im Anschluss erfolgte die Analyse im Durchflusszytometer. Separat wurde nach 12 Stunden Inkubation der Zustand der nur am Boden angewachsenen Zellen unter sonst unveränderten Bedingungen analysiert.

Durchflusszytophotometrisch wurden die Annexin-V-Fluos-Signale im grünen Wellenlängenbereich und die Propidiumiodid-Signale im roten Wellenlängenbereich detektiert. Um ein Überlappen beider Emissionsspektren ausschließen zu können, wurden pro Bedingung ungefärbte Zellen, nur mit Annexin-V-Fluos gefärbte Zellen, nur mit Propidiumiodid gefärbte Zellen und mit Annexin-V-Fluos und Propidiumiodid doppelgefärbte Zellen separat analysiert. Die Analyse erfolgte mit einem FACSCanto und der passenden FACSDiva ${ }^{\mathrm{TM}}$ Software Version 6.1.3 (BD Biosciences, Heidelberg), wobei jeweils 20.000 Zellen erfasst wurden.

\subsubsection{TOPflash/ FOPflash Dual-Luciferase ${ }^{\circledR}$ Reporter Assay}

\section{Nukleofektion adhärenter Zellen}

\begin{tabular}{ll}
\hline $5 \times 10^{6}$ & Zellen \\
$100 \mu \mathrm{l}$ & Nukleofektion-Kit V \\
$100 \mathrm{ng}$ & TOPflash Plasmid oder FOPflash Plasmid \\
$10 \mathrm{ng}$ & Renilla Luciferase Plasmid \\
\hline
\end{tabular}

Tabelle 11: Pipettierschema zur Nukleofektion

Zur Untersuchung des Einflusses von Niclosamid auf die Aktivität des Wnt-Signalweges wurden 5 x $10^{6}$ Zellen der Linie CC531 mit 100 ng des Plasmids TOPflash 
(Millipore, Schwalbach) transfiziert, das sechs Bindungsstellen für den Transkriptionsfaktor LEF/ TCF enthält. Dieses Konstrukt stellt die Expression einer Luciferase unter die Kontrolle von LEF/ TCF, also der Endstrecke des kanonischen Wnt-Signalweges. Als dazugehörige Negativkontrolle wurden parallel Zellen mit der gleichen Menge des Plasmids FOPflash (Millipore, Schwalbach) transfiziert. FOPflash enthält aufgrund gezielter Mutationen keine Bindungsstellen für LEF/ TCF. Die Zellen wurden jeweils mit 10 ng eines Plasmids mit der konstitutiv aktiven Renilla-Luciferase aus der Koralle Renilla reniformis (Promega, Mannheim) kotransfiziert, um experimentelle Variabilitäten wie ungleichmäßige Transfektionseffizienzen oder Zellvitalität zu minimieren.

1 Million CC531 Zellen wurden in der speziellen Nukleofektionslösung (vgl. Tabelle 11) suspendiert und mit der in Vorexperimenten ermittelten, optimalen DNA-Menge der Plasmide supplementiert. Die Transfektion erfolgte mithilfe des Nucleofector ${ }^{\circledR}$ II (Lonza, Basel, Schweiz). Im Anschluss wurden die Zellen in $1 \mathrm{ml}$ des Kulturmediums aufgenommen und gleichmäßig auf die Schalen einer 6er Well Platte verteilt. Die Zellen wurden 24 Stunden unter optimalen Bedingungen im Brutschrank kultiviert. Anschließend wurden das Kulturmedium gewechselt und die Zellen mit aufsteigenden Konzentrationen des Niclosamids $(3 \mu \mathrm{M}, 10 \mu \mathrm{M}, 50 \mu \mathrm{M})$ oder des höchsten eingesetzten Volumens von DMSO $(15 \mu \mathrm{l})$ für 12 Stunden inkubiert. Außerdem wurden Zellen als Mediumkontrolle in reinem Kulturmedium belassen. Die relative Aktivität des Wnt-Signalweges wurde anschließend ermittelt.

\section{Dual-Luciferase ${ }^{\circledR}$ Reporter Assay}

\begin{tabular}{ll}
\hline $500 \mu \mathrm{l}$ & Passive Lysis Buffer (PLB) \\
$100 \mu \mathrm{l}$ & Luciferase Assay Reagenz II (LAR II) \\
$100 \mu \mathrm{l}$ & Stop \& Glo® Reagenz
\end{tabular}

Tabelle 12: $\quad$ Pipettierschema zum Dual-Luciferase ${ }^{\circledR}$ Reporter Assay

Der Dual-Luciferase ${ }^{\circledR}$ Reporter Assay ermöglicht es, die Aktivitäten von zwei aus unterschiedlichen Spezies isolierten Luciferasen bioluminometrisch sequentiell $\mathrm{zu}$ ermitteln. Das verwendete Plasmid TOPflash enthält eine Firefly-Luciferase aus dem Leuchtkäfer Photinus pyralis, deren Expression von der Aktivität des Transkriptionsfaktors 
LEF/ TCF und damit des kanonischen Wnt-Signalweges kontrolliert wird. Wenn die Aktivität des Wnt-Signalweges beispielsweise durch die Zugabe eines Inhibitors sinkt, werden die Expression dieser Luciferase und damit deren absolute Aktivität reduziert, sodass auch das bioluminometrische Signal abnimmt. Auch das Kontrollplasmid FOPflash enthält die Firefly-Luciferase.

Nach 12 Stunden Inkubation mit Niclosamid in einer 6 Well Zellkulturplatte wurde das Kulturmedium verworfen und mögliche FCS-Rückstände durch Inkubation mit $3 \mathrm{ml}$ PBS für 5 Minuten entfernt. Nachfolgend wurden die adhärent gewachsenen Zellen mit $250 \mu \mathrm{l}$ PLB bedeckt, für 15 Minuten inkubiert und hierdurch lysiert. $20 \mu \mathrm{l}$ des Lysates wurden pro Bedingung als Triplikat in die Schalen einer 96 Well Zellkulturplatte pipettiert. Zur Kontrolle wurde eine Schale mit $20 \mu \mathrm{l}$ reinem PLB befüllt. Mithilfe eines Luminometers (Berthold Technologies, Oak Ridge, USA) wurden zunächst $100 \mu$ LAR II, welches Luciferin im Überschuss enthält, in die Schalen einer 96 Well Zellkulturplatte gegeben und dann der Umsatz der Firefly-Luciferase gemessen. Im Anschluss wurden $100 \mu \mathrm{l}$ des Stop \& Glo Reagenz hinzugefügt, welches Coelenterazin im Überschuss enthält. Dadurch wurde sowohl die Reaktion der Firefly-Luciferase gestoppt als auch die der Renilla-Luciferase initiiert. Die Enzymumsätze wurden jeweils in RLU (relative light units) angegeben.

Nach Abzug der im reinen PLB ermittelten Autolumineszenzwerte der Substrate wurden die Werte der TOPflash Firefly zunächst durch die Werte der Renilla-Luciferase dividiert. Die relative Promotoraktivität konnte als Quotient der TOPflash Firefly-Luciferase und der FOPflash Firefly-Luciferase angegeben werden.

\subsubsection{Real-time Reverse Transcription-Polymerase Chain Reaction (RT-PCR)}

\section{Extraktion von RNA für die RT-PCR}

Nach 12 Stunden Inkubation mit $1 \mu \mathrm{M}, 3 \mu \mathrm{M}, 10 \mu \mathrm{M}$ und $50 \mu \mathrm{M}$ Niclosamid wurden die adhärent am Boden haftenden Zellen mit peqGOLD TriFast bestehend aus Phenol und Guanidinisothiocyanat (peqlab, Erlangen) entsprechend des Protokolls des Herstellers lysiert (vgl. Tabelle 13). Zur Kontrolle wurden unbehandelte Zellen (Mediumkontrolle) und mit der höchsten eingesetzten Menge des Lösungsmittels DMSO (15 $\mu$ l) inkubierte Zellen 
lysiert. Im Anschluss wurde die RNA aus dem Lysat extrahiert, gelöst und dann bei $-80{ }^{\circ} \mathrm{C}$ gelagert.

1. Entfernen des Mediums und möglicher FCS-Rückstände durch dreimaliges Waschen mit $3 \mathrm{ml}$ PBS für jeweils 5 Min.

2. Lyse der Zellen durch Zugabe von $1 \mathrm{ml}$ peqGOLD TriFast pro Schale einer 6er Well Platte; Inkubation für 5 Min. bei RT zur Dissoziation von Nukleotidkomplexen

3. Zugabe von $0,2 \mathrm{ml}$ Chloroform und Inkubation für $10 \mathrm{Min}$.

4. Zentrifugation für $15 \mathrm{Min}$. bei $12.000 \mathrm{xg}$ und $4^{\circ} \mathrm{C}$; Bildung von drei Phasen (rote Phenol-ChloroformPhase, durchsichtige wässrige Phase, Interphase); RNA ausschließlich in wässriger Phase enthalten

5. Überführung der wässrigen Phase in frisches Röhrchen und Zugabe von 0,5 ml Isopropanol zur Präzipitation der RNA; Inkubation für 15 Min. auf Eis

6. Zentrifugation für $10 \mathrm{Min}$. bei $12.000 \mathrm{xg}$ und $4^{\circ} \mathrm{C}$; Verwerfen des Isopropanolüberstandes

7. Waschen des RNA-Pellets durch Zugabe von $1 \mathrm{ml} 75 \%$ Ethanol und anschließender Zentrifugation für 10 Min. bei $12.000 \mathrm{xg}$ und $4^{\circ} \mathrm{C}$

8. Wiederholung von Schritt 7

9. Trocknen des RNA-Pellets bei $57^{\circ} \mathrm{C}$ in einem Block Thermomixer

10. Lösen der RNA durch Zugabe von $20 \mu \mathrm{l}$ RNase freiem Wasser; Erhitzen der Lösung auf $57^{\circ} \mathrm{C}$ in einem Block Thermomixer für 10 Min. zur effizienteren Lösung der RNA

11. Messung der RNA-Menge (ng/ $\mu \mathrm{l})$ im Spectrophotometer

\section{Tabelle 13: $\quad$ Protokoll zur Extraktion von RNA}

\section{Reverse Transkription}

Mithilfe einer Reversen Transkriptase wird aus RNA sogenannte cDNA (complementary DNA) synthetisiert. Hierfür wird die Hybrid-abhängige Exoribonuklease-Aktivität (RNase H) der Reversen Transkriptase genutzt, die die RNA aus RNA-DNA-Hybriden entfernt. Mithilfe der verwendeten QuantiTect Reverse Transcription Kit (Qiagen, Hilden) wird vor der Synthese der cDNA die genomische DNA aus RNA Lösungen eliminiert, sodass die spätere cDNA keine Introns mehr enthält. Da die Sequenz der cDNA dann der Sequenz 
der mRNA (messenger RNA) entspricht, ist es möglich, Aussagen über die Transkription eines spezifischen Genabschnittes zu treffen. Entsprechend den Angaben des Herstellers wurden von jedem RNA-Template $3 \mu \mathrm{g}$ in cDNA umgeschrieben (vgl. Tabelle 14). Die Aliquots mit der hergestellten cDNA, die in der real-time PCR eingesetzt wurde, wurden bei $-20{ }^{\circ} \mathrm{C}$ gelagert.

1. Lösung von $3 \mu \mathrm{g}$ des RNA-Templates mit $6 \mu \mathrm{l}$ gDNA Wipeout Buffer (7x) und Auffüllen mit RNAse freiem Wasser auf $14 \mu \mathrm{l}$

2. Inkubation für $2 \mathrm{Min}$. bei $42^{\circ} \mathrm{C}$ im Thermocycler; sofortige Lagerung auf Eis

3. Herstellung des Reverse-Transkriptase Master Mixes aus $3 \mu \mathrm{l}$ Quantiscript Reverse Transcriptase, $12 \mu$ l Quantiscript RT Buffer (5x) und $3 \mu$ RT Primer Mix

4. Zugabe der unter 2 von genomischer DNA eliminierten RNA

5. Inkubation für $15 \mathrm{Min}$. bei $42^{\circ} \mathrm{C}$ im Thermocycler zur Synthese der cDNA

6. Inkubation für $3 \mathrm{Min}$. bei $42^{\circ} \mathrm{C}$ im Thermocycler zur Terminierung der reversen Transkription

\section{Tabelle 14: $\quad$ Protokoll zur Synthese von cDNA}

\section{Prinzip der real-time PCR}

Die real-time PCR ermöglicht die Quantifizierung der Expression von Genabschnitten. Somit kann indirekt auf die Höhe einer spezifischen Genexpression geschlossen werden (WONG \& MEDRANO 2005). Dabei ist es möglich, Unterschiede in der Expression eines Genes in verschiedenen Proben ab 23 \% zu erfassen (GENTLE et al. 2001).

Die Methode gliedert sich in drei Abschnitte: Zunächst kommt es durch Erhöhung der Temperatur auf $95{ }^{\circ} \mathrm{C}$ zur Denaturierung, also zur Trennung der Doppelstrang cDNA. Anschließend wird die Temperatur auf variable Werte, die dem Temperaturoptimum der eingesetzten Primer entsprechen, gesenkt. Primer sind Oligonukleotidsequenzen, die bei ihrem Temperaturoptimum an ihrer komplementären Einzelstrang-DNA-Sequenz binden (Annealing). Sie markieren den Beginn und das Ende der zu amplifizierenden mRNASequenz und sind die Bindestelle der Taq-Polymerase. Diese aus dem Bakterium Thermus aquaticus stammende thermostabile Polymerase terminiert einen Zyklus mit der Elongation, also der Synthese des komplementären Zweitstranges. Dieser Zyklus aus 
Denaturierung, Anlagerung (Annealing) und Elongation wird 40-mal wiederholt, wobei es nach jedem Zyklus zur Verdopplung der DNA- Menge gekommen ist.

Die Quantifizierung der DNA wird durch Zugabe von iQ SYBR Green Supermix (Bio-Rad, München) ermöglicht. Dieser interkaliert mit der synthetisierten Doppelstrang-DNA und emittiert nach Laseranregung Licht der Wellenlänge $520 \mathrm{~nm}$. Mithilfe eines ThermalCyclers (Bio-Rad, München) kann das emittierte Licht detektiert werden. Als threshold (Schwellenwert) bezeichnet man die Zykluszahl, bei der die Fluoreszenzemission das Hintergrundrauschen signifikant übersteigt ( $\mathrm{C}_{\mathrm{t}}-\mathrm{Wert}$ ). Die Zykluszahl, an dem der $\mathrm{C}_{\mathrm{t}}$-Wert liegt, richtet sich nach der Menge der ursprünglich in der Probe enthaltenen mRNA. Je mehr mRNA eine Probe enthält, desto weniger PCR Zyklen sind notwendig, um die Menge an DNA zu amplifizieren, deren Fluoreszenzsignal das Grundrauschen übersteigt (TICHOPAD et al. 2003).

Die ermittelten $\mathrm{C}_{\mathrm{t}}$-Werte werden relativ quantifiziert, indem man die Expression des Zielgenes in der betrachteten Probe in Relation zu einer Referenzgruppe (unbehandelte Mediumkontrolle) setzt. Diese relative Quantifizierung hat den Vorteil, dass eine Steigerung oder Reduzierung einer Genexpression durch eine spezielle Behandlung, wie in der vorliegenden Arbeit mit Niclosamid, erfasst werden kann (LIVAK et al. 2001). Zusätzlich wird die Expression mit zwei sogenannten housekeeping oder Referenzgenen normalisiert, deren Expression nach Möglichkeit unabhängig vom Experimentaufbau in den verschiedenen Proben konstant sein sollte (SCHMITTGEN et al. 2000).

\section{Real-time PCR}

Zur Durchführung der PCR wurde der $\mathrm{iQ}^{\mathrm{TM}} \mathrm{SYBR}^{\circledR}$ Green Supermix (Bio-Rad, München) verwendet. Dieser Mix enthält zum einen eine thermostabile Taq-Polymerase und zum anderen den Fluoreszenzfarbstoff Fluorescein. Auf einer 96er PCR-Platte wurden Triplikate jeder Probe als $25 \mu \mathrm{l}$ Reaktionen nach nachfolgendem Schema (vgl. Tabelle 15) pipettiert, anschließend zur vollständigen Vereinigung der einzelnen Komponenten zentrifugiert und bei $-20^{\circ} \mathrm{C}$ gelagert. 


\begin{tabular}{lll}
\hline Komponente & Volumen pro Reaktion & Konzentration \\
iQ SYBR Green Super Mix & $12,5 \mu \mathrm{l}$ & $1 \mathrm{x}$ \\
forward Primer & $0,5 \mu \mathrm{l}$ & $200 \mathrm{nM}$ \\
reverse Primer & $0,5 \mu \mathrm{l}$ & $200 \mathrm{nM}$ \\
$\mathrm{H}_{2} \mathrm{O}$ & $10,5 \mu \mathrm{l}$ & \\
cDNA-Template & $1 \mu \mathrm{l}$ (enthält 50 ng DNA)
\end{tabular}

Tabelle 15: Pipettierschema für die real-time PCR

Nach Auftauen der Platten und nochmaliger Zentrifugation wurden die Proben anhand eines vorgegebenen Temperaturprogrammes (vgl. Tabelle 16) im LightCycler (Bio-Rad, München) analysiert. Als Reinheitskontrolle wurde für jeden Primer ein Triplikat ohne Zugabe von cDNA mitgeführt. Die Schmelzkurve wurde zum Nachweis der Genspezifität anhand von Einzelpeaks erstellt. Die Auswertung in Relation zur Mediumkontrolle erfolgte mit der CFX Manager ${ }^{\mathrm{TM}}$ Software Version 1.5 (Bio-Rad, München).

\begin{tabular}{llll}
\hline Zyklusschritt & Temperatur $\left[{ }^{\circ} \mathbf{C}\right]$ & Zeit [Min.] & Wiederholungen \\
Aktivierung der Taq-Polymerase & 95 & 5 & 0 \\
Denaturierung & 95 & 0,3 & 40 \\
Annealing & Primer spezifisch & 0,3 & 40 \\
Schmelzkurve & $55-95$ & 13,3 & 0 \\
& (Steigerung um $0,5^{\circ} \mathrm{C}$ alle 0,1 Min.) & \\
\hline
\end{tabular}

Tabelle 16: PCR-Temperaturprogramm

\subsubsection{Immunfluoreszenznachweis von aktivem $\beta$-Catenin}

Zur Klärung der Frage, ob Niclosamid den Anteil der nukleären aktiven Form des $\beta$ Catenins verändert, wurde aktives $\beta$-Catenin immunfluoreszenzmikroskopisch analysiert. 20.000 Zellen der Linie CC531 wurden für 24 Stunden auf Chamber Slides kultiviert. Anschließend wurden die Zellen mit frischem Medium versorgt und aufsteigende Niclosamid-Konzentrationen hinzugefügt $(0 \mu \mathrm{M}, 3 \mu \mathrm{M}, 10 \mu \mathrm{M}, 50 \mu \mathrm{M})$. Zur Kontrolle wurden Zellen zusätzlich mit $15 \mu \mathrm{l}$ des Lösungsmittels DMSO inkubiert. Nach weiteren 24 Stunden wurde das Medium verworfen und mögliche FCS-Rückstände durch zweimaliges Waschen mit 3 ml PBS entfernt. Die Fixation der Zellen auf den Chamber Slides 
erfolgte anschließend für 2 Minuten bei $-20^{\circ} \mathrm{C}$ in Methanol. Der Nachweis von aktivem $\beta$ Catenin erfolgte nach dem Protokoll in Tabelle 17.

1. Zweimaliges Waschen der Chamber Slides für 5 Min. in Tris-Puffer

2. 20 minütiges Kochen der Chamber Slides in Target Retrieval Solution im Steamer

3. Abkühlen der Chamber Slides auf $37^{\circ} \mathrm{C}$

4. Zweimaliges Waschen der Chamber Slides für 5 Min. in Tris-Puffer

5. Blockierung kreuzreaktiver Proteine durch Inkubation mit einem Fishblock für 20 Min.

6. Zweimaliges Waschen der Chamber Slides für 5 Min. in Tris-Puffer

7. Inkubation mit monoklonalem Antikörper gegen aktives $\beta$-Catenin, verdünnt in Antikörperdiluent im Verhältnis $1: 50$ bei $4^{\circ} \mathrm{C}$ über Nacht

8. Zweimaliges Waschen der Chamber Slides für 5 Min. in Tris-Puffer

9. Inkubation mit einem polyklonalen Goat-Anti-Mouse-Fluoreszenzantikörper verdünnt in Tris-Puffer im Verhältnis 1:400 für 60 Min. bei RT

10. Darstellung der Zellkerne mit DAPI

11. Eindeckeln der Chamber Slides mit Vectashield

Tabelle 17: Färbeprotokoll zum Nachweis von aktivem $\beta$-Catenin 


\subsubsection{Western Blot}

\section{Zellauftrennung}

$\begin{array}{ll}\text { Puffer A: } & 100 \mathrm{mM} \mathrm{Hepes}^{\mathrm{KOH}} \mathrm{pH} 7,9 \\ & 1,5 \mathrm{mM} \mathrm{MgCl} \\ & 10 \mathrm{mM} \mathrm{KCl} \\ & \\ & \\ & 20 \mathrm{mM} \text { Hepes-KOH pH 7,9 } \\ & 420 \mathrm{mM} \mathrm{NaCl} \\ & 15 \mathrm{mM} \mathrm{MgCl} 2 \\ & 0,2 \mathrm{mM} \mathrm{EDTA} / \mathrm{NaOH} \\ & 25 \% \text { Glycerol } \\ & 1 \% \mathrm{NP}-40 \text { (IgPAL) } \\ & 0,5 \% \text { Na-Doc }\end{array}$

Vor Gebrauch jeweils Zugabe von: $\quad 5 \mu \mathrm{DTT}$

$10 \mu \mathrm{lPMSF}$

$100 \mu$ l Phospho-Stop

$10 \mu$ Protease-Inhibitor-Cocktail

\section{Tabelle 18: Pipettierschema zur Zellauftrennung für Western Blot}

Nach 12 Stunden Inkubation mit aufsteigenden Konzentrationen des Niclosamids $(0 \mu \mathrm{M}$, $1 \mu \mathrm{M}, 3 \mu \mathrm{M}, 10 \mu \mathrm{M}$ und $50 \mu \mathrm{M}$ ) oder den entsprechenden Volumina der Trägersubstanz DMSO als Kontrolle (3 $\mu \mathrm{l}$ und $15 \mu \mathrm{l}$ ) wurden die Zellen nach dem Protokoll in Tabelle 19 lysiert und in eine Zytosol- und eine Kernfraktion aufgetrennt. Zur Kontrolle wurden unbehandelte Zellen analog mitgeführt. Anschließend erfolgte die Bestimmung der Proteinkonzentration im Multilable Reader VICTOR TM X4 (PerkinElmer, Waltham, USA) und der zugehörigen Software in der Version 4.00 mit dem Pierce ${ }^{\circledR}$ BCA Protein Assay Kit entsprechend den Angaben des Herstellers (Thermo Scientific, Waltham, USA).

1. Waschen der Zellen mit $5 \mathrm{ml}$ PBS; Lösung der Zellen durch Zugabe von 0,3 ml Trypsin-EDTA (10x); Resuspension in $3 \mathrm{ml}$ Zellkulturmedium; Zentrifugation (750 rpm, 5 Min.)

2. Entfernen des Überstandes und Resuspension in $1 \mathrm{ml}$ PBS

3. Zentrifugation ( $200 \mathrm{xg}, 10 \mathrm{Min}$.)

4. Verwerfen des Überstandes und Resuspension des Zellpellets in $100 \mu$ l eisgekühltem Puffer A (vgl. Tabelle 18)

5. Inkubation auf Eis (10 Min.); Zellen schwellen an 
6. Zugabe von NP-40 (10 \%ig) mit Endkonzentration von 0,5\% und Zentrifugation ( $750 \mathrm{xg}, 1$ Min.)

7. Im Überstand befindet sich die Zytosolfraktion.

8. Resuspension des Pellets in $20 \mu \mathrm{l}$ eisgekühltem Puffer B (vgl. Tabelle 18)

9. Inkubation im Kühlraum auf dem Vortex (30 Min.)

10. Zentrifugation (7700 rpm, 5 Min.)

11. Im Überstand befindet sich die Kernfraktion.

Tabelle 19: $\quad$ Protokoll zur Zelllyse für Western Blot

\section{SDS-Polyacrylamidgel-Elektrophorese}

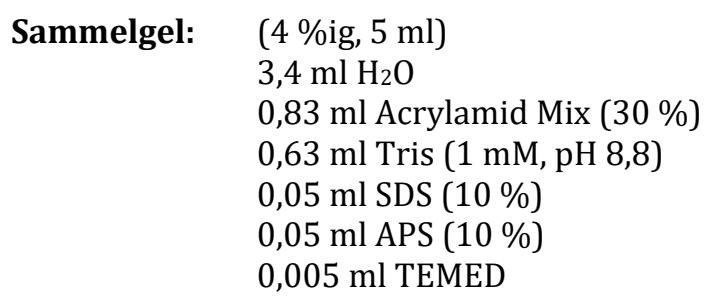

Trenngel: $\quad(10 \% \mathrm{ig}, 20 \mathrm{ml})$

7,9 $\mathrm{ml} \mathrm{H}_{2} \mathrm{O}$

6,7 ml Acrylamid Mix (30\%)

$5 \mathrm{ml}$ Tris $(1 \mathrm{mM}, \mathrm{pH} 8,8)$

$0,2 \mathrm{ml} \mathrm{SDS}(10 \%)$

$0,2 \mathrm{ml}$ APS (10\%)

$0,008 \mathrm{ml}$ TEMED

Laufpuffer: $\quad(10 \mathrm{x}, 100 \mathrm{ml})$

$25 \mathrm{mM}$ Tris

192 mM Glycin

$0,025 \%$ SDS

$+700 \mathrm{ml} \mathrm{H} 20$

$+200 \mathrm{ml}$ Methanol

Tabelle 20: $\quad$ Pipettierschema zur Herstellung der Western Blot-Gele

Aufgrund ihrer Nettoladung wandern Proteine im elektrischen Feld, sodass sie mithilfe der SDS-Polyacrylamid-Gelelektrophorese entsprechend ihrer Ladung und Größe aufgetrennt werden können. Kleine Proteine wandern dabei schneller durch die Polyacrylamidgele als große. Folglich befinden sich die kleinsten negativ geladenen Proteine am Ende am nächsten an der Anode und vice versa.

Jeweils $40 \mu \mathrm{g}$ der verschiedenen Proteinproben wurden entsprechend den Angaben des Herstellers mit Roti ${ }^{\circledR}$-Load 1 (Carl Roth GmbH+Co. KG, Karslruhe) im Verhältnis 4:1 
verdünnt und anschließend im Wärmeblock für 5 Minuten bei $95{ }^{\circ} \mathrm{C}$ inkubiert. Nach Einbringung der Gele in die Elektrophoresekammern und Auffüllung der Kammern mit dem Laufpuffer (1x) wurden die Proben in die Geltaschen pipettiert. Zusätzlich wurde in die erste Tasche der sogenannten Rainbow-Marker (GE Healthcare Amersham, Freiburg) zur Orientierung und in die letzte Tasche der sogenannte MagicMark ${ }^{\mathrm{TM}}$ XF Western Protein Standard (Invitrogen, Darmstadt) zur späteren Visualisierung einer Proteinstandardbande pipettiert. Nach Anschluss an das Power-Supply (Bio-Rad, München) sind die Proteine zunächst bei $130 \mathrm{~V}$ in das Sammelgel (vgl. Tabelle 20) eingelaufen (30 Min.). Abschließend folgte der Lauf im Trenngel (vgl. Tabelle 20) bei $200 \mathrm{~V}$ für 2 Stunden.

\section{Proteintransfer}

\begin{tabular}{ll}
\hline Blotpuffer (10x, pH 8,3): & 25 mM Tris \\
& 192 mM Glycin \\
& $0,025 \%$ SDS
\end{tabular}

Tabelle 21: Pipettierschema zur Pufferherstellung für Western Blot

Zur späteren Visualisierung der Proteine mithilfe spezifischer Antikörper wurden die Proteine im nächsten Schritt vom Trenngel auf eine in Methanol vorinkubierte PVDF-Membran transferiert (= geblottet). Dazu wurde das sogenannte Tank-BlottingVerfahren angewandt.

Nach Entfernung des Sammelgels wurde das Trenngel zusammen mit der PVDF-Membran und 6 Filterpapieren in die Blotkammer (Bio-Rad, München) eingebracht. Nach Verdünnung des Blotpuffers (1x) und Zugabe von $200 \mathrm{ml}$ Methanol wurde die Blotkammer mit dem Puffer aufgefüllt. Anschließend erfolgte der Transfer der Proteine auf die PVDFMembran durch Anschluss an den Power Supply (Bio-Rad, München) bei 0,26 A für 3 Stunden.

\section{Visualisierung der Proteine}

Nach erfolgtem Transfer der Proteine auf die PVDF-Membran wurde diese zunächst in TBS-T supplementiert mit $5 \%$ Magermilchpulver zur Blockierung unspezifischer Bindestellen der Membran gewaschen. Über Nacht wurden die Membranen nachfolgend mit den jeweiligen Primärantikörpern verdünnt in TBS-T supplementiert mit $5 \%$ 
Magermilchpulver respektive $5 \%$ BSA inkubiert. Vor Inkubation mit den Sekundärantikörpern ( $1 \mathrm{~h}$ bei RT) wurden die Membranen dreimal für 5 Minuten in TBS-T gewaschen, um überschüssige Primärantikörper zu entfernen. Die Sekundärantikörper waren ebenfalls in TBS-T mit $5 \%$ Magermilchpulver respektive BSA zugesetzt verdünnt und jeweils an eine horseradish peroxidase (Meerrettich-Peroxidase) gekoppelt. Abschließend wurden die Membranen nach Entfernung überschüssiger Sekundärantikörper nach den Angaben des Herstellers mit dem ECL-Advance ${ }^{\mathrm{TM}}$ Western blotting detection kit (GE Healthcare, Little Chalfont, UK) inkubiert. Durch die Reaktion dieses chemilumineszenten Substrates mit der Horesradish-Peroxidase konnten die Proteine schlussendlich mithilfe des ImageQuant LAS 400 mini (GE Healthcare, Little Chalfont, UK) und der zugehörigen Software in der Version 1.2 detektiert werden. Initial wurde jeweils die Histon Deacetylase (HDAC) nachgewiesen. Da dieses Enzym prädominant in den Zellkernen eukaryoter Zellen exprimiert wird, wurde es zur Kontrolle der Trennung von zytosolischer und nukleärer Proteinfraktion herangezogen.

\subsubsection{Statistik}

Alle Versuche wurden jeweils mindestens dreimal unabhängig voneinander wiederholt. Anschließend wurden die ermittelten Daten als Mittelwert zusammengefasst. Die berechnete positive Standardabweichung wurde in allen Darstellungen erfasst. Signifikante Veränderungen nach Niclosamid-Inkubation verglichen mit der Mediumkontrolle (unbehandelte Zellen) wurden mithilfe des t-Testes ermittelt. Anhand der $p$-Werte wurden zwei Signifikanzniveaus definiert: $p$-Werte kleiner als 0,05 wurden in den Darstellungen mit einem Sternchen $\left({ }^{*}\right)$ und $p$-Werte kleiner als 0,01 mit zwei Sternchen $\left({ }^{* *}\right)$ markiert. 


\section{Ergebnisse}

\subsection{Wachstum und Zytotoxizität nach Inkubation mit Niclosamid}

\subsubsection{Zellzahlreduktion}

Kolorektale Tumorzelllinien verschiedener Spezies (Mensch, Ratte) und Fibroblasten aus Ratten wurden für 24 und 12 Stunden mit Niclosamid in Konzentrationen zwischen 1 und $50 \mu \mathrm{M}$ inkubiert. Als Kontrolle wurden Zellen mit Zellkulturmedium ohne jeden Zusatz und mit Zusatz der Trägersubstanz DMSO inkubiert. Anschließend wurde die Zellzahl in der Neubauer-Zählkammer bestimmt (vgl. Kapitel 2.2.6). Der therapeutische Bereich sollte ermittelt werden, in dem der zytotoxische Effekt auf neoplastische Zellen mit konstitutiv erhöhter Wnt-Aktivität nachweisbar war.

\section{Erforderliche Parameter fehlen oder sind falsch.}

a) Wachstum unter 24 Stunden Inkubation mit Niclosamid

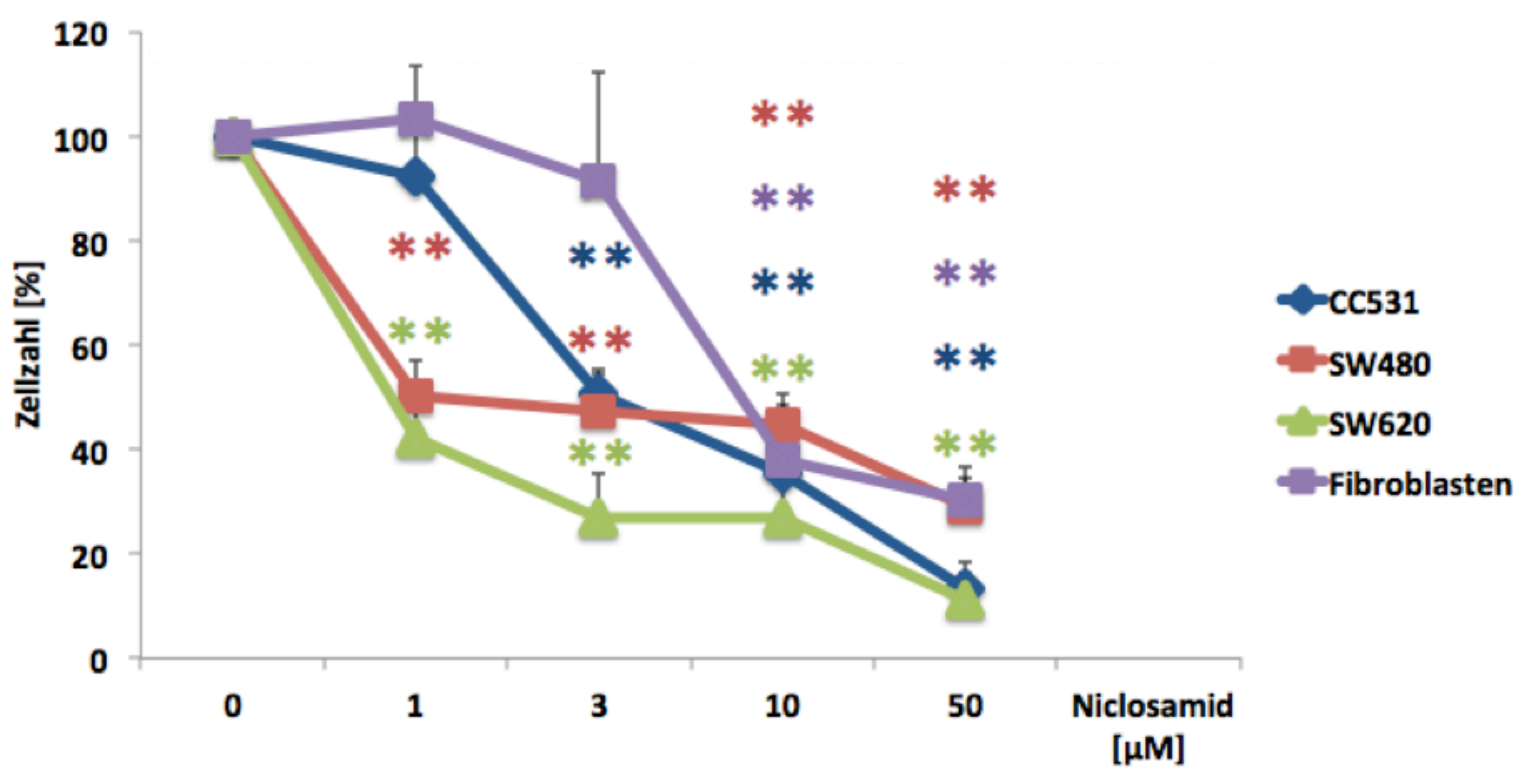


b) Wachstum unter 12 Stunden Inkubation mit Niclosamid
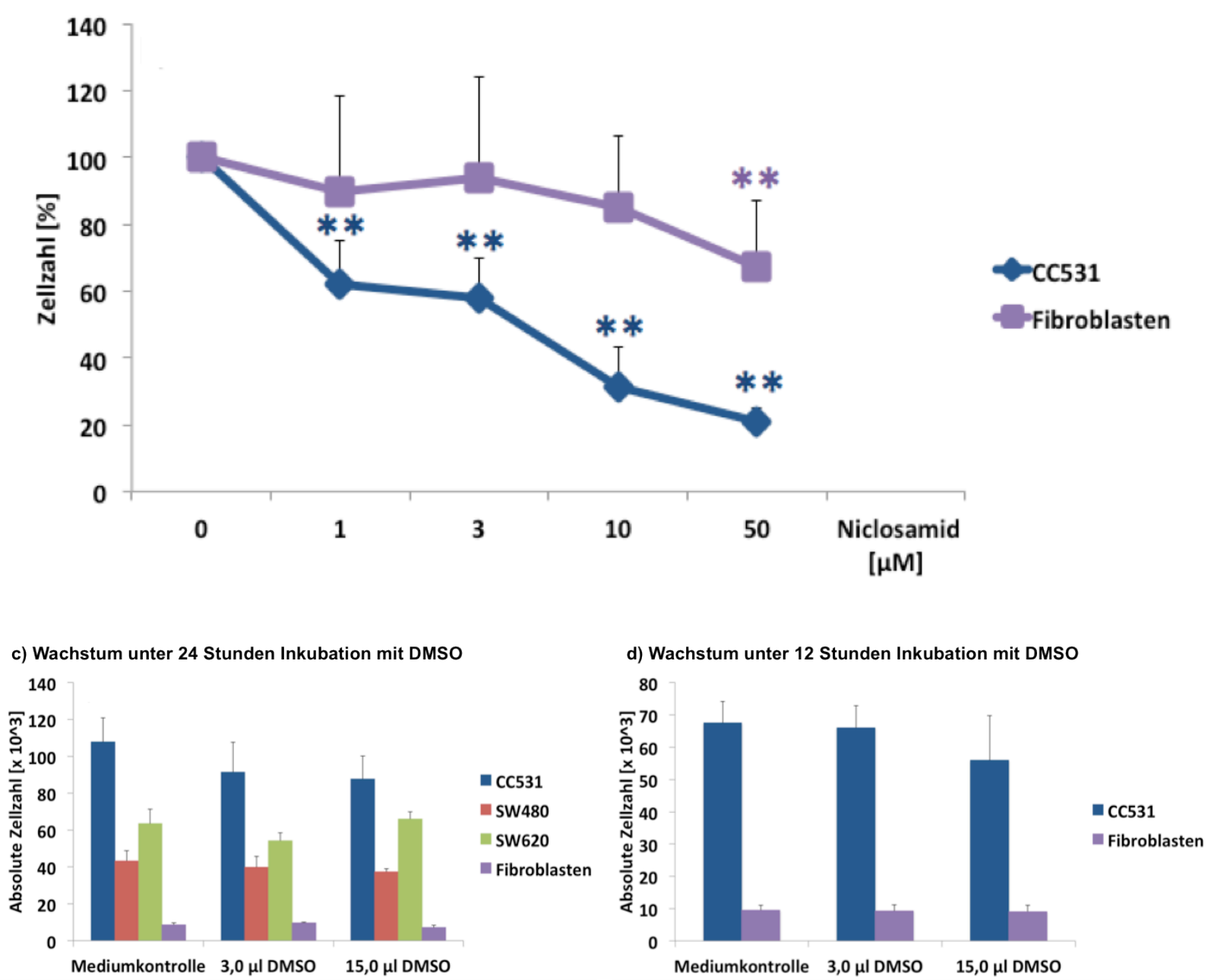

Abbildung 5: Relative Zellzahlreduktion nach Inkubation mit Niclosamid. Kolorektale Tumorzellen (CC531, SW480, SW620) sowie Fibroblasten wurden mit Niclosamid $(1 \mu \mathrm{M}, 3 \mu \mathrm{M}, 10 \mu \mathrm{M}$, $50 \mu \mathrm{M}$ ) inkubiert und die relative Zellzahl nach a) 24 respektive b) 12 Stunden normiert an der Mediumkontrolle (unbehandelte Zellen) ermittelt. Zusätzlich wurden die Zellen für c) 24 respektive d) 12 Stunden mit der Tägersubstanz DMSO (3 $\mu \mathrm{l}, 15 \mu \mathrm{l}$ ) zur Kontrolle inkubiert. Signifikante Unterschiede $(p<0,01)$ sind mit Sternchen $\left({ }^{* *}\right)$ markiert. Unter Inkubation mit Niclosamid ergab sich für alle Zelllinien eine dosisabhängige Reduktion der Zellzahl, wobei der Effekt auf Fibroblasten erst bei höheren Konzentrationen des Niclosamids einsetzte. Eine Inkubation mit DMSO (c und d) beeinflusste die Zellzahl nach beiden Inkubationszeiten nicht. 
Als Grundvoraussetzung wurde die Vitalität der Zellen bestimmt. Hierfür wurden die Zellen mit Trypan-Blau gefärbt, wobei der Anteil der vitalen Zellen sowohl nach 24 als auch nach 12 Stunden Inkubation jeweils zwischen 90 und $100 \%$ lag.

Die relative Zellzahl aller betrachteten Zellinien sank nach einer Inkubationszeit von 24 Stunden deutlich dosisabhängig ab. Verglichen mit der Mediumkontrolle konnte die Zellzahl bei den humanen Zelllinien SW480 und SW620 bei Einsatz von $1 \mu \mathrm{M}$ Niclosamid signifikant auf 50 respektive $42 \%$ gesenkt werden. Bei der Rattenzellinie CC531 waren $3 \mu \mathrm{M}$ des Niclosamids ausreichend, um die Zellzahl zu halbieren. Bei derselben Konzentration wurde die Zahl der gesunden Fibroblasten nur um 10 \% gesenkt. In höheren Konzentrationen $(\geq 10 \mu \mathrm{M})$ waren antiproliferative Effekte auch auf die Fibroblasten festzustellen (vgl. Abbildung 5a).

Nachfolgend wurde die Zellzahl der Karzinomzelllinie CC531 und der Fibroblasten zusätzlich nach einer verkürzten Inkubationszeit von 12 Stunden bestimmt. Bereits $1 \mu \mathrm{M}$ Niclosamid reduzierte die Proliferation von Zellen der Linie CC531 signifikant um mehr als ein Drittel. Im Gegensatz dazu blieb die Zahl der Fibroblasten zunächst bis einschließlich einer Konzentration von $10 \mu \mathrm{M}$ Niclosamid relativ konstant. Erst $50 \mu \mathrm{M}$ Niclosamid vermochten die Zahl der Fibroblasten auf etwa zwei Drittel (67,2 \%) der ursprünglich eingesetzten Zellzahl signifikant zu senken. $50 \mu \mathrm{M}$ Niclosamid reduzierten die Zahl der CC531 Zellen auf 21,7 \% (vgl. Abbildung 5b).

Zusätzlich wurden die Zelllinien mit den eingesetzten Volumina der Trägersubstanz DMSO (3 $\mu \mathrm{l}, 15 \mu \mathrm{l}$ ) für 24 und 12 Stunden inkubiert, um einen antiproliferativen Effekt auszuschließen. Dosisunabhängig blieb die Zellzahl verglichen mit der unbehandelten Mediumkontrolle konstant (vgl. Abbildung 5c und d).

Kolorektale Karzinomzellen wurden nach 24 und 12 Stunden bereits durch geringe Konzentrationen des Niclosamids (1 und $3 \mu \mathrm{M})$ in ihrem Wachstum gehemmt. Im Vergleich blieb das Wachstum der Fibroblasten in diesem Dosierungsbereich unbeeinflusst. Nach 12 Stunden vermochten erst $50 \mu \mathrm{M}$ Niclosamid das Wachstum der Fibroblasten signifikant zu hemmen. Dabei fiel der Effekt auf CC531 Zellen annäherungsweise dreifach so hoch aus wie auf die Fibroblasten (Reduktion der Zellzahl auf 21,7 \% vs. 67,2 \%). Das hierdurch ermittelte therapeutische Fenster zwischen 1 und $50 \mu \mathrm{M}$ Niclosamid nach 12-stündiger 
Inkubation erachteten wir als hinreichend für weiterführende Versuche an Zellen der Linie CC531.

\subsubsection{Effektivität des Niclosamids unter Betrachtung des APC- respektive $\beta$-Catenin- Mutationsstatus}

Die Effektivität der unter 3.1.1 beschriebenen Wachstumsinhibition des Niclosamids wurde im nächsten Schritt in Abhängigkeit vom Mutationsstatus der kolorektalen Tumorzellen nach einer Inkubationszeit von 24 Stunden betrachtet. In Tabelle 22 sind die verwendeten Zelllinien und deren Mutationsstatus (APC vs. $\beta$-Catenin) gegen die Zellzahl in Prozent bezogen auf die Mediumkontrolle dargestellt.

\begin{tabular}{|c|c|c|c|c|c|}
\hline \multirow[t]{2}{*}{ Zelllinie } & \multirow{2}{*}{$\begin{array}{l}\text { APC- } \\
\text { Mutation }\end{array}$} & \multirow{2}{*}{$\begin{array}{l}\beta \text {-Catenin- } \\
\text { Mutation }\end{array}$} & \multicolumn{3}{|c|}{ Zellzahl [\%] bezogen auf Mediumkontrolle (= $100 \%$ ) } \\
\hline & & & $1 \quad 3$ & 10 & 50 Niclosamid $[\mu \mathrm{M}]$ \\
\hline CC531 & & $\mathrm{x}^{1}$ & 88 & 36 & 15 \\
\hline SW480 & $x^{2}$ & & 50 & 38 & 30 \\
\hline SW620 & $x^{3}$ & & 42 & 26 & 11 \\
\hline
\end{tabular}

Tabelle 22: Vergleich des Mutationsstatus mit der Proliferationshemmung durch Niclosamid.

Kolorektale Tumorzellen (CC531, SW480, SW620) wurden mit Niclosamid (1 $\mu$ M, $3 \mu \mathrm{M}$, $10 \mu \mathrm{M}, 50 \mu \mathrm{M}$ ) inkubiert und die relative Zellzahl nach 24 Stunden normiert an der Mediumkontrolle (unbehandelte Zellen) ermittelt. Darstellung des Mutationsstatus gegen die ermittelten Zellzahlen. ${ }^{1}$ GERMANN et al. 2003, ${ }^{2}$ YANG et al. 2006, ${ }^{3}$ DIHLMANN et al. 1999

Die Zellzahl der Zelllinien mit einer loss-of-function-Mutation des Tumorsuppressorgens APC (SW480 und SW620) wurde durch die kleinste eingesetzte Konzentration (1 $\mu \mathrm{M}$ Niclosamid) bereits signifikant reduziert. Bei derselben Konzentration blieb die Zellzahl der Linie CC531 konstant. In dieser Zelllinie wurde eine gain-of-function-Mutation des Protoonkogens $\beta$-Catenin nachgewiesen. $10 \mu \mathrm{M}$ Niclosamid reduzierten die Zellzahl aller betrachteten kolorektalen Karzinomzellen dann unabhängig vom Mutationsstatus mit etwa gleicher Effektivität auf durchschnittlich $30 \%$ der Mediumkontrolle (unbehandelte Zellen). Schließlich war der Effekt nach Inkubation mit einer Konzentration von $50 \mu \mathrm{M}$ Niclosamid bei der Zelllinie CC531 im Vergleich zur Zelllinie SW480 ausgeprägter (15 vs. 30 \%).

Somit konnte Niclosamid insgesamt wachstumsinhibierende Wirksamkeit auf kolorektale Karzinomzellen zugeschrieben werden. Der Effekt war unabhängig von verschiedenen Mutationen innerhalb des kanonischen Wnt-Signalweges. 


\subsubsection{Morphologische Veränderungen der Zellen}

Nach Inkubation mit 10 und $50 \mu \mathrm{M}$ Niclosamid über 12 Stunden wurden die morphologischen Veränderungen von CC531 Zellen lichtmikroskopisch analysiert. Dafür wurden die Zellen nach Fixierung wie unter 2.2.6 beschrieben mit einer Gram-Kristallviolettlösung zur präziseren Beurteilung der Morphologie gefärbt. Hierdurch sollten makroskopische und mikroskopische Rückschlüsse auf die potentiell zytotoxische Wirksamkeit des Niclosamids gezogen werden.
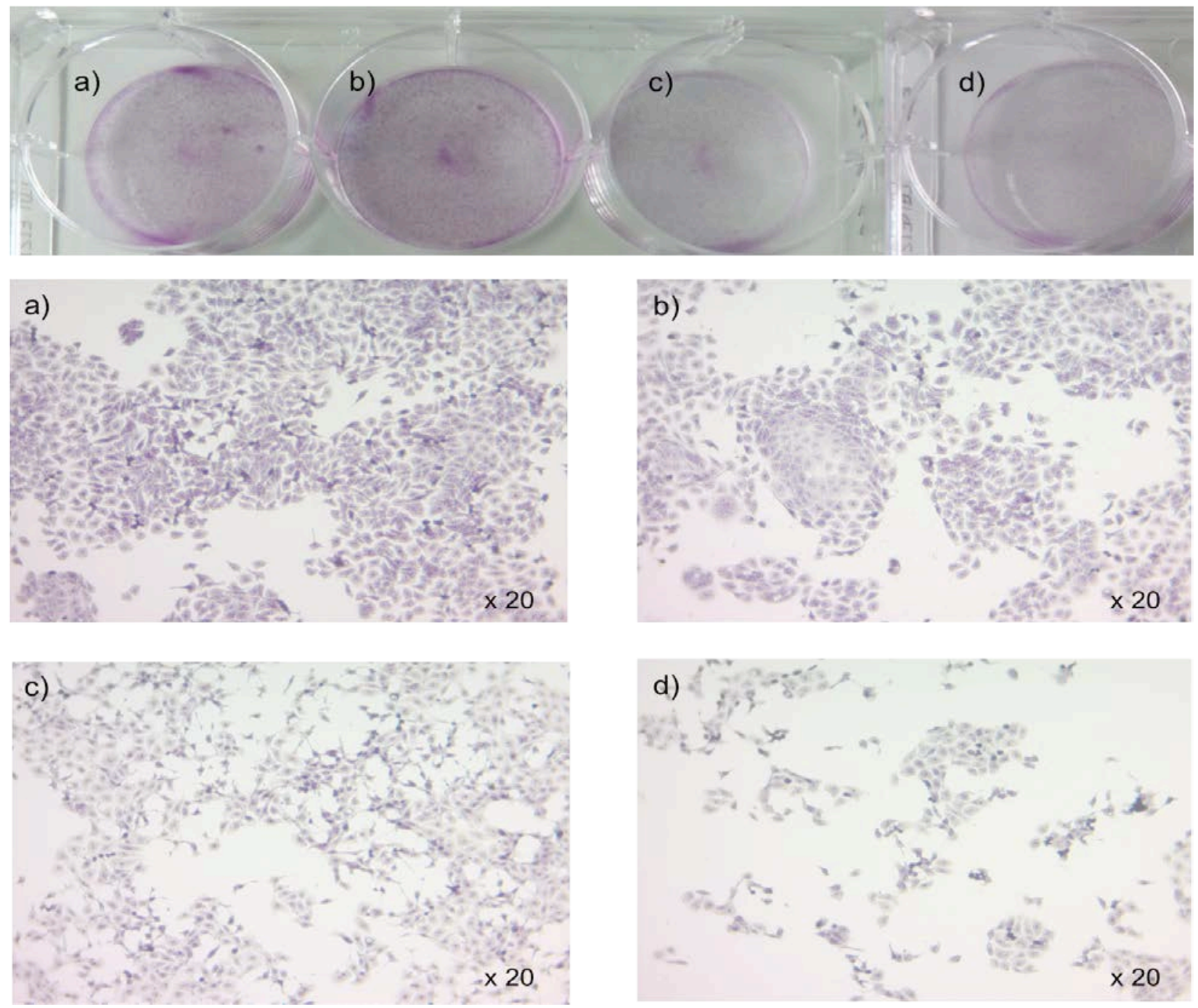

Abbildung 6: Zelldichte und -morphologie nach Inkubation mit Niclosamid. Lichtmikroskopische Aufnahme von Zellen der Linie CC531 nach 12 Stunden Inkubation mit a) reinem Zellkulturmedium, b) $15 \mu \mathrm{l}$ DMSO, c) $10 \mu \mathrm{M}$ Niclosamid und d) $50 \mu \mathrm{M}$ Niclosamid. Die Zellen wurden mit einer Gram-Kristallviolettlösung gefärbt. Die Zelldichte nahm in Abhängigkeit von der Niclosamid-Konzentration ab. 
CC531 Zellen wurden nach 12 Stunden Kultivierung unter Einfluss von reinem Zellkulturmedium (vgl. Abbildung 6a) im Vergleich zu Zellen betrachtet, die zur Kontrolle mit $15 \mu \mathrm{l}$ DMSO (vgl. Abbildung 6b) respektive 10 und $50 \mu \mathrm{M}$ Niclosamid (vgl. Abbildung 6c und d) inkubiert wurden. Die Zelldichte nahm in der Übersichtsdarstellung in Abhängigkeit von der Konzentration des Niclosamids deutlich ab (vgl. Abbildung 6a bis d). In 20facher Vergrößerung wurde die veränderte Zellmorphologie unter Niclosamid-Einfluss deutlich. Die in reinem Zellkulturmedium gewachsenen Zellen bildeten einen geordneten Verband rundlicher bis ellipsoider Zellen. Mit zunehmender Konzentration des Niclosamids wuchsen die Zellen einzeln isoliert oder bildeten abgegrenzte Zellaggregate. Die Zellen bildeten multiple Ausläufer aus, über die sie weiterhin Kontaktflächen aufrecht erhielten. Unter Inkubation mit DMSO kam es nicht zu morphologischen Veränderungen der CC531 Zellen. Zusammenfassend betrachtet bewirkte Niclosamid eine Schrumpfung und vermehrte Ablösung der adhärenten CC531 Zellen vom Untergrund. Inwieweit Niclosamid Zytotoxizität zugeschrieben werden musste, wurde nachfolgend durch Bestimmung der Zelltodrate nach Inkubation von CC531 Zellen mit der Substanz evaluiert (vgl. Kapitel 3.1.4).

\subsubsection{Rate und Art des Zelltodes}

Durch Doppelfärbung mit Annexin-V-Fluos und Propidiumiodid und anschließender durchflusszytophotometrischer Analyse (vgl. Kapitel 2.2.6) konnte zwischen vitalen, apoptotischen und nekrotischen Zellen der Linie CC531 unterschieden werden. Dadurch sollte die Frage geklärt werden, ob Niclosamid in kolorektalen Karzinomzellen Zelltod induziert. Im Folgenden sind jeweils exemplarische Dotplot-Darstellungen und anschließend die aus drei unabhängigen Versuchen zusammengefassten Daten als Liniendiagramme dargestellt. 
a) Durchflusszytophotometrie nach 24 Stunden Inkubation mit Niclosamid
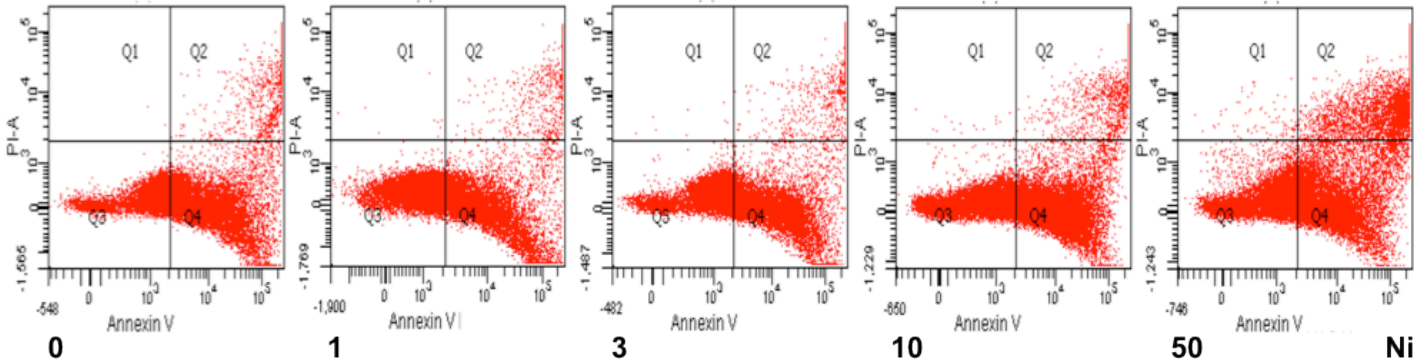

b) Zellvitalität nach 24 Stunden Inkubation mit Niclosamid

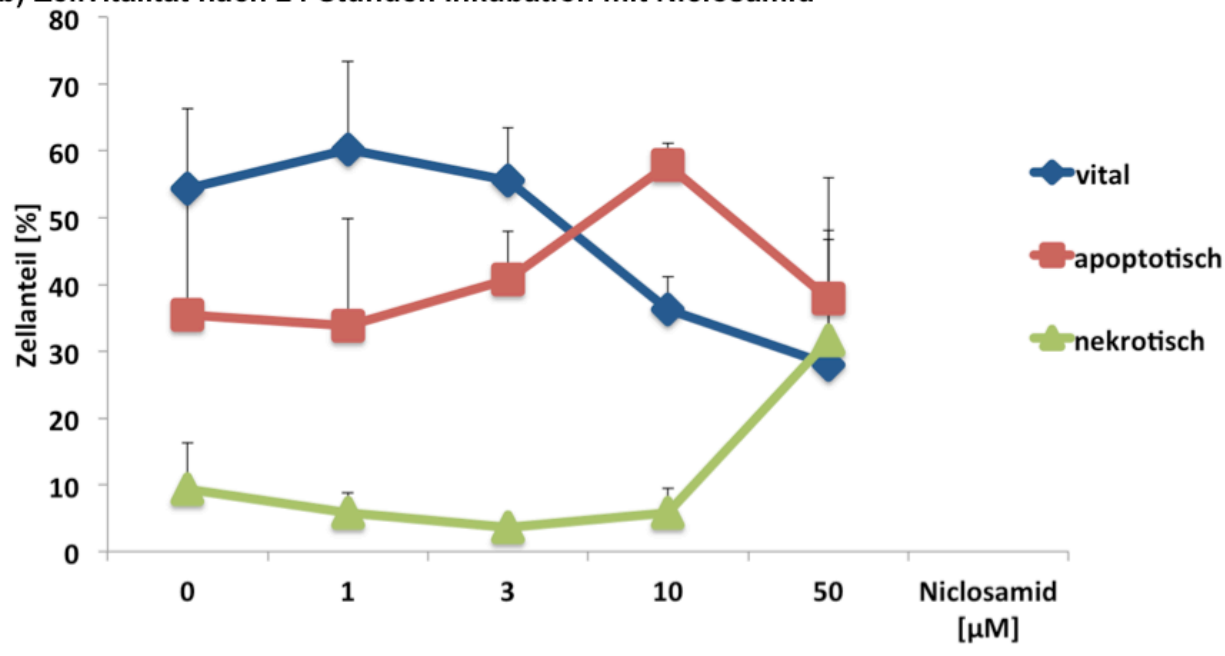

c) Durchflusszytophotometrie nach 12 Stunden Inkubation mit Niclosamid
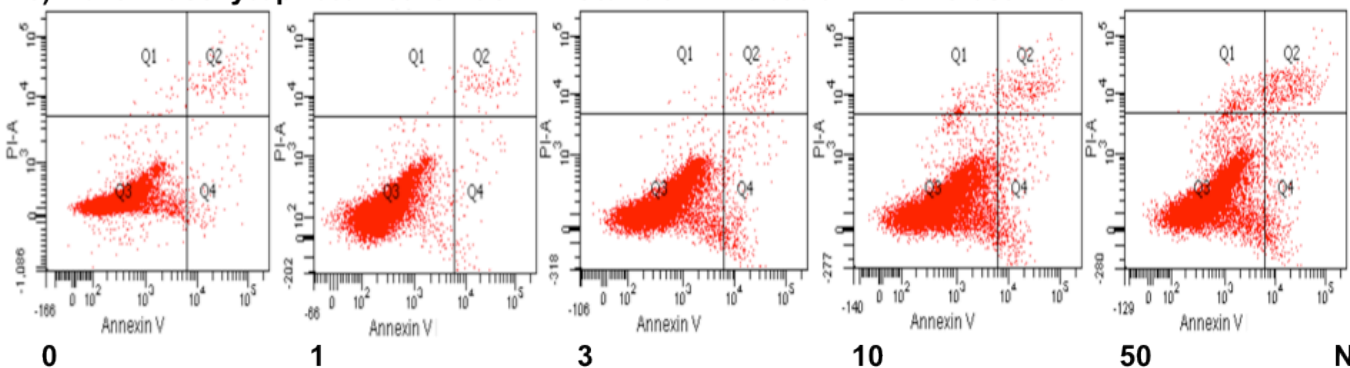

d) Zellvitalität nach 12 Stunden Inkubation mit Niclosamid

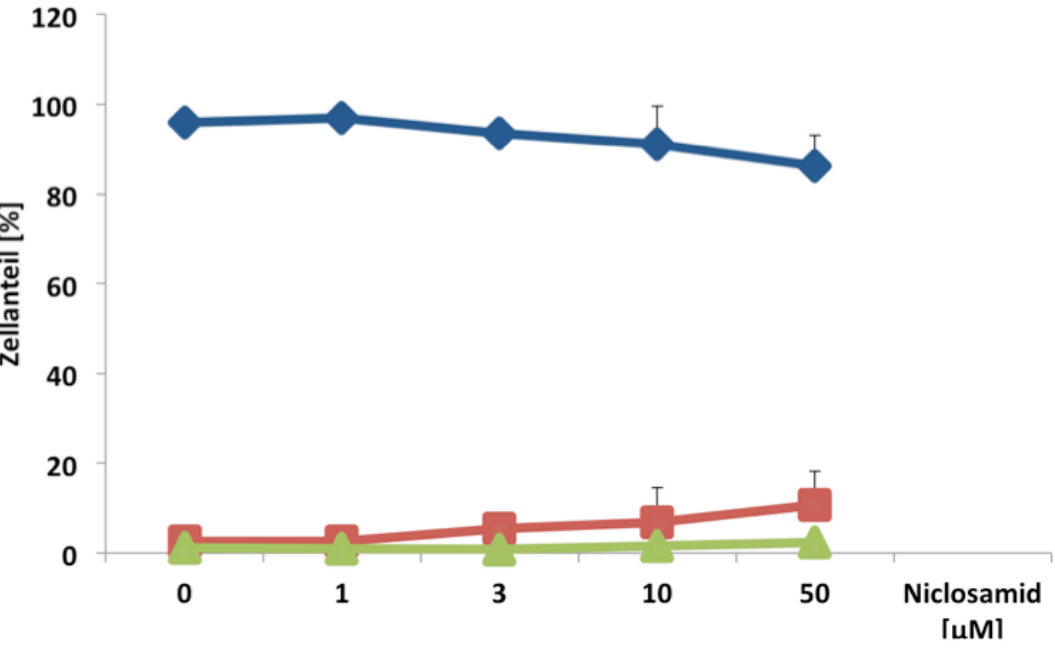



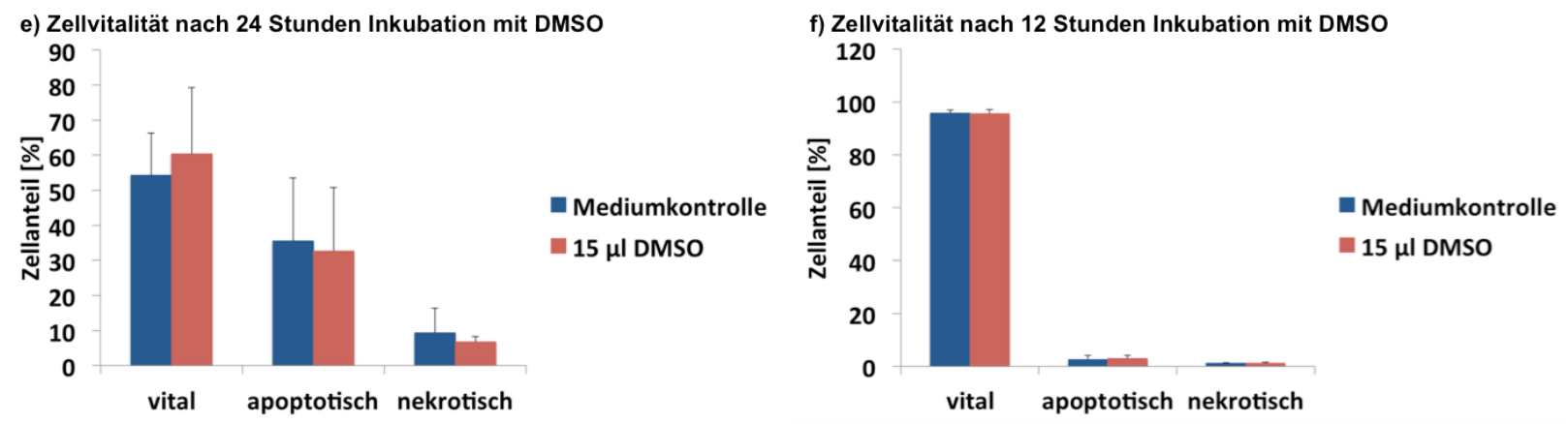

Abbildung 7: Apoptose- und Nekroseraten nach Inkubation mit Niclosamid. Zellen der Linie CC531 wurden mit aufsteigenden Konzentrationen von Niclosamid inkubiert $(0 \mu \mathrm{M}, 1 \mu \mathrm{M}, 3 \mu \mathrm{M}$, $10 \mu \mathrm{M}, 50 \mu \mathrm{M}$ ) und anschließend mit Annexin-V-Fluos und Propidiumiodid doppelgefärbt. In den Dotplots ist Annexin (Abszisse) gegen Propidiumiodid (Ordinate) dargestellt. In Feld Q3 kommem die vitalen, in Feld Q4 die apoptotischen und in Feld Q2 die nekrotischen Zellen zur Darstellung. a) und b) Inkubationszeit von 24 Stunden. Dosisabhängige Zunahme avitaler Zellen. c) und d) Inkubationszeit von 12 Stunden. Dosisunabhängig sind die Zellen mehrheitlich vital. Eine Inkubation mit $15 \mu$ DMSO hatte nach beiden Inkubationszeiten keinen Einfluss auf die Zellvitalität (e und f).

In den Dotplots nach 24 Stunden Inkubation mit Niclosamid (vgl. Abbildung 7a) zeigte sich eine Abnahme des Signals in Feld Q3, in dem vitale Zellen detektiert wurden. Gleichzeitig nahm das Signal für nekrotische Zellbestandteile (Feld Q2) deutlich zu. Nach Auswertung von drei unabhängigen Versuchen wurde beobachtet, dass die Verteilung vitaler und avitaler Zellen bis zu einer Konzentration von $3 \mu \mathrm{M}$ Niclosamid zunächst konstant blieb (vgl. Abbildung 7b). Demgegenüber sank die Vitalität der Zellen ab einer Konzentration von $10 \mu \mathrm{M}$ Niclosamid. Gleichzeitig stieg zunächst der Anteil apoptotischer Zellen auf $60 \%$ an. Bei Inkubation mit $50 \mu \mathrm{M}$ Niclosamid nahm die Zahl der apoptotischen Ereignisse (37 \%) wieder ab, wohingegen vermehrt nekrotische Zellen (31 \%) auftraten.

Zusätzlich wurden Zellen nach 12 Stunden Inkubation mit Niclosamid durchflusszytophotometrisch analysiert. Die Dotplots eines exemplarischen Versuches in Abbildung 7c belegen, dass es nach Verkürzung der Inkubationszeit auf 12 Stunden zu keiner Umverteilung der Zellen auf die apoptotische (Feld Q4) oder nekrotische (Feld Q2) Fraktion kam. Stattdessen blieb das Signal des vitalen Zellanteils (Feld Q3) unverändert, was dosisunabhängig für eine größtenteils vitale Zellpopulation sprach. Tatsächlich war die 
Vitalität der Zellen konstant (> $85 \%$ aller Zellen nach Inkubation mit $50 \mu \mathrm{M}$ Niclosamid). Entsprechend gering war die Rate apoptotischer (10\%) respektive nekrotischer Zellen (2\%) trotz steigender Konzentration des Niclosamids (vgl. Abbildung 7d).

Sowohl nach 12 als auch nach 24 Stunden zeigte sich nach Inkubation mit $15 \mu \mathrm{l}$ der Trägersubstanz DMSO keine Zunahme avitaler Zellen und ein zytotoxischer Effekt konnte ausgeschlossen werden (vgl. Abbildung 7e und f).

Somit war festzustellen, dass es nach 24-stündiger Inkubation mit Niclosamid dosisabhängig zu einer ausgeprägten Zunahme avitaler Zellen kam. $50 \mu \mathrm{M}$ Niclosamid reduzierten den Anteil vitaler Zellen auf $32 \%$. Durch Halbierung der Inkubationsdauer auf 12 Stunden wurde der Anteil vitaler Zellen bei derselben Konzentration auf über $85 \%$ stabilisiert. Alle weiteren Versuche wurden daher nach einer Zeitspanne von 12 Stunden terminiert, um einen ausreichenden Anteil vitaler Zellen zu gewährleisten. 


\subsection{Wirkung von Niclosamid auf das Wnt-Netzwerk}

\subsubsection{Effekt des Niclosamids auf den kanonischen Wnt-Signalweg}

\section{Aktivität des kanonischen Wnt-Signalweges (TOPflash/ FOPflash)}

Zellen der Linie CC531 wurden mit dem LEF/ TCF-responsiven TOPflash/ FOPflash Luciferase-Plasmid zur Bestimmung der Wnt-Aktivität transfiziert (vgl. 2.2.7). Aktivitätsänderungen des kanonischen Wnt-Signales konnten dadurch in Abhängigkeit von der eingesetzten Niclosamid-Konzentration nach 12 Stunden Inkubation gemessen werden.

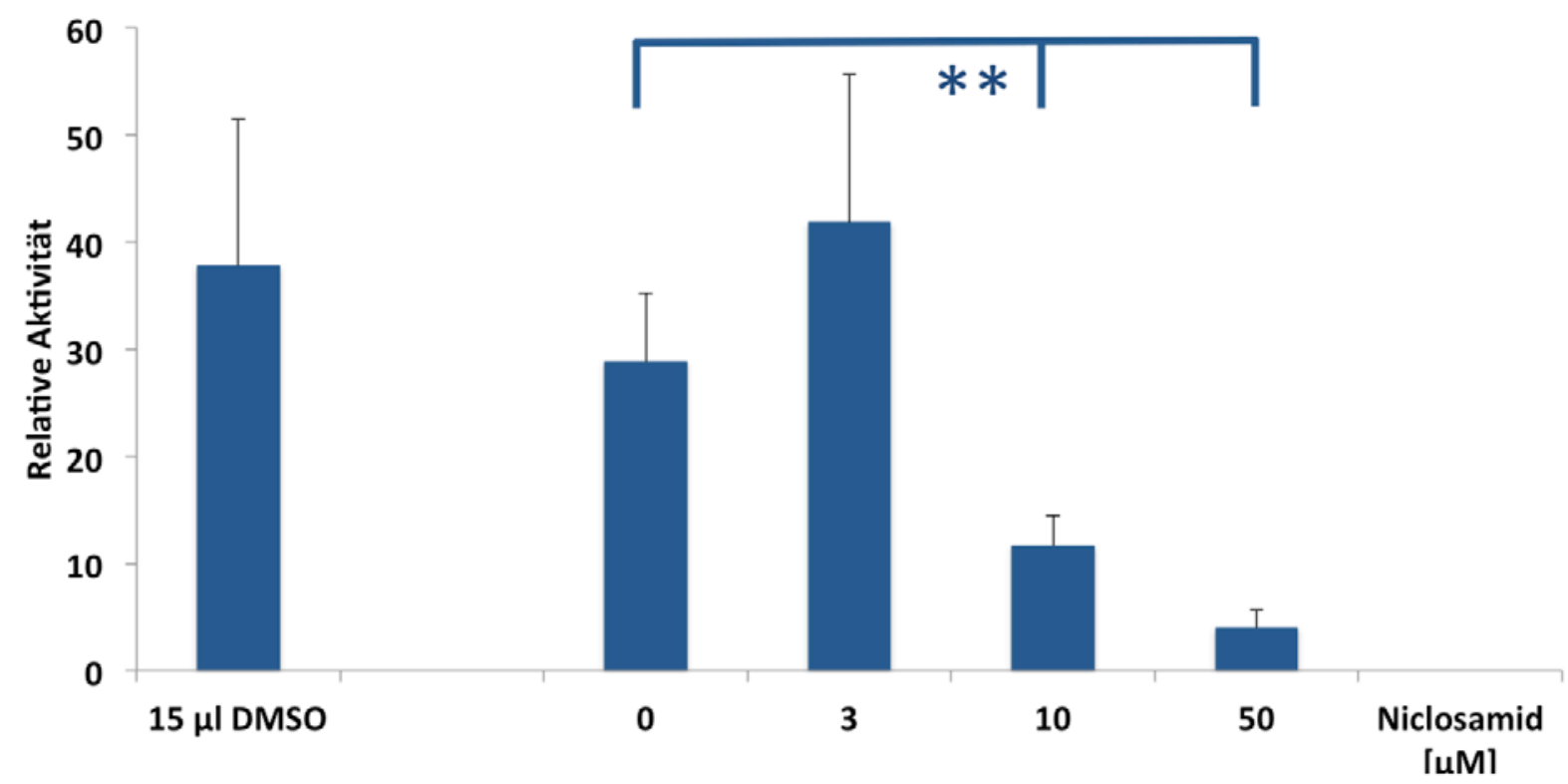

Abbildung 8: Relative Wnt-Aktivität nach Inkubation mit Niclosamid. Die Wnt-Aktivität in Zellen der Linie CC531 wurde nach Transfektion der Zellen mit dem Wnt-responsiven Plasmid TOPflash und nachfolgender Inkubation mit Niclosamid (3 $\mu \mathrm{M}, 10 \mu \mathrm{M}, 50 \mu \mathrm{M})$ für 12 Stunden bioluminometrisch gemessen. Als Vergleich diente jeweils die Mediumkontrolle. Signifikante Unterschiede mit $p<0,01$ wurden mit Sternchen $\left({ }^{* *}\right)$ markiert. Es ergab sich eine signifikante Reduktion der relativen kanonischen Wnt-Aktivität ab einer Konzentration von $10 \mu \mathrm{M}$ Niclosamid.

Dosisabhängig wurde die kanonische Wnt-Aktivität deutlich reduziert (vgl. Abbildung 8). Als Kontrollen dienten die unbehandelte Mediumkontrolle (unbehandelte Zellen) und die Inkubation mit $15 \mu \mathrm{l}$ der Trägersubstanz DMSO. Die niedrigste Konzentration des Niclosamids $(3 \mu \mathrm{M})$ bewirkte zunächst einen geringen Anstieg der Wnt-Aktivität im 
Vergleich zur Mediumkontrolle. Ab einer Konzentration von $10 \mu \mathrm{M}$ Niclosamid konnte dann eine deutlich signifikante Inhibierung des kanonischen Wnt-Signalweges gemessen werden. Bei Einsatz von $10 \mu \mathrm{M}$ Niclosamid wurde die Wnt-Aktivität auf ein Drittel, bei $50 \mu \mathrm{M}$ auf $10 \%$ der ursprünglichen Aktivität reduziert. Die Trägersubstanz DMSO zeigte keinen signifikanten Effekt auf die Aktivität des kanonischen Wnt-Signalweges.

Zusammenfassend betrachtet konnte im TOPflash/ FOPflash eine Inhibierung des kanonischen Wnt-Signales durch Niclosamid nachgewiesen werden. Nachfolgend galt es, dieses Ergebnis zu verifizieren und den genauen Wirkmechanismus zu entschlüsseln.

\section{Analyse kanonischer Wnt-Komponenten auf Transkriptionsebene}

Die Transkriptionsraten kanonischer Wnt-Komponenten auf verschiedenen Ebenen innerhalb dieses Signalweges wurden mittels real-time RT-PCR analysiert (vgl. Kapitel 2.2.8). Hierfür wurde die relative Expression der Gene in Abhängigkeit von der Niclosamid-Konzentration nach einer Inkubationszeit von 12 Stunden bestimmt. Zur Normierung wurden als Referenzgene $\beta_{2}$-Microglobulin sowie HPRT herangezogen. 
a) Wif1

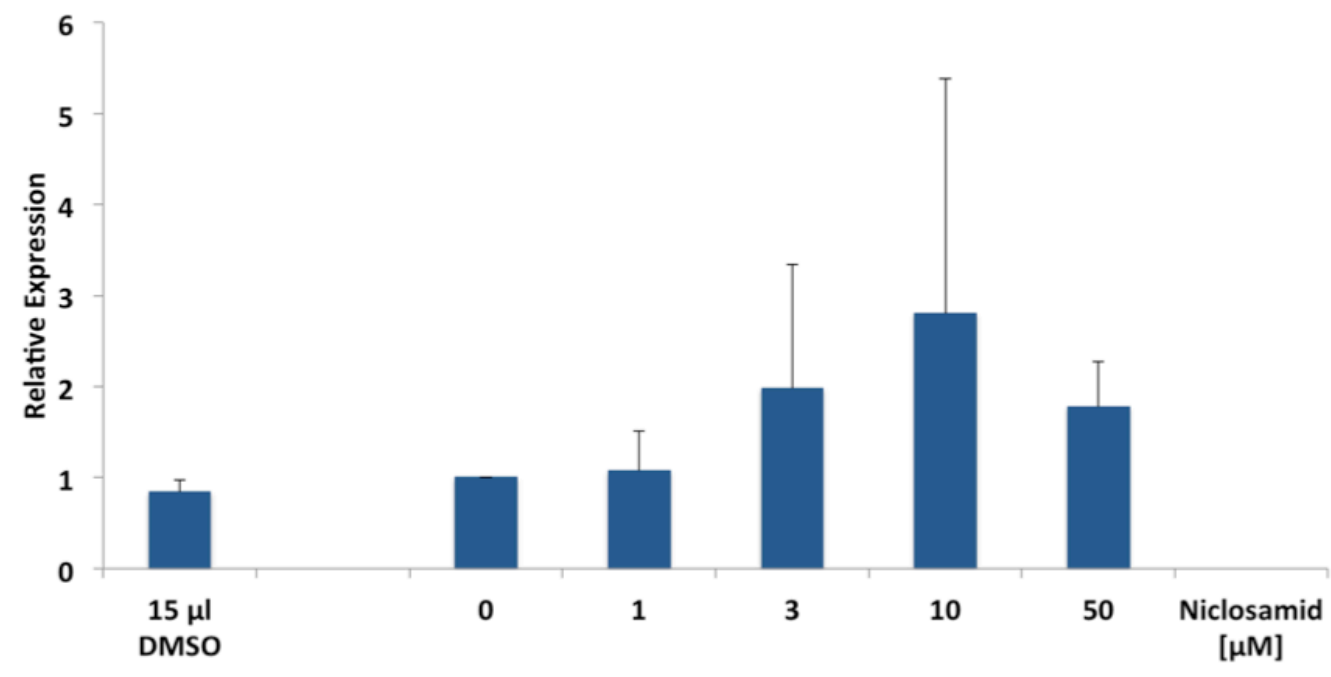

b) Axin2

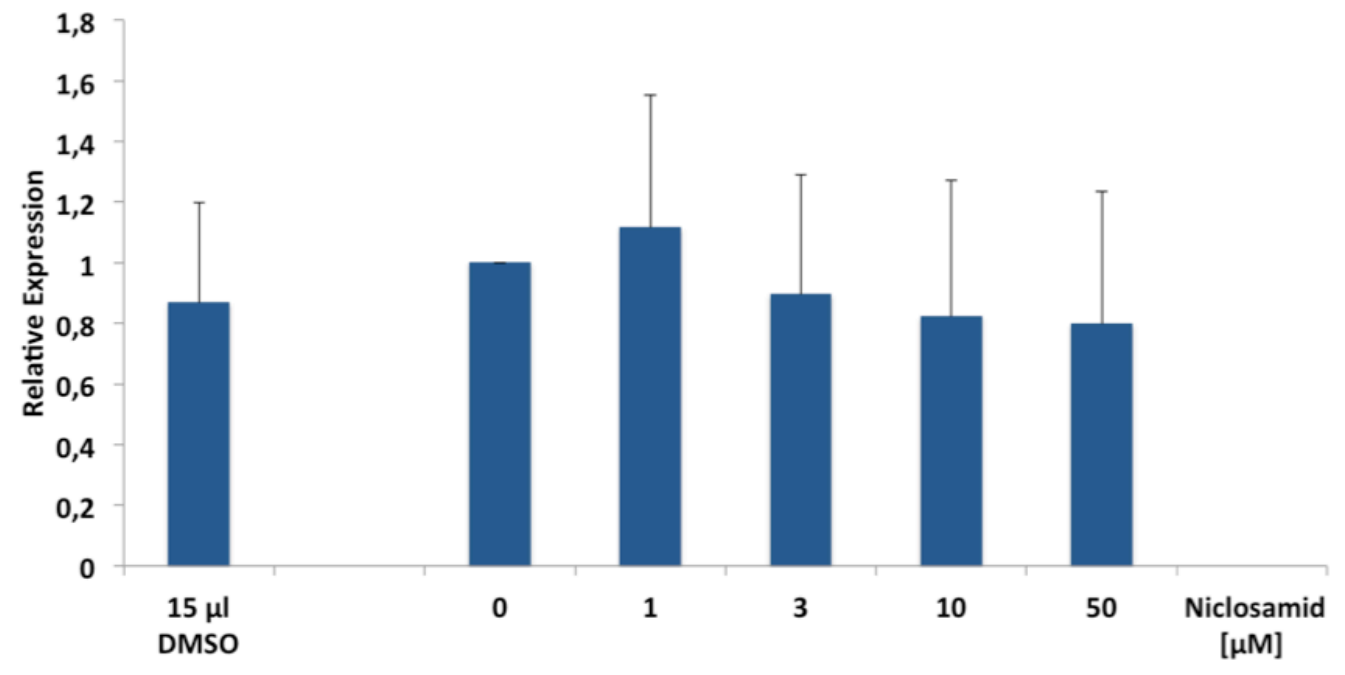

c) GSK $3 \beta$

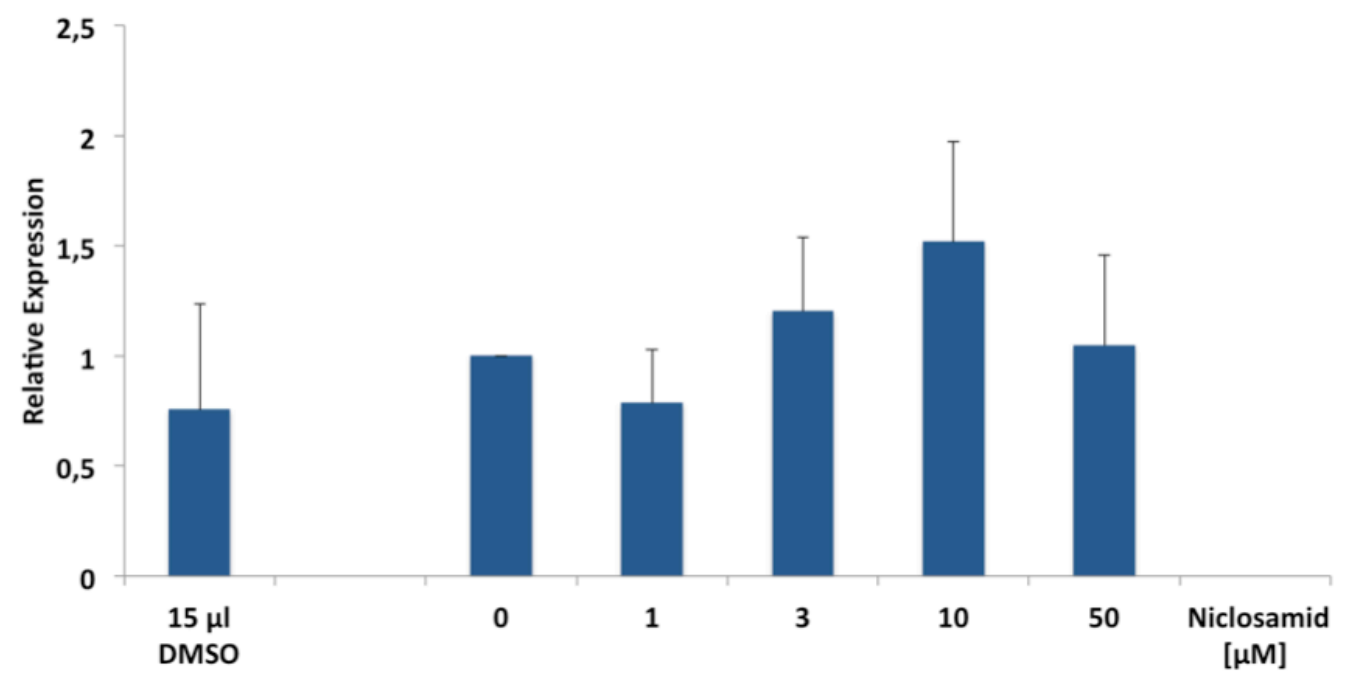


Erforderliche Parameter fehlen oder sind falsch.

Erforderliche Parameter fehlen oder sind falsch.

Erforderliche Parameter fehlen oder sind falsch. 
d) Bcl-9

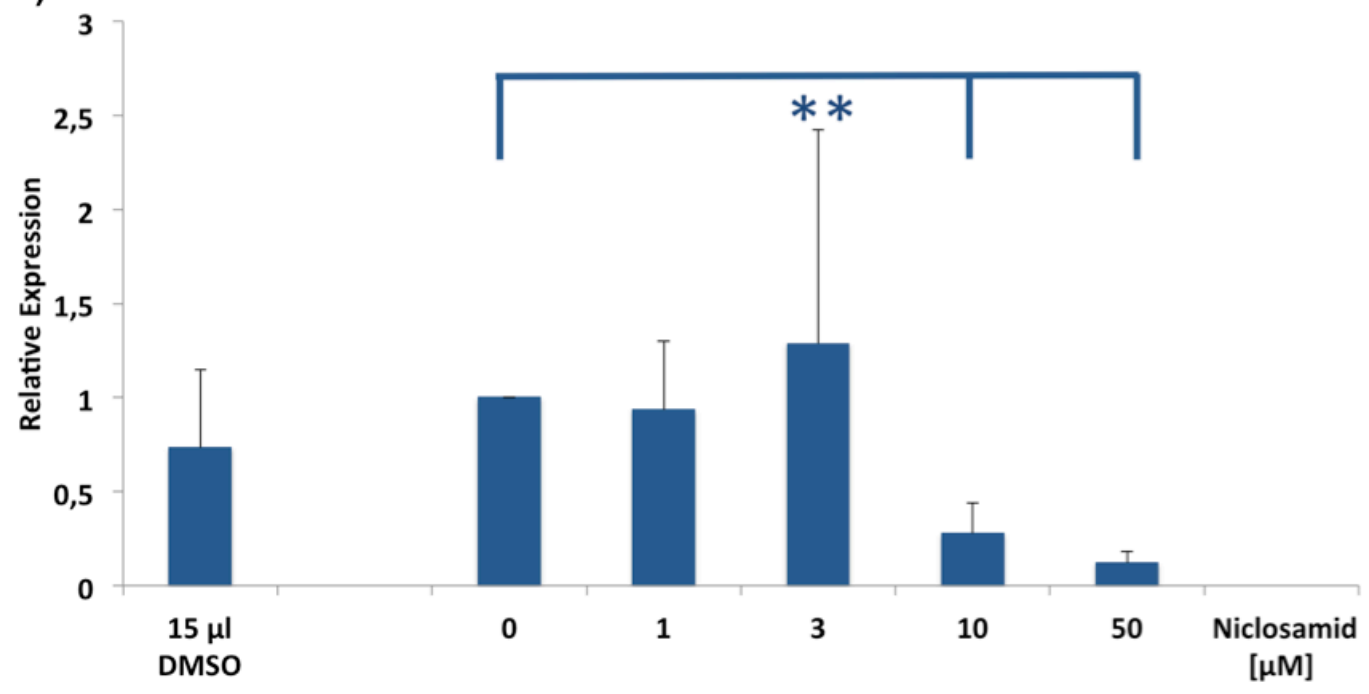

e) MMP7

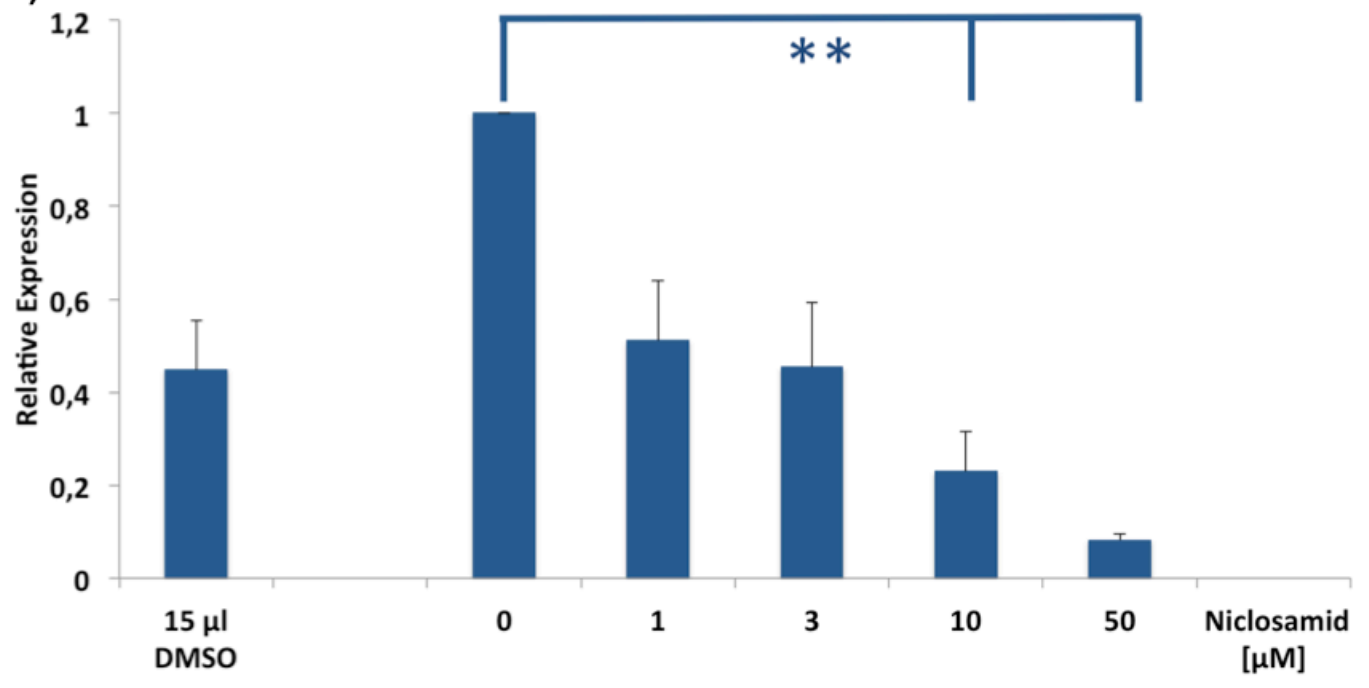

\section{f) Cyclin D1}

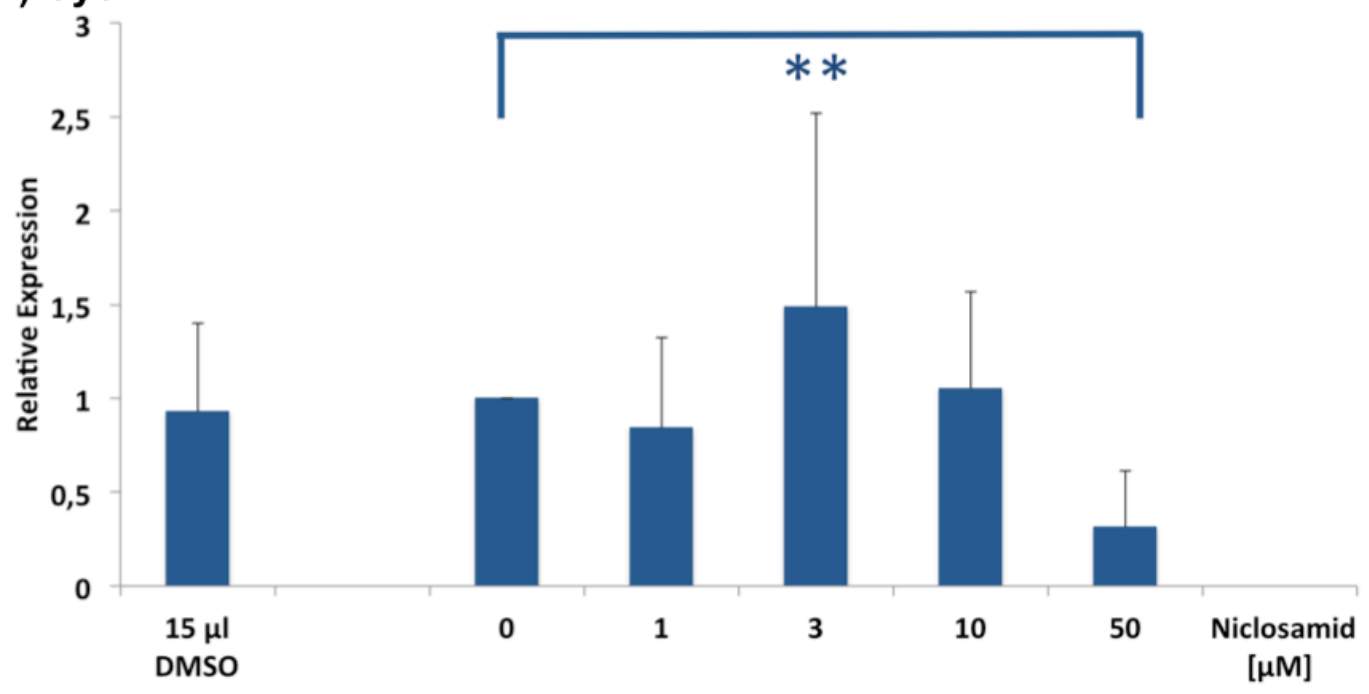




\section{Erforderliche Parameter fehlen oder sind falsch.}

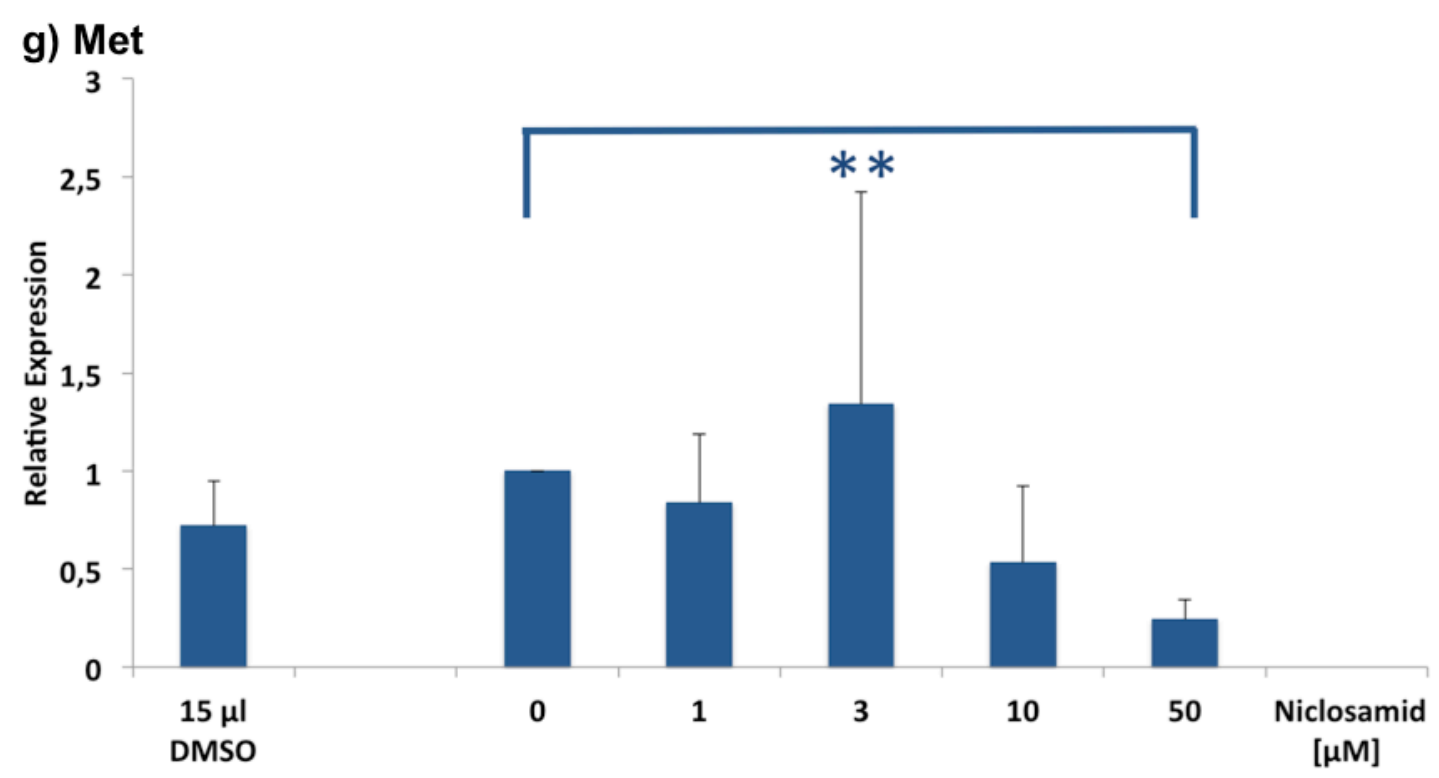

Abbildung 9: Relative transkriptionelle Expression kanonischer Wnt-Komponenten nach Inkubation mit Niclosamid. RT-PCR mit Zelllysaten der Linie CC531 nach Inkubation mit aufsteigenden Konzentrationen des Niclosamids $(0 \mu \mathrm{M}, 1 \mu \mathrm{M}, 3 \mu \mathrm{M}, 10 \mu \mathrm{M}, 50 \mu \mathrm{M})$ für 12 Stunden. Die relative Expression der Mediumkontrolle (unbehandelte Zellen) wurde als 1 definiert. Signifikante Unterschiede mit $p<0,01$ wurden mit Sternchen (**) markiert. a) Statistisch unveränderte Expression des Wnt-Inhibitors Wif1. b) und c) Statistisch unveränderte Expression von Bestandteilen des $\beta$-Catenin-Degradationskomplexes (Axin2, GSK 3ß). d) Signifikant gesteigerte Expression des kanonischen Wnt-Koaktivators Bcl-9 nach Inkubation mit 10 und $50 \mu \mathrm{M}$ Niclosamid. e), f) und g) Signifkant reduzierte Expression ausgewählter Wnt-Zielgene nach Inkubation mit $10 \mu \mathrm{M}$ (MMP7) respektive $50 \mu \mathrm{M}$ (MMP7, Cyclin D1, Met) Niclosamid.

Der Wnt-Inhibitor Wif1 wurde nach Inkubation mit Niclosamid vermehrt transkribiert, ohne dass statistisch ein signifikanter Effekt berechnet werden konnte. 3 und $50 \mu \mathrm{M}$ Niclosamid vermochten die Transkription annäherungsweise zu verdoppeln, $10 \mu \mathrm{M}$ Niclosamid führten zu einer Verdreifachung der Expression (vgl. Abbildung 9a).

Als exemplarische Bestandteile des $\beta$-Catenin-Degradationskomplexes wurden nachfolgend das Protein Axin2 sowie die GSK $3 \beta$ betrachtet. Die Transkriptionsraten blieben dosisunabhängig jeweils relativ unverändert. Mit einer Zunahme der Transkription um $50 \%$ nach Inkubation mit $10 \mu \mathrm{M}$ Niclosamid war der Effekt für die GSK $3 \beta$ am 
ausgeprägtesten. Jedoch war auch diese Steigerung als nicht-signifikant zu bewerten (vgl. Abbildung 9b und c).

Auf Ebene der Transkriptionsfaktoren bewirkte Niclosamid hingegen eine signifikante Inhibierung des kanonischen Koaktivators Bcl-9. Nach 12 Stunden Inkubation mit $10 \mu \mathrm{M}$ Niclosamid waren noch 27 \% des Ausgangswertes zu messen. Dieser Effekt wurde auf 12 \% bei einer Konzentration von $50 \mu \mathrm{M}$ gesteigert (vgl. Abbildung 9d).

Die Transkription ausgewählter Wnt-Zielgene im kolorektalen Karzinom wurde ebenfalls durch Inkubation mit Niclosamid signifikant gehemmt. $10 \mu \mathrm{M}$ Niclosamid waren ausreichend, um die Transkription des Proteins MMP7 auf ein Viertel zu reduzieren; bei einer Steigerung der Konzentration auf $50 \mu \mathrm{M}$ waren weniger als $10 \%$ des Ausgangswertes nachweisbar. Auch die Transkriptionsraten von Cyclin D1 und der Rezeptor-Tyrosinkinase Met wurden nach Inkubation mit $50 \mu \mathrm{M}$ Niclosamid jeweils auf nahezu ein Viertel reduziert (vgl. Abbildung 9e, f und g).

In Zusammenschau vermochten $50 \mu \mathrm{M}$ Niclosamid die Transkription ausgewählter kanonischer Wnt-Zielgene (MMP7, Cyclin D1, Met) signifikant zu inhibieren. $10 \mu \mathrm{M}$ Niclosamid waren bereits ausreichend, um die Transkriptionsrate des kanonischen Koaktivators Bcl-9 auf etwa ein Viertel zu reduzieren. Demgegenüber wurde die Expression des Wnt-Inhibitors Wif-1 tendenziell gesteigert. Dosisunabhängig blieb die Transkription von exemplarischen Komponenten des $\beta$-Catenin-Degradationskomplexes (Axin2 und GSK $3 \beta$ ) unbeeinflusst.

\section{Analyse von aktivem $\beta$-Catenin fluoreszenzmikroskopisch und auf Proteinebene}

Niclosamid konnte die Aktivität des kanonischen Wnt-Signalweges in kolorektalen Tumorzellen dosisabhängig inhibieren. Zur Klärung des Wirkmechanismus wurde nachfolgend aktives unphosphoryliertes $\beta$-Catenin immunhistochemisch (vgl. Kapitel 2.2.9) und auf Proteinebene (vgl. Kapitel 2.2.10) in CC531 Zellen untersucht. Unphosphoryliertes $\beta$-Catenin ist das Schlüsselprotein des kanonischen Wnt-Signalweges. Für die Beurteilung ist vorrangig der nukleäre Anteil entscheidend, der die Transkription der Wnt-Zielgene initiiert (vgl. Kapitel 1.3.1). Daher wurde sowohl die Menge als auch die Verteilung des Proteins auf Zytosol und Kern analysiert. 

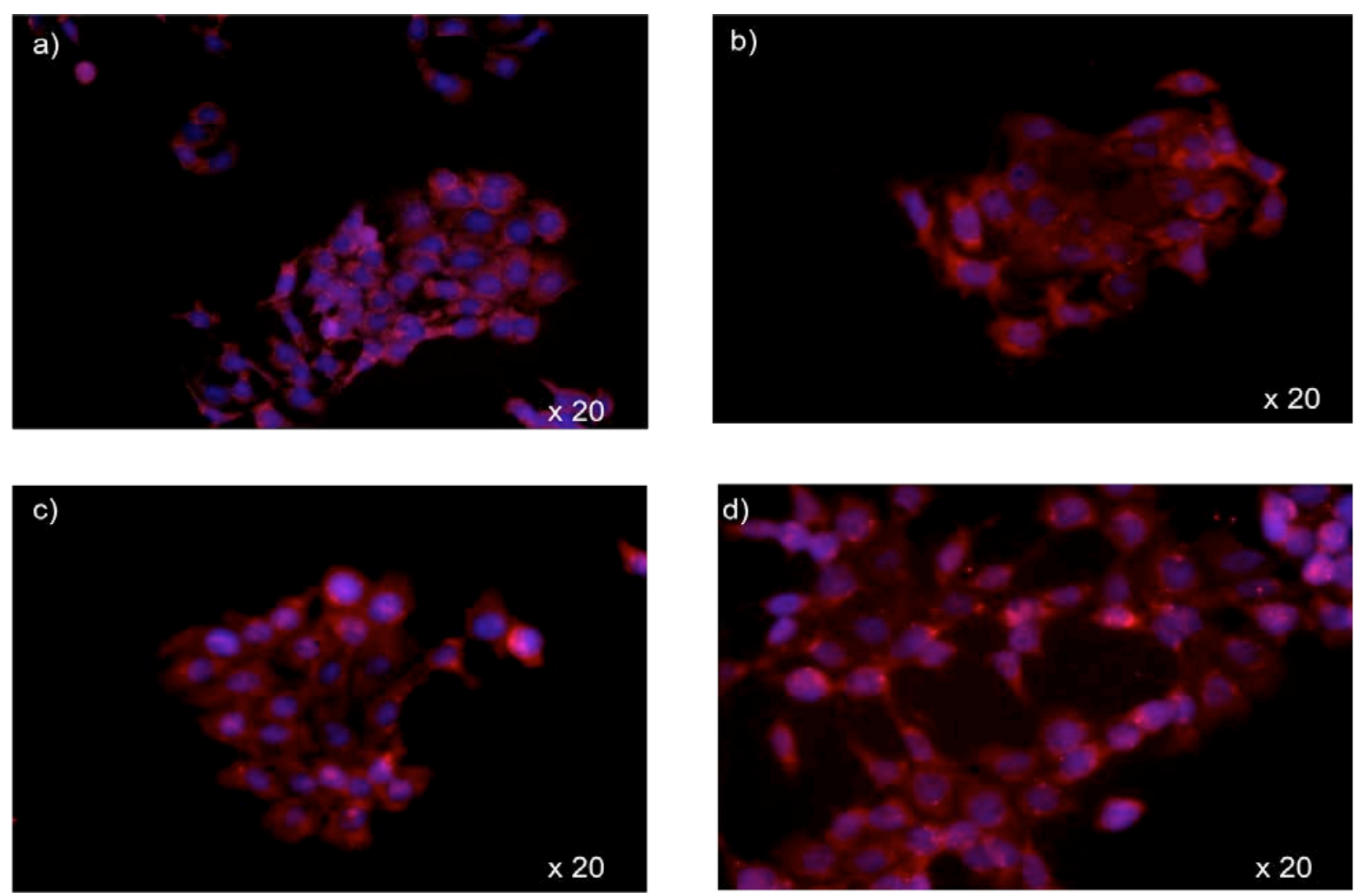

e)

Niclosamid $[\mu \mathrm{M}]$

DMSO $[\mu \mathrm{l}]$

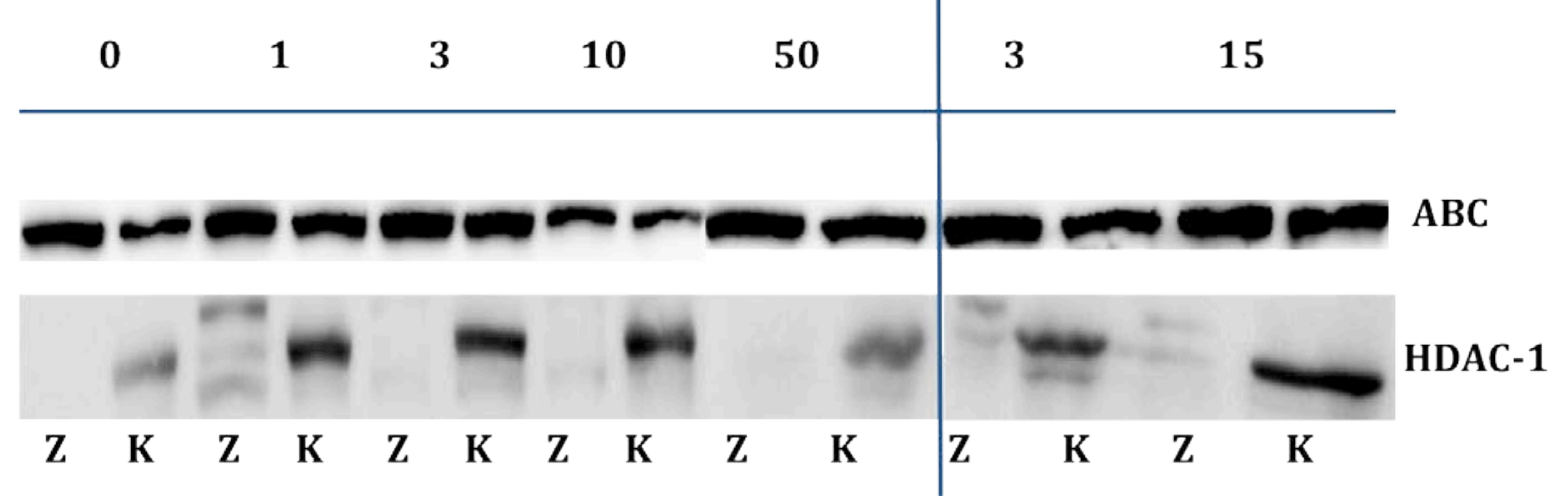

Abbildung 10: Analyse der Expression von aktivem $\beta$-Catenin (ABC) nach Inkubation mit Niclosamid.

a) bis d) Fluoreszenzmikroskopische Dokumentation nach 12 Stunden Inkubation mit a) reinem Zellkulturmedium, b) $15 \mu \mathrm{l}$ DMSO, c) $3 \mu \mathrm{M}$ Niclosamid und d) $10 \mu \mathrm{M}$ Niclosamid. Unabhängig von einer Inkubation mit Niclosamid respektive DMSO blieb das Expressionsmuster unverändert. e) Translationale Expression des ABC nach 12 Stunden Inkubation mit Niclosamid. Western Blot mit Zelllysat der Linie CC531 nach Inkubation mit aufsteigenden Konzentrationen des Niclosamids $(0 \mu \mathrm{M}, 1 \mu \mathrm{M}, 3 \mu \mathrm{M}, 10 \mu \mathrm{M}, 50 \mu \mathrm{M})$ für 12 Stunden. Z repräsentiert die zytosolische Fraktion und K die Kernfraktion. Die Relation zwischen den beiden Fraktionen blieb unverändert. 
In unbehandelten, auf Chamber Slides fixierten CC531 Zellen wurde aktives $\beta$-Catenin immunhistochemisch vorwiegend im Zytosol nachgewiesen. Das Signal im Kern war insgesamt eher schwach ausgeprägt. Dies ließ die Schlussfolgerung zu, dass der kanonische Wnt-Signalweg in CC531 Zellen konstitutiv aktiv war (vgl. Abbildung 10a). Weder 3 noch $10 \mu \mathrm{M}$ Niclosamid führten zu einem reduzierten Signal in den Zellen. Vor allem blieb auch die Verteilung des Proteins auf die beiden zellulären Kompartimente (Zytosol und Kern) unverändert (vgl. Abbildung 10c und d). $50 \mu \mathrm{M}$ Niclosamid führten zu ausgeprägter Ablösung der adhärenten CC531 Zellen von den Chamber Slides. Ein immunhistochemischer Nachweis von aktivem $\beta$-Catenin war daher aus technischen Gründen nicht möglich. Die Trägersubstanz DMSO führte zu keiner immunhistochemisch nachweisbaren Veränderung der Expression von aktivem $\beta$-Catenin (vgl. Abbildung 10b). Zur Verifizierung des Ergebnisses wurde aktives $\beta$-Catenin (MW 94 kD) in CC531 Zellen mittels Western Blot untersucht (vgl. Kapitel 2.2.10). Zusätzlich wurden die Membranen mit einem Antikörper gegen HDAC (MW 62 kD) inkubiert, um die korrekte Auftrennung des Lysates in die Kern- und Zytosolfraktion zu belegen. In der Kernfraktion blieb das Signal für aktives $\beta$-Catenin unabhängig von der eingesetzten Konzentration des Niclosamids (1 bis $50 \mu \mathrm{M}$ ) im Vergleich zur Mediumkontrolle (unbehandelte Zellen) konstant. Insbesondere kam es nicht zu einer Umverteilung des Proteins zwischen Kern und Zytosol. In den Kontrollen mit 3 und $15 \mu$ DMSO blieb das Signal im Vergleich zur Mediumkontrolle (unbehandelte Zellen) unverändert (vgl. Abbildung 10e).

Zusammenfassend betrachtet blieben sowohl die Signalintensität als auch die nukleozytoplasmatische Verteilung von aktivem $\beta$-Catenin trotz Niclosamid-Inkubation unverändert.

\subsubsection{Effekt des Niclosamids auf den nicht-kanonischen Wnt/ JNK-Signalweg}

Die Tyrosinkinase c-jun ist das Schlüsselprotein des nicht-kanonischen Wnt/ JNKSignalweges und diente orientierend als Marker für dessen Aktivität. Ihre Expression wurde sowohl auf Transkriptions- (vgl. Kapitel 2.2.8) als auch auf Proteinebene (vgl. Kapitel 2.2.10) unter Einfluss steigender Niclosamid-Konzentrationen ( 0 bis $50 \mu \mathrm{M}$ ) untersucht. Dabei wurde jeweils sowohl der inaktive als auch der aktive phosphorylierte Anteil von cjun erfasst. 

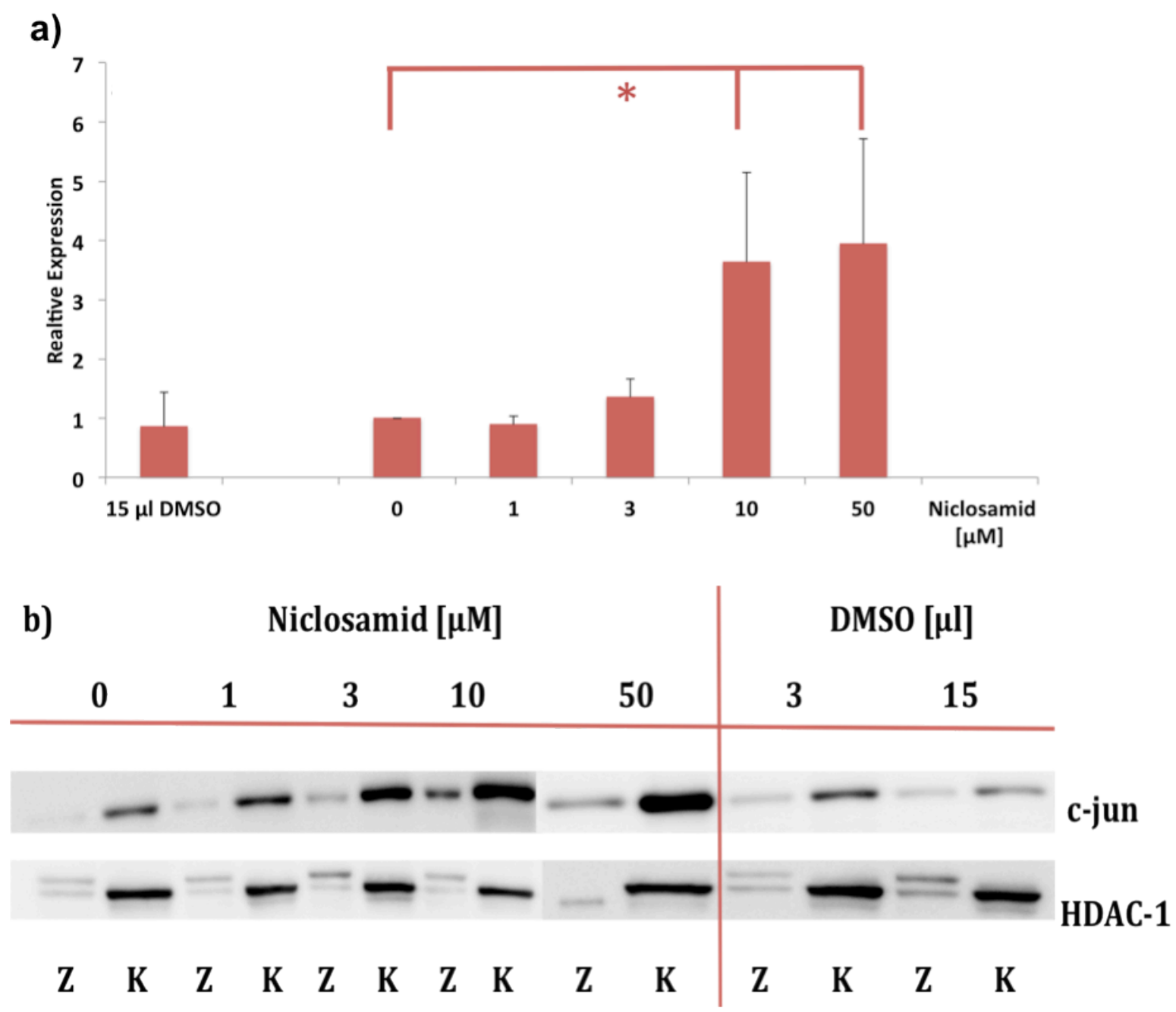

Abbildung 11: Analyse der Expression von c-jun nach Inkubation mit Niclosamid. a) Relative transkriptionelle Expression von c-jun nach 12 Stunden Inkubation mit Niclosamid. RT-PCR mit Zelllysat der Linie CC531 nach Inkubation mit aufsteigenden Konzentrationen des Niclosamids ( $0 \mu \mathrm{M}, 1 \mu \mathrm{M}, 3 \mu \mathrm{M}, 10 \mu \mathrm{M}, 50 \mu \mathrm{M})$. Signifikante Unterschiede mit $p<0,05$ sind mit Sternchen $\left(^{*}\right)$ markiert. Es zeigte sich eine dosisabhängige Zunahme der Expression von c-jun. b) Translationale Expression nach 12 Stunden Inkubation mit Niclosamid. Western Blot mit Zelllysat der Linie CC531 nach Inkubation mit aufsteigenden Konzentrationen des Niclosamids $(0 \mu \mathrm{M}, 1 \mu \mathrm{M}, 3 \mu \mathrm{M}, 10 \mu \mathrm{M}, 50 \mu \mathrm{M})$. Z repräsentiert die zytosolische und $\mathrm{K}$ die Kernfraktion. Es zeigte sich eine dosisabhängige Zunahme der Expression von c-jun in der Kernfraktion.

Die Transkriptionsrate der Tyrosinkinase c-jun wurde nach 12 Stunden Inkubation mit 10 und $50 \mu \mathrm{M}$ Niclosamid annäherungsweise vervierfacht $(p<0,05)$. Durch Kultivierung mit Zugabe von $15 \mu \mathrm{l}$ DMSO blieb die Transkription unverändert (vgl. Abbildung 11a). 
Zusätzlich wurde die Expresssion von c-jun mittels Western Blot (MW 48 kD) in CC531 Zellen bestimmt. Verglichen mit der Mediumkontrolle (unbehandelte Zellen) nahm das Signal dosisabhängig deutlich zu. Insbesondere kam es nach Inkubation mit aufsteigenden Niclosamid-Konzentrationen zu einer Intensivierung der nukleären Bande; nukleär ist das c-jun-Protein in seiner aktiven phosphorylierten Form zu erwarten. Das Signal blieb durch Zugabe der Trägersubstanz DMSO unbeeinflusst (vgl. Abbildung 11b).

Sowohl auf Transkriptions- als auch auf Proteinebene nahm die Expression des nichtkanonischen Schlüsselproteins c-jun unter Niclosamid-Einwirkung zu. Dies ist mit einer gesteigerten Aktivität des Wnt/ JNK-Signalweges vereinbar.

\subsection{Immunhistochemischer Nachweis von Fibroblasten}

Vor Beginn der Experimente wurden aus dem subkutanen Fettgewebe einer gesunden Fischer-Ratte Zellen isoliert. Zur Kontrolle wurde das mesenchymale Intermediärfilament Vimentin mittels immunhistochemischer Färbung nachgewiesen (vgl. Kapitel 2.2.5). Hierdurch sollte belegt werden, dass es sich bei diesen Zellen um Fibroblasten handelte.

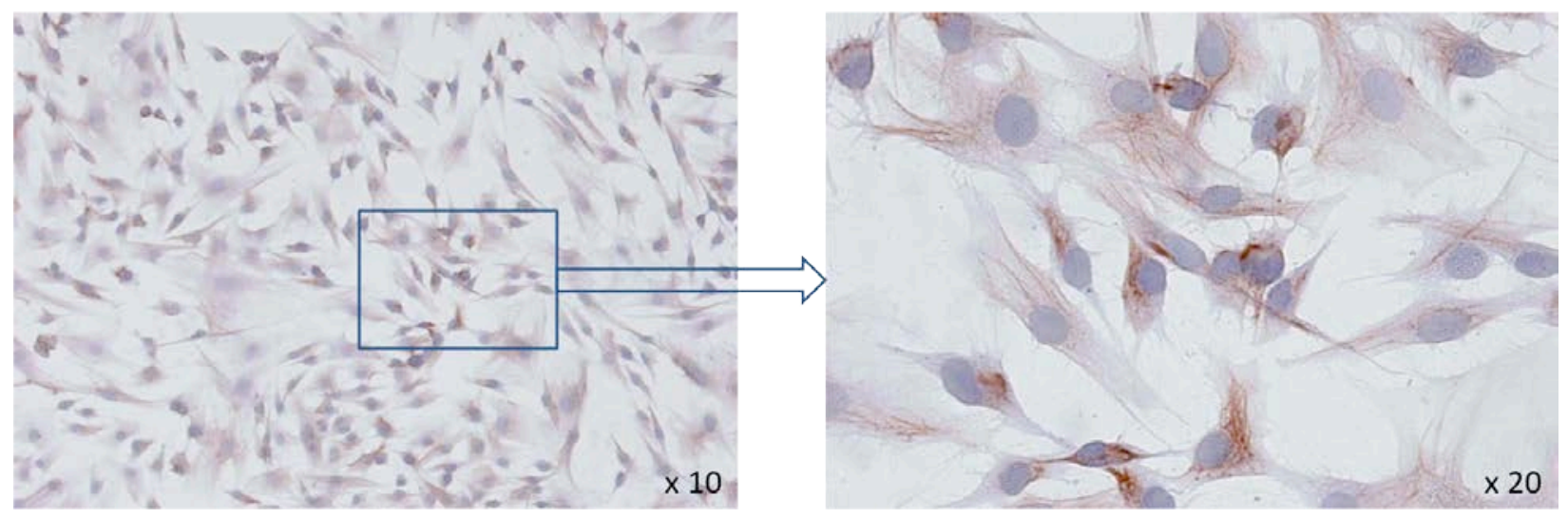

Abbildung 12: Vimentin-Expression in primären Fibroblasten. Immunhistochemischer Nachweis des Intermediärfilamentes Vimentin in primären Zellen (Ursprung: Fischer-Ratte). Hierdurch konnte deren mesenchymale Herkunft belegt werden.

Die lichtmikroskopischen Bilder in Abbildung 12 belegen, dass die kultivierten Zellen Vimentin exprimierten. Somit konnte deren mesenchymale Identität bewiesen werden. Diese Zellen konnten nachfolgend in den Versuchen im Sinne nicht-neoplastisch veränderter Zellen als Kontrolle eingesetzt werden. 


\section{Diskussion}

Aberrationen innerhalb des Wnt-Netzwerkes nehmen eine exponierte Stellung in der kolorektalen Karzinogenese ein. Molekulare Therpieansätze zu dessen Modulation sind bisher aber rein experimenteller Natur. Eine Fokussierung auf das Wnt-Netzwerk als Angriffspunkt in der Therapie des kolorektalen Karzinoms ist jedoch notwendig: $40 \%$ aller betroffenen Patienten sind mit einer hämatogenen Metastasierung in die Leber konfrontiert, wodurch die 5-Jahres-Überlebensrate der Patienten drastisch sinkt (vgl. Kapitel 1).

In der vorliegenden Arbeit wurde die Wirkung des als Wnt-Inhibitor charakterisierten Antihelminthikums Niclosamid auf kolorektale Karzinomzelllinien untersucht. Dabei wurden neue Erkenntnisse zum genauen Wirkmechanismus der Substanz innerhalb des Wnt-Netzwerkes gewonnen.

\subsection{Therapeutischer Bereich des Niclosamids nach 24 und 12 Stunden Inkubation}

Zunächst sollte der therapeutische Bereich von Niclosamid evaluiert werden. Dafür wurde das Wachstum von kolorektalen Karzinomzellen (CC531, SW480 und SW620) mit dem Wachstum von Ratten-Fibroblasten nach Inkubation mit Niclosamid verglichen (vgl. Kapitel 3.1.1). Für verschiedene solide und hämatologische Tumoren wurden im Vorfeld Konzentrationen bis 11,7 $\pm 2,3 \mu \mathrm{M}$ bei Inkubationszeiten zwischen 24 und 72 Stunden in vitro als antiproliferativ wirksam beschrieben (PAN et al. 2012). Deshalb wurden für die vorliegende Arbeit Konzentrationen des Niclosamids zwischen 1 und $50 \mu \mathrm{M}$ gewählt. Die Inkubationszeiten wurden auf 24 und 12 Stunden begrenzt; dadurch sollte gewährleistet werden, dass molekulare Veränderungen möglichst frühzeitig erfasst wurden. Aufgrund seiner hydrophilen Eigenschaften musste Niclosamid in DMSO gelöst werden (DEVARAKONDA et al. 2005). Dabei wurde DMSO mit einer maximalen Konzentration von $0,5 \%$ eingesetzt, sodass von einem zytotoxischen Effekt nicht auszugehen war (DA VIOLANTE et al. 2002).

Niclosamid inhibierte nach 12 und 24 Stunden dosisabhängig das Wachstum der kolorektalen Karzinomzelllinien. Dieser antiproliferative Effekt war dabei in niedriger 
Konzentration des Niclosamids zunächst selektiv auf die neoplastischen Zellen begrenzt. So wurde das Wachstum kolorektaler Tumorzellen nach beiden Inkubationszeiten bereits durch 1 und $3 \mu \mathrm{M}$ Niclosamid signifikant gehemmt. Für eine signifikant reduzierte Zellzahl der Fibroblasten war hingegen nach 24 Stunden der Einsatz von $10 \mu \mathrm{M}$ und nach 12 Stunden sogar von $50 \mu \mathrm{M}$ Niclosamid notwendig (vgl. Kapitel 3.1.1, Abbildung 5a und b). Dieser antiproliferative Effekt ging lichtmikroskopisch mit einer erheblich reduzierten Zelldichte einher. Der geordnete Zellverband unbehandelter Zellen löste sich auf, die Zellen schrumpften und verloren ihre Adhärenz. Zusammengenommen belegten diese morphologischen Veränderungen eine Störung der zellulären Integrität, die bereits nach 12-stündiger Inkubation mit Niclosamid einsetzte (vgl. Kapitel 3.1.3, Abbildung 6).

In zahlreichen Studien wurden Niclosamid sowohl für solide als auch für hämatologische Tumoren chemotherapeutische Eigenschaften zugeschrieben (vgl. Kapitel 1.5). Die Wirkung der Substanz setzte in vitro bereits bei einer Dosierung im niedrigen nano- bis mikromolaren Bereich $(0,25 \pm 0,07 \mu \mathrm{M}$ beim Cervixkarzinom bis 11,7 $\pm 2,3 \mu \mathrm{M}$ beim Prostatakarzinom) ein (PAN et al. 2012). Dies wird durch die Daten der vorliegenden Arbeit gestützt. Auch die hier ermittelte verzögerte Wirkung auf gesunde Fibroblasten deckt sich mit Beobachtungen verschiedener Publikationen zum Einsatz von Niclosamid bei Neoplasien. So blieb die Zahl von Monozyten, B-Lymphozyten sowie CD4+- und CD8+-T-Zellen im Bereich bis $1 \mu \mathrm{M}$ nach 7 Tagen Inkubation im Gegensatz zur Zellzahl multipler Myelomzellen konstant (KHANIM et al. 2011). Darüber hinaus wurde die Viabilität humaner neuronaler Zellen im Vergleich zu Glioblastomzellen im Bereich bis 1,2 $\mu$ M nach 5 Tagen Inkubation mit Niclosamid nicht reduziert (WIELAND et al. 2013). Auch die Viabilität embryonaler Fibroblasten einer Maus, humaner Fibroblasten und gesunder Knochenmarkszellen blieb im Vergleich zu AML-Zellen bis 95 nM nach 72 Stunden unverändert (JIN et al. 2010).

Für weiterführende Versuche wurde eine Inkubationszeit von 12 Stunden gewählt, um einen angemessenen therapeutischen Bereich des Niclosamids zwischen 1 und $50 \mu \mathrm{M}$ betrachten zu können. In diesem Bereich wurde das Wachstum der kolorektalen CC531 Karzinomzellen mit aberrant aktiviertem Wnt-Netzwerk sensitiver gehemmt als das Wachstum physiologischer Fibroblasten. 


\subsection{Unabhängigkeit der Niclosamid-Effektivität vom Mutationsstatus kolorektaler Karzinomzellen}

Nachdem gezeigt werden konnte, dass Niclosamid selektiv antiproliferativ auf die kolorektalen Karzinomzelllinien CC531, SW480 und SW620 wirkte, stellte sich die Frage nach einem Zusammenhang zwischen der effektiven Wirksamkeit der Substanz und den zugrundeliegenden Mutationen der Zellen (vgl. Kapitel 3.1.2). Die humanen Karzinomzelllinien SW480 und SW620 wiesen beide eine loss-of-function-Mutation des Tumorsuppressorgenes APC auf (DIHLMANN et al. 1999, YANG et al. 2006), während für die Zelllinie CC531 aus der Ratte eine gain-of-function-Mutation des Protoonkogenes $\beta$-Catenin vorbekannt war (GERMANN et al. 2003). Diese Veränderungen der ausgewählten Zelllinien repräsentierten exemplarisch die charakteristischen genetischen Veränderungen der kolorektalen Karzinogenese innerhalb des Wnt-Netzwerkes (vgl. Kapitel 1.2).

Durch eine Inkubationszeit von 24 Stunden mit Niclosamid wurde das Wachstum der humanen Zelllinien (SW480, SW620) bereits mit $1 \mu \mathrm{M}$ Niclosamid signifikant inhibiert. $3 \mu \mathrm{M}$ Niclosamid wirkten dann auch signifikant antiproliferativ auf die Rattenzelllinie CC531. Das Ausmaß der Zellzahlreduktion glich sich mit steigender Konzentration des Niclosamids in allen drei Zelllinien an (vgl. Kapitel 3.1.2, Tabelle 22).

Die wachstumsinhibierende Eigenschaft des Niclosamids auf kolorektale Karzinomzelllinien erfolgte also unabhängig von einem speziellen Mutationsstatus innerhalb des Wnt-Netzwerkes (APC vs. $\beta$-Catenin). Auch OSADA et al. (2011) konnten nach einer Inkubationszeit von 72 Stunden belegen, dass Niclosamid trotz unterschiedlicher Mutationen im APC-Protein vergleichbare chemotherapeutische Effizienz auf die verwendeten kolorektalen Karzinomzelllinien bei einer Konzentrierung bis $10 \mu \mathrm{M}$ aufwies. Die Ergebnisse der vorliegenden Arbeit ließen in Zusammenschau mit der Literatur den Schluss zu, dass Niclosamid sowohl unabhängig vom Schlüsselprotein des kanonischen Wnt-Signalweges $\beta$-Catenin als auch von dessen Degradationskomplex, der unter anderem von APC gebildet wird, seine Wirkung entfaltet. 


\subsection{Apoptose- und Nekroseinduktion in kolorektalen Karzinomzellen nach Inkubation mit Niclosamid}

In einem nächsten Schritt wurde die potentiell zytotoxische Wirkung des Niclosamids untersucht. Hierfür wurde analysiert, in welchem Ausmaß eine Inkubation mit Niclosamid für 24 und 12 Stunden Zelltod in CC531 Zellen induzierte (vgl. Kapitel 3.1.4). In der Literatur wurde die Entkopplung der oxidativen Phosphorylierung in den Mitochondrien als möglicher Angriffspunkt bei der antihelminthischen Wirkungsentfaltung der Substanz diskutiert (WEINBACH \& GARBUS 1969). Entsprechend wurden die Mitochondrien auch in neoplastischen Zellen bereits zuvor als Wirkungsort betrachtet, wobei der Schwerpunkt auf den Nachweis einer Zelltodinduktion durch Niclosamid gelegt wurde. In verschiedenen neoplastischen Zelllinien (AML-Zellen und AML-Stammzellen, Karzinomzellen der Prostata und der Mamma, multiple Myelomzellen, kolorektale Karzinomzellen, ovarielle Karzinomzellen und NSCLC-Zellen) konnte hierbei eine gesteigerte Zelltodrate nach Behandlung mit Niclosamid dokumentiert werden (JIN et al. 2010, LU et al. 2011, KHANIM et al. 2011, OSADA et al. 2011, YO et al. 2012, YE et al. 2014, LEE et al. 2014, LIU et al. 2014).

Die Ergebnisse der vorliegenden Arbeit zeigen, dass der Anteil avitaler Zellen nach einer Inkubationszeit von 24 Stunden in höheren Konzentrationen des Niclosamids (> $10 \mu \mathrm{M}$ ) konstant auf mehr als $60 \%$ anstieg. Während bis zu einer Konzentration von $10 \mu \mathrm{M}$ Niclosamid vorwiegend Apoptose in den Zellen induziert wurde, stieg bei $50 \mu \mathrm{M}$ auch der Anteil nekrotischer Zellen deutlich auf annäherungsweise $30 \%$ an. Im Gegensatz dazu konnte nach Reduktion der Inkubationszeit auf 12 Stunden eine konstant hohe Zellvitalität (> $85 \%$ ) nachgewiesen werden (vgl. Kapitel 3.1.4, Abbildung 7).

Demnach wirkte Niclosamid nach 12 Stunden Inkubation überwiegend zytostatisch im ermittelten therapeutischen Bereich (vgl. Kapitel 4.1). Durch Verdopplung der Inkubationszeit auf 24 Stunden wurden außerhalb des therapeutischen Bereiches $(>10 \mu \mathrm{M}$ Niclosamid) zytotoxische Effekte im Sinne einer Apoptose- und in höheren Konzentrationen (50 $\mu \mathrm{M}$ Niclosamid) auch einer Nekroseinduktion festgestellt. Diese Beobachtung stimmt mit Ergebnissen anderer Arbeitsgruppen überein (JIN et al. 2010, KHANIM et al. 2011, LU et al. 2011, OSADA et al. 2011, YO et al. 2012, WANG et al. 2013, YE et al. 2014, LEE et al. 2014, LIU et al. 2014). Für das kolorektale Karzinom konnten OSADA et al. (2011) nach 72 Stunden Inkubation mit 
$20 \mu \mathrm{M}$ Niclosamid durchflusszytophotometrisch zeigen, dass der Anteil apoptotischer Zellen auf 80 \% anstieg. Analog zu OSADAs Daten wurden bei ebenfalls deutlich längeren Inkubationszeiten zwischen 48 und 72 Stunden Zelltodraten bis $80 \%$ in leukämischen Zellen, Multiplen-Myelomzellen, Mamma-Karzinomzellen und Prostatakarzinomzellen nach Inkubation mit Niclosamid beschrieben (JIN et al. 2010, KHANIM et al. 2011, LU et al. 2011, LIU et al. 2014, YE et al. 2014). Als ursächlich für die gesteigerten Zelltodraten wurden die Bildung reaktiver Sauerstoffspezies, der Verlust des mitochondrialen Membranpotenzials und eine Aktivierung des p38 MAPK-c-jun-Signalweges diskutiert (JIN et al. 2010, KHANIM et al. 2011, YO 2012, LEE et al. 2014). Ergänzend konnte im Gegensatz zu kolorektalen Tumorzellen nach 72 Stunden Inkubation keine gesteigerte Zelltodrate bis zu einer Konzentration von $20 \mu \mathrm{M}$ Niclosamid bei Fibroblasten, epithelialen Mammazellen oder mononukleären peripheren Blutzellen ermittelt werden (OSADA et al. 2011). Ebenso blieb die Vitalität epithelialer Prostatazellen im Vergleich zu Prostatakarzinomzellen nach Inkubation mit 0,5 $\mu \mathrm{M}$ Niclosamid für 24 Stunden unverändert (LIU et al. 2014).

Sowohl die eigenen erhobenen Daten als auch die anderer Arbeitsgruppen legen nahe, dass Niclosamid dosis- und zeitabhängig selektiv zytotoxisch wirkt. Angesichts der hohen Zelltodrate ab einer Konzentration von $10 \mu \mathrm{M}$ Niclosamid bei einer Inkubationszeit von 24 Stunden wurden alle weiterführenden Versuche lediglich nach einer Inkubationszeit von 12 Stunden durchgeführt. Entsprechend den Daten der vorliegenden Arbeit ist Niclosamid in diesem Zeitfenster bereits als wachstumsinhibierend (vgl. Kapitel 4.1), jedoch noch nicht als zytotoxisch zu charakterisieren. Somit war eine ausreichende Vitalität der kolorektalen Karzinomzelllinie CC531 gewährleistet, um den molekularen Wirkmechanismus von Niclosamid aufzuklären. 


\subsection{Interaktion von Niclosamid mit dem Wnt-Netzwerk}

Als grundlegende Frage der vorliegenden Arbeit galt es, die modulierende Wirkung von Niclosamid auf das Wnt-Netzwerk zu entschlüsseln. Dabei standen verschiedene Ebenen innerhalb des Wnt-Netzwerkes im Fokus der Untersuchungen (vgl. Kapitel 1.4.4). Zuvor konnte bereits belegt werden, dass Niclosamid den kanonischen Wnt-Pfad beeinflusst (CHEN et al. 2009, LU et al. 2011, OSADA et al. 2011, SACK et al. 2011, WIELAND et al. 2013, WANG et al. 2013, ONO et al. 2014, LONDONO-JOSHI et al. 2014).

\subsubsection{Inhibierung des kanonischen Wnt-Signalweges durch Niclosamid Reduktion der relativen Wnt-Aktivität nach Inkubation mit Niclosamid}

CC531 Zellen wurden mit dem Wnt-responsiven TOPflash/ FOPflash Luciferase Plasmid transfiziert, um die relative kanonische Wnt-Aktivität kolorektaler Karzinomzellen unter Einfluss von Niclosamid zu ermitteln. Es zeigte sich eine deutliche Blockierung der kanonischen Wnt-Aktivität durch Niclosamid. Die ursprüngliche Aktivität der unbehandelten Zellen konnte nach 12 Stunden durch $10 \mu \mathrm{M}$ Niclosamid signifikant auf ein Drittel reduziert werden (vgl. Kapitel 3.2.1, Abbildung 8).

Nach 24 Stunden waren bei kolorektalen Karzinomzellen $1 \mu \mathrm{M}$ (SACK et al. 2011, OSADA et al. 2011), bei ovariellen Karzinomezellen $8 \mu \mathrm{M}$ (AREND et al 2014) und bei Mammakarzinomzellen 0,25 $\mu \mathrm{M}$ Niclosamid (LONDONO-JOSHI et al. 2014) ausreichend, um das TOPflash/ FOPflash-Signal signifikant zu reduzieren. Außerdem konnte der stimulierende Effekt von Wnt3A sowie von Lithiumchlorid auf die kanonische Wnt-Aktivität durch Niclosamid antagonisiert werden (CHEN et al. 2009, LU et al. 2011, LONDONO-JOSHI et al. 2014, ONO et al. 2014).

Zusammengenommen kann Niclosamid innerhalb des ermittelten therapeutischen Bereiches (vgl. Kapitel 4.1) schon im niedrigen mikromolaren Bereich als potenter Inhibitor des kanonischen Wnt-Signalweges bezeichnet werden. 


\section{Reduzierte Transkription kanonischer Wnt-Zielgene nach Inkubation mit Niclosamid}

Die transkriptionelle Expression verschiedener kanonischer Wnt-Zielgene wurde in der RT-PCR betrachtet. Nach Niclosamid-Inkubation wurde eine dosisabhängige Reduktion der Genexpression ausgewählter Proteine (MMP7, Cyclin D1 und Met) beobachtet. Für MMP7 konnte eine signifikante Abnahme der Transkription auf $20 \%$ des Ausgangswertes innerhalb des therapeutischen Bereiches nach Inkubation mit $10 \mu \mathrm{M}$ Niclosamid gezeigt werden. Darüber hinaus wurden MMP7, Cyclin D1 und Met außerhalb des therapeutischen Bereiches nach Inkubation mit $50 \mu \mathrm{M}$ Niclosamid signifikant gehemmt (vgl. Kapitel 3.2.1, Abbildung 9e, f und g).

Folglich konnte auf Transkriptionsebene nach einer 12-stündigen Inkubationszeit ein dosisabhängiger Rückgang der Expression kanonischer Wnt-Zielgene nachgewiesen werden. Die Ergebnisse stehen im Einklang mit Daten, die an leukämischen Zellen, kolorektalen Karzinomzellen, Glioblastom-Zellen und Stammzell-ähnlichen Vorläuferzellen des Mammakarzinoms erhoben wurden. Nach deutlich längeren Inkubationszeiten (> 24 Stunden) konnte die Expression zahlreicher kanonischer Wnt-Zielgene (Cyclin D1, c-myc, S100A4, Protein Patched Homolog, Hairy and Enhancer of Split 1) nach Inkubation mit Niclosamid signifikant reduziert werden (WANG et al. 2009, SACK et al. 2011, WIELAND et al. 2013, WANG et al. 2013). Darüber hinaus konnten ONO et al. (2014) einen stimulierenden Effekt von Lithiumchlorid auf die transkriptionelle Expression von Axin2 durch Inkubation mit $10 \mu \mathrm{M}$ Niclosamid für 24 Stunden aufheben. Die in der Literatur vorbeschriebene reduzierte Transkription exemplarischer kanonischer Zielgene nach Inkubation mit Niclosamid wurde in dieser Arbeit für die Zielgene Cyclin D1, MMP7 und Met bestätigt. Ergänzend war auch auf Proteinebene dosisabhängig ein inhibierender Effekt auf die Expression der Zielgene Cyclin D1, Axin2, S100A4 und Survivin vorbeschrieben (SACK et al. 2011, Lu et al. 2011, WIELAND et al. 2013, AREND et al. 2014, LONDONO-JOSHI et al. 2014).

In Zusammenschau mit den dargestellten Literaturdaten lassen unsere PCR-Ergebnisse zu kanonischen Wnt-Zielgenen nach Inkubation mit Niclosamid den Schluss $\mathrm{zu}$, dass Niclosamid den kanonischen Wnt-Signalweg inhibiert. Dadurch wird das oben analysierte Ergebnis des TOPflash/ FOPflash Dual-Luciferase ${ }^{\circledR}$ Reporter Assays bestätigt. Nachfolgend 
galt es, den genauen Wirkmechanismus zu eruieren, über den Niclosamid diesen Effekt bewirkt.

\section{Unabhängigkeit des Niclosamid-Wirkmechanismus vom zytosolischen $\beta$-Catenin- Degradationskomplex}

Zunächst wurde überprüft, ob Niclosamid die kanonische Wnt-Aktivität in Abhängigkeit vom zytosolischen $\beta$-Catenin-Degradationskomplex inhibierte. Dafür wurde exemplarisch mittels RT-PCR die Transkriptionsrate der GSK $3 \beta$ und des Proteins Axin2, die beide Bestandteile des $\beta$-Catenin-Degradationskomplexes sind, nach 12 Stunden Inkubation mit Niclosamid analysiert. Dosisunabhängig wurde keine statistisch-relevante Veränderung in der Genexpression beider Komponenten gefunden (vgl. Kapitel 3.2.1, Abbildung 9b und c). Folglich ist eine Aktivierung des Degradationskomplexes durch Niclosamid als Wirkmechanismus zur Hemmung der kanonischen Wnt-Aktivität unwahrscheinlich. An dieser Stelle wird die bereits in Kapitel 4.2 formulierte These bestätigt, dass Niclosamid seine Wirkung unabhängig vom Degradationskomplex und damit auch unabhängig vom klassischen APC-Mutationsstatus kolorektaler Tumorzellen entfaltet.

\section{Unabhängigkeit des Niclosamid-Wirkmechanismus vom aktiven unphosphorylierten $\beta$-Catenin}

Nachfolgend wurde aktives $\beta$-Catenin als Schlüsselprotein des kanonischen WntSignalweges nach 12 Stunden Inkubation mit Niclosamid untersucht. Immunhistochemisch blieb sowohl die Intensität des Signals als auch das Verteilungsmuster des Proteins zwischen Zytosol und Nukleus in CC531 Zellen nach Inkubation mit 3 und $10 \mu \mathrm{M}$ Niclosamid im Vergleich zur Mediumkontrolle (unbehandelte Zellen) unverändert. $50 \mu \mathrm{M}$ Niclosamid schädigten die zelluläre Integrität bereits in einem Ausmaß, dass eine Fixierung und nachfolgende immunhistochemische Analyse technisch nicht mehr möglich waren. Im Western Blot konnte die unveränderte Verteilung in den subzellulären Kompartimenten bestätigt werden. Es zeichnete sich eine konstante Proteinmenge in der Kernfraktion $\mathrm{ab}$, in der der Großteil des unphosphorylierten $\beta$-Catenins lokalisiert ist. Von besonderer Bedeutung war, dass es zu keiner Umverteilung des aktiven $\beta$-Catenins 
zwischen der nukleären und der zytosolischen Fraktion kam (vgl. Kapitel 3.2.1, Abbildung 10).

Folgerichtig konnte eine aktivitätsinhibierende Wirkung des Niclosamids auf den kanonischen Wnt-Signalweg über die Regulation der Proteinmenge an aktivem $\beta$-Catenin ausgeschlossen werden. In der Literatur wurden bisher lediglich Daten zur Gesamtmenge an $\beta$-Catenin erhoben und keine Differenzierung der aktiven und inaktiven Form vorgenommen. Initial wurde bei einer Untersuchung an Osteosarkomzellen eine stabile Expression von zytosolischem und Membran-gebundenem $\beta$-Catenin im Western Blot nach Inkubation mit 7,5 $\mu \mathrm{M}$ Niclosamid beschrieben (CHEN et al. 2009). Auch SACK et al. (2011) konnten im Western Blot eine konstante Proteinexpression von nukleärem totalem $\beta$-Catenin nach einer Inkubation mit $1 \mu \mathrm{M}$ Niclosamid über eine Zeitspanne von 18 Stunden in kolorektalen Karzinomzellen nachweisen. Im Gegensatz dazu wurde nach Inkubation mit Niclosamid in kolorektalen Karzinomzellen, ovariellen Karzinomzellen und Mammakarzinomzellen totales $\beta$-Catenin vermindert nachgewiesen; die Inkubationszeiten von jeweils 24 Stunden waren in diesen Studien jedoch doppelt so lang (LU et al. 2011, OSADA et al. 2011, ONO et al. 2014, AREND et al. 2014, LONDONO-JOSHI et al. 2014). Durch die vorliegende Arbeit werden die Ergebnisse der Literatur präzisiert. Statt der gesamten Proteinmenge, die auch die inaktiven Formen des $\beta$-Catenins erfasst, wurde erstmals die aktive Fraktion des $\beta$-Catenins gesondert analysiert. Demnach inhibiert Niclosamid den kanonischen WntSignalweg nicht über eine Aktivitätsänderung des Proteins $\beta$-Catenin. Dieses Ergebnis steht im Einklang mit der anfänglichen Beobachtung, dass Niclosamid unabhängig von einer speziellen $\beta$-Catenin-Mutation in verschiedenen Zellinien wachstumsinhibierend wirkte (vgl. Kapitel 4.2). Es konnte in dieser Arbeit bereits gezeigt werden, dass die Effektivität des Niclosamids ebenfalls unabhängig vom zytosolischen $\beta$-Catenin-Degradationskomplex war. Niclosamid muss seine inhibierende Wirkung auf die kanonische Wnt-Aktivität also entweder auf nukleärer Ebene über Hemmung des LEF/ TCF-Transkriptionsfaktors oder aber außerhalb der kanonischen Wnt-Signalkaskade entfalten. 


\section{Blockierung kanonischer Wnt-Koaktivatoren und Aktivierung kanonischer Wnt- Inihibitoren durch Niclosamid}

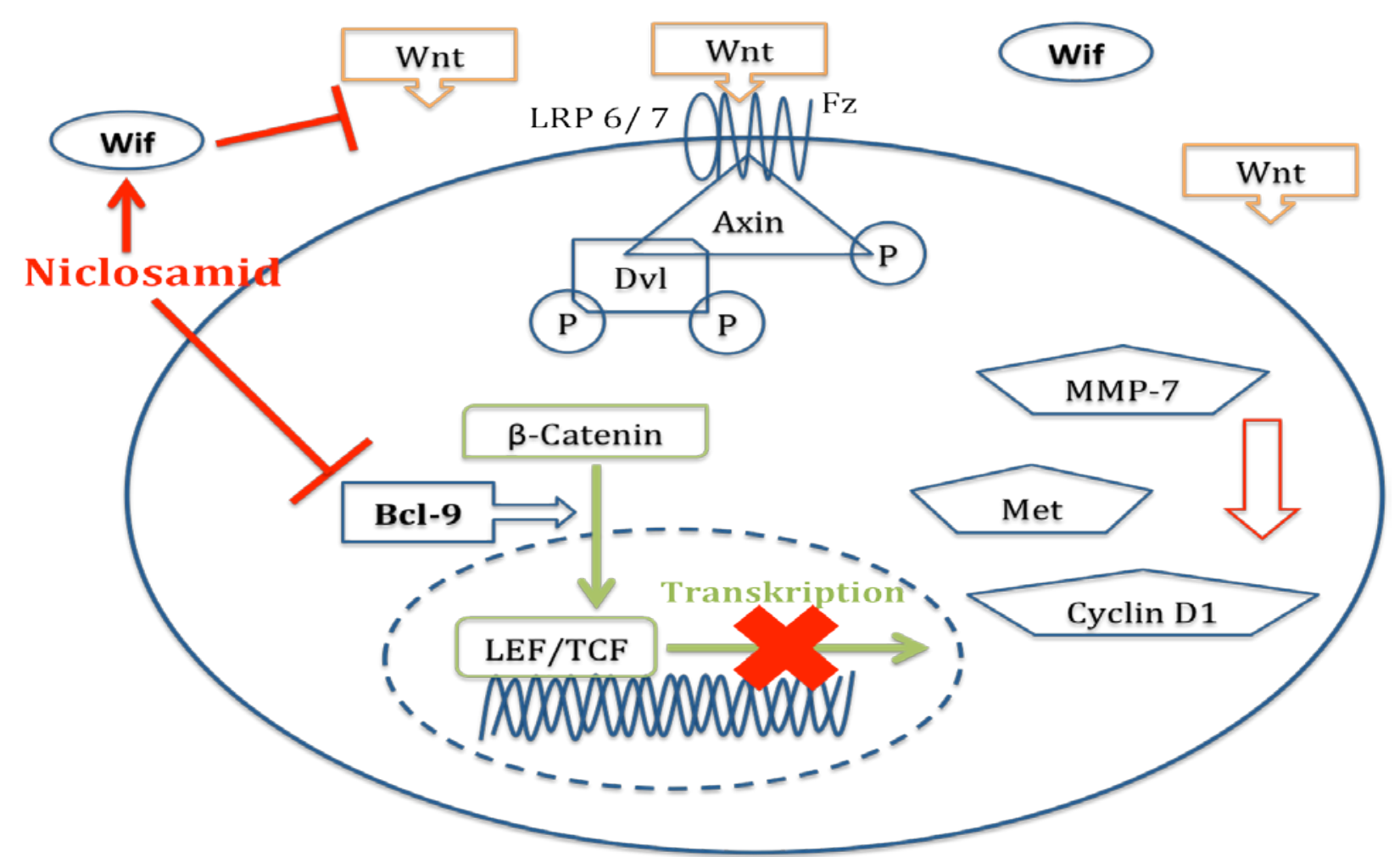

Abbildung 13: Inhibierung des kanonischen Wnt-Signalweges durch Niclosamid. Niclosamid hemmt die Expression des Wnt-Koaktivators Bcl-9. Hierdurch kann die reduzierte Aktivität des Transkriptionsfaktors LEF/ TCF und die dadurch verminderte Transkription kanonischer Wnt-Zielgene erklärt werden. Die in der vorliegenden Arbeit herausgefundenen Modulationen sind in rot dargestellt.

Mit Bcl-9 und Wif1 wurden schließlich die Transkriptionsraten von Proteinen analysiert, die in die Feinregulation der kanonischen Wnt-Aktivität involviert sind. Nach einer Inkubationszeit von 12 Stunden mit aufsteigenden Niclosamid-Konzentrationen zeichnete sich innerhalb des therapeutischen Bereiches $(10 \mu \mathrm{M})$ eine signifikant reduzierte transkriptionelle Expression des Koaktivators Bcl-9 auf ein Viertel des Ausgangswertes (unbehandelte Zellen) ab. Die Transkription des Inhibitors Wif1 wurde nach Inkubation mit Niclosamid hingegen tendenziell gesteigert (vgl. Kapitel 3.2.1, Abbildung 9a und b). 
Abbildung 13 fasst zusammen, wie diese transkriptionellen Veränderungen ursächlich für die zuvor beschriebene reduzierte kanonische Wnt-Aktivität sein könnten. SACK et al. (2011) haben eine konstante Proteinmenge von aktivem $\beta$-Catenin nach Inkubation mit $1 \mu \mathrm{M}$ Niclosamid über 18 Stunden nachgewiesen und eine gestörte Komplexbildung von $\beta$-Catenin mit dem LEF/ TCF-Transkriptionsfaktor diskutiert. Die reduzierte Expression von Bcl-9 präzisiert diese These nun. Die verminderte kanonische Wnt-Aktivität wäre durch den fehlenden Stimulus von Bcl-9 auf den Komplex von aktivem $\beta$-Catenin mit LEF/ TCF zu erklären. Erstmals stellt dieses Ergebnis die veränderte Expression Wnt-regulierender Proteine als potentiellen Wirkmechanismus des Niclosamids in Bezug auf die Blockierung des kanonischen Wnt-Signalweges zur Diskussion. Gerade die Inhibierung des nukleären Triple-Komplexes aus Bcl-9 mit aktivem $\beta$-Catenin und LEF/ TCF gilt als vielversprechender Ansatz im Hinblick auf ein möglichst geringes Ausmaß an unerwünschten Arzneimittelwirkungen. Diese Annahme ist dadurch begründet, dass die Formation dieses Triple-Komplexes unabhängig von anderen $\beta$-CateninProteininteraktionen ist. Von einer gestörten $\beta$-Catenin-vermittelten Zelladhäsion nach Inkubation mit Niclosamid wäre somit nicht auszugehen (HE \& AXELROD 2006, SAMPIETRO et al. 2006). 


\subsubsection{Aktivierung des nicht-kanonischen Wnt/ JNK-Signalweges}

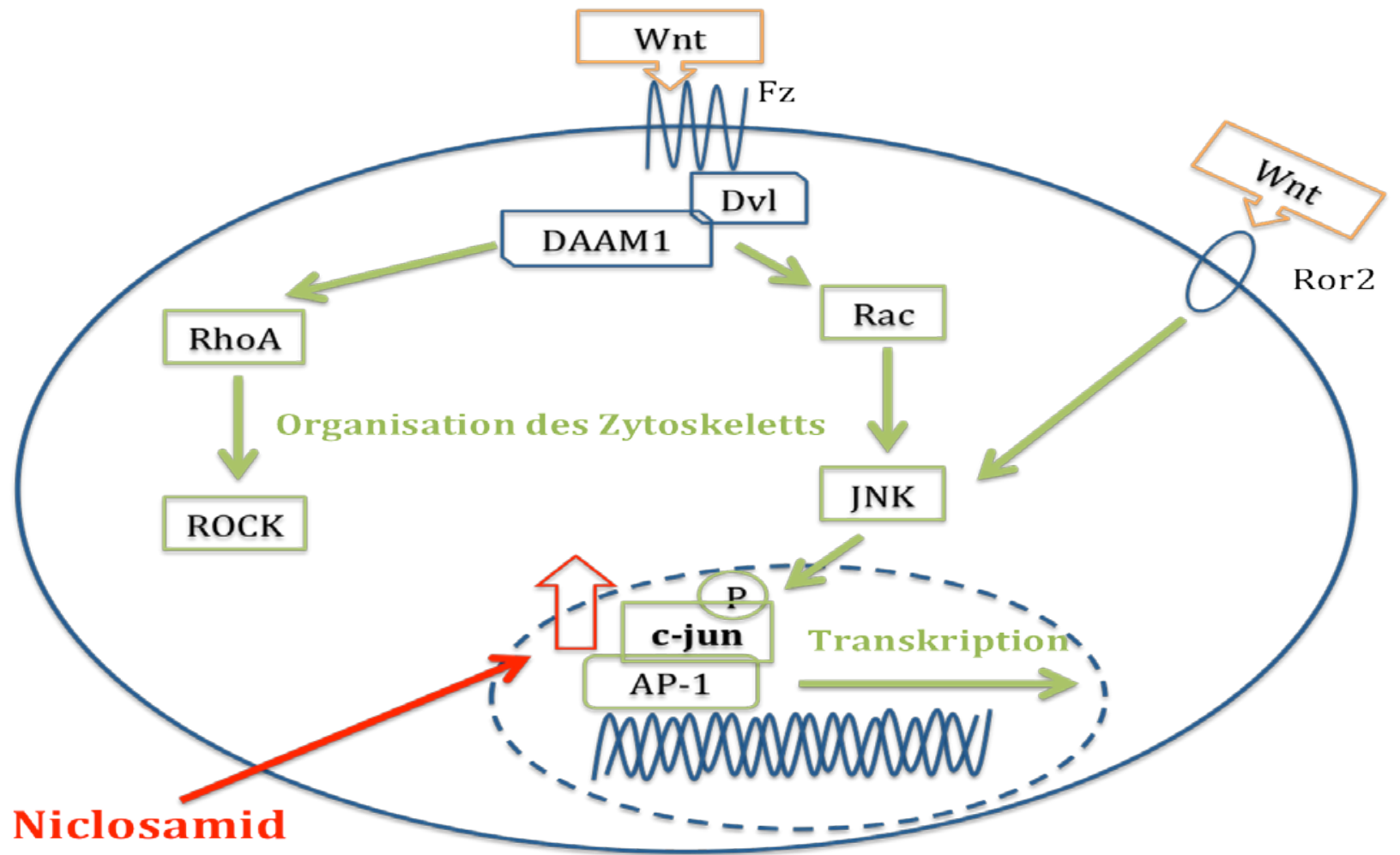

Abbildung 14: Aktivierung des nicht-kanonischen Wnt/ JNK-Signalweges durch Niclosamid.

Niclosamid steigert die Expression des nicht-kanonischen Wnt-Schlüsselproteins c-jun. Dies lässt auf eine insgesamt gesteigerte Aktivität des nicht-kanonischen WNT/ JNK-Signalweges schließen. Die in der vorliegenden Arbeit herausgefundenen Modulationen sind in rot dargestellt.

Abschließend wurde die Aktivität des nicht-kanonischen Wnt/ JNK-Signalweges nach Inkubation von CC531 Zellen mit Niclosamid untersucht. Dafür wurden die Transkriptionsund Translationsraten des Schlüsselproteins c-jun evaluiert. Es zeichnete sich eine signifikante Zunahme der transkriptionellen Expression von c-jun um den Faktor 4 nach Inkubation mit $10 \mu \mathrm{M}$ Niclosamid innerhalb des therapeutischen Bereiches ab (vgl. Kapitel 3.2.2, Abbildung 11a). Bestätigt wurde diese Beobachtung durch eine dosisabhängige Zunahme der Proteinmenge der c-jun-Tyrosinkinase. Entscheidend war, dass das Signal vor allem in der Kernfraktion deutlich zunahm, die den aktivierten phosphorylierten Anteil von c-jun repräsentiert (vgl. Kapitel 3.2.2, Abbildung 11b). 
Die zunehmende Expression des Schlüsselproteins c-jun - insbesondere im Nukleus spricht für eine gesteigerte Aktivität des nicht-kanonischen Wnt/ JNK-Pfades durch Inkubation mit Niclosamid (vgl. Abbildung 14). LEE et al. (2014) konnten auf Proteinebene für nicht-kleinzellige Lungenkarzinomzellen und für kolorektale Karzinomzellen zeigen, dass die Gesamtmenge von c-jun nach Inkubation mit $2 \mu \mathrm{M}$ Niclosamid über 2 Stunden anstieg. Bedeutend war, dass der gesondert betrachtete Anteil der aktiven phosphorylierten Form von c-jun zunahm. Die Autoren begründeten dadurch die zuvor beobachtete gesteigerte Apoptoserate (vgl. Kapitel 4.3), ohne Rückschlüsse auf eine gesteigerte Aktivität des nichtkanonischen Wnt-Signalweges zu ziehen.

Inhibitorische Effekte des nicht-kanonischen Wnt/ JNK-Signalweges auf das kanonische Wnt/ $\beta$-Catenin-Signal wurden in der Literatur bereits beschrieben. Die in dieser Arbeit nachgewiesene reduzierte kanonische LEF/ TCF-Aktivität könnte also auch auf die Aktivierung des nicht-kanonischen Wnt/ JNK-Signalweges nach Inkubation mit Niclosamid zurückzuführen sein. Unlängst wurde gezeigt, dass die klassischerweise nicht-kanonisch assoziierte Gruppe der Wnt-5A-Proteine die Aktivität des kanonischen Wnt-Signalweges nach Bindung an einen der Fz-Rezeptoren hemmen kann (TOPOL et al. 2003). Darüber hinaus kann das kanonische Signal nach Bindung von Wnt-5A an den Ror2-Rezeptor über den Wnt/ JNK- Signalweg destabilisiert werden (MIKELS \& NUSSE 2006). Auch JNK wird ein direkter antagonisierender Effekt auf die kanonische Wnt-Aktivität zugeschrieben (LIAO et al. 2006). Allerdings stehen diesen Daten zu inhibierenden Interaktionen kontrovers Daten gegenüber, die auf stimulierende Wechselwirkungen zwischen den Wnt-Signalwegen hindeuten (vgl. Kapitel 1.3.3). Auch wird in der Literatur Wnt-5A strittig teils als Tumorsuppressor, teils als Tumorpromotor charakterisiert (McDONALD \& SILVER 2009, PUKROP \& BINDER 2008). Weitere Untersuchungen sind somit notwendig, um die beschriebenen Veränderungen nach Inkubation mit Niclosamid im Kontext bewerten zu können. 


\subsection{Ausblick}

Die Ergebnisse der vorliegenden Dissertationsarbeit belegen, dass der antihelminthischen Substanz Niclosamid chemotherapeutische Wirkungen auf kolorektale Karzinomzellen zugeschrieben werden können. Die erhobenen Daten bestätigen damit Ergebnisse anderer Forschungsgruppen, die Niclosamid in zahlreichen soliden und hämatologischen Tumoren als insgesamt hemmend und antiproliferativ charakterisierten. Im Fokus dieser Arbeit stand vorrangig die Untersuchung der Modulation des Wnt-Netzwerkes durch die Substanz. Niclosamid inhibierte die Aktivität des kanonischen Wnt/ $\beta$-Catenin-Signalweges. Auf der einen Seite wurde der Koaktivator Bcl-9 nach Inkubation mit Niclosamid reduziert transkribiert. Nachfolgend wird hierdurch die Formation des Triple-Komplexes aus Bcl-9 mit aktivem $\beta$-Catenin und dem Transkriptionsfaktor LEF/ TCF gestört. Auf der anderen Seite wurde sowohl auf Transkriptions- als auch auf Proteinebene c-jun vermehrt nachgewiesen. C-jun ist das Schlüsselprotein für den nicht-kanonischen Wnt/ JNKSignalweg. Eine gesteigerte Aktivität dieses Wnt-Pfades ließ sich somit herleiten. Sowohl die reduzierte Expression von Bcl-9 als auch die Stimulation von c-jun können die reduzierte kanonische Wnt-Aktivität bedingen.

Die neuen Erkenntnisse zum Wirkmechanismus des Niclosamids innerhalb des WntNetzwerkes sollen nun in vivo verifiziert werden. Bisher sind lediglich Daten in immundefizienten Mausmodellen erhoben worden. Niclosamid verminderte das heterotope Tumorwachstum in vivo bei der AML, dem kolorektalen Karzinom, dem Bronchialkarzinom, dem Ovarialkarzinom, dem Mammakarzinom, dem Prostatakarzinom sowie dem Glioblastoma multiforme (vgl. Kapitel 1.5). Die Behandlung mit Niclosamid wurde durch regelmäßige Kontrolle des Körpergewichtes sowie hepatischer, renaler und hämatologischer Organfunktionstests (ALT, AST, BUN, Leukozytenzahl, $\mathrm{Hb}$ und Thrombozytenzahl) überwacht. Es zeichnete sich insgesamt eine gute Verträglichkeit ab (LI et al. 2013a, LI et al. 2013b, YOU et al. 2013, YE et al. 2014, LONDONO-JOSHI et al. 2014).

Im Anschluss an die hier beschriebenen in vitro-Experimente ist eine präklinische Evaluierung von Niclosamid in einem syngenen Tiermodell geplant. Die Daten der vorliegenden Arbeit wurden bereits an der Rattenzelllinie CC531 erhoben, um die Ergebnisse perspektivisch auch im passenden Tiermodell bestätigen zu können. In dem 
anvisierten Modell werden syngene CC531 Zellen subkapsulär in die Leber von immunkompetenten WAG/ Rij-Ratten implantiert. Dadurch kann das hepatische Metastasierungsverhalten kolorektaler Karzinome imitiert und eine mutmaßlich anzunehmende Hemmung des Metastasenwachstums durch die Therapie mit Niclosamid untersucht werden. Aus Voruntersuchungen ist bekannt, dass 85 bis 90 \% der Tiere in dem gewählten Modell innerhalb von 3 Tagen nach Implantation hepatische Mikrometastasen entwickeln; diese imponieren nach einer Zeitspanne von 2 Wochen bereits makroskopisch (KRAUSE et al. 2013). Geplant ist, die Tiere ab Tag 3 mit Niclosamid in einer Konzentration von $20 \mathrm{mg} / \mathrm{kg}$ Körpergewicht zu behandeln. Diese Konzentration hat sich bei verschiedenen Tumorentitäten in vivo bereits als progessionshemmend erwiesen (JIN et al. 2010, ODSADA et al. 2011, SACK et al. 2011, WIELAND et al. 2013, WANG et al. 2013, LI et al 2013a, LI et al. 2013b, YOU et al. 2013, YE et al. 2014, LONDONO-JOSHI et al. 2014, LIU et al. 2014). Aufgrund der hydrophilen Eigenschaften der Substanz (DEVARAKONDA et al. 2005) muss Niclosamid für die in vivo-Versuche in der gängigen Arzneimittelträgersubstanz Polyethylenglycol (PEG) in Lösung gebracht und anschließend appliziert werden. Am Tag 14 wird das Metastasenwachstum evaluiert. Die Daten der vorliegenden Arbeit lassen in Zusammenschau mit der Literatur ein reduziertes oder stagnierendes Wachstum der induzierten Metastasen erwarten. 


\section{$5 \quad$ Zusammenfassung}

Die Wnt/ $\beta$-Catenin-Signaltransduktion nimmt eine exponierte Stellung in der kolorektalen Karzinogenese ein. Niclosamid ist ein Derivat der Salicylsäure, das bei Bandwurminfektionen eingesetzt wird. Es konnte gezeigt werden, dass Niclosamid den Wnt/ $\beta$-Catenin-Signalweg moduliert. Ziel der vorliegenden Arbeit war es, den therapeutischen Einsatz des Niclosamids beim kolorektalen Karzinom zu evaluieren.

Die Zellproliferation von kolorektalen Karzinomzellinien (humane SW480 und SW620 Zellen sowie CC531 Zellen einer Ratte) und von Rattenfibroblasten wurde nach 12 und 24 Stunden Inkubation mit Niclosamid durch lichtmikroskopische Zellzahlbestimmungen beurteilt. Die Apoptoseraten wurden mit einem Zelltod-Assay ermittelt. Eine Immunfluoreszenzfärbung gab Aufschluss über das Expressionsmuster von aktivem $\beta$-Catenin. Die Promotoraktivität des LEF/ TCF-Transkriptionsfaktors wurde nach Transfektion mit TOPflash mithilfe eines Luciferase Assays analysiert. Die Genexpression von Wnt-modulierenden Faktoren (Bcl-9 und Wif1), von Komponenten des ß-CateninDegradationskomplexes (Axin2 und GSK 3 $\beta$ ), von kanonischen Zielgenen (Met, MMP7 und Cyclin D1) und von c-jun als Schlüsselprotein des nicht-kanonischen Wnt/ JNK-Signalweges wurde in der RT-PCR untersucht. Auf Proteinebene wurden zur Bestätigung zusätzlich Western Blots mit Antikörpern gegen aktives $\beta$-Catenin und c-jun durchgeführt.

Die Zellproliferation kolorektaler Karzinomzelllinien wurde dosisabhängig inhibiert, und Niclosamid führte zu Apoptose. Nach Inkubation mit Niclosamid kam es nicht zur Umverteilung von aktivem $\beta$-Catenin von der nukleären in die zytosolische Fraktion. Die Wnt-Promotor-Aktivität von LEF/ TCF wurde nach 12 Stunden Inkubation mit 10 und $50 \mu \mathrm{M}$ Niclosamid jedoch signifikant gesenkt. Kanonische Wnt-Zielgene (Met, MMP7 und Cyclin D1) sowie der Koaktivator Bcl-9 wurden auf Transkriptionsebene gehemmt, während das nicht-kanonische Schlüsselprotein c-jun aktiviert wurde.

Fasst man zusammen, so führt die Inkubation mit Niclosamid zu inhibitorischen Effekten auf kolorektale Karzinomzelllinien und zu einer reduzierten kanonischen Wnt-Aktivität. Diese Effekte können durch eine gestörte Formation des Triple-Komplexes aus Bcl-9, $\beta$ Catenin und LEF/ TCF und einer Aktivierung von c-jun und damit des nicht-kanonischen Wnt/ JNK-Signalweges bedingt sein. In in vivo-Untersuchungen beabsichtigen wir, in einem 
Tiermodell die Daten zu verifizieren und so den Einsatz des Niclosamids als Option für Patienten mit metastasiertem kolorektalem Karzinom weiterführend zu beurteilen. 


\section{Summary}

Wnt/ $\beta$-catenin-signalling is known to play an important role in colorectal cancer. Niclosamide, a salicylamide derivative used for the treatment of tapeworm infections, targets the Wnt/ $\beta$-catenin-pathway. The objective of this study was to investigate niclosamide as a therapeutic drug for colorectal cancer.

Direct cell count determined the effects of niclosamide on cell proliferation of human (SW480 and SW620) and rodent (CC531) colorectal cancer cell lines as well as rodent fibroblasts following 12 and 24 hours of incubation. Cell death assay was used to detect apoptosis. Immunofluorescence staining demonstrated the expression pattern of active $\beta$ catenin. The promoter activity of the LEF/ TCF-transcription factor was analysed by luciferase assay after transfection of TOPflash. Gene expression of Wnt-modulating factors (Bcl-9 and Wif1), destruction complex interacts (axin2 and GSK3 $\beta$ ), target genes (met, MMP7 and cyclin D1) and c-jun as the key player of the non-canonical Wnt/ JNK-pathway were analysed by RT-PCR. Western blot analysis was performed with antibodies detecting active $\beta$-catenin and c-jun.

Cell proliferation in colorectal cancer cell lines was blocked dose-dependently and apoptosis contributed to niclosamide's inhibitory potency. Following treatment on CC531, there was no shifting of active $\beta$-catenin protein from the nuclear to cytosolic pool. However, the Wnt promoter activity of LEF/ TCF significantly decreased with niclosamide at 10 und $50 \mu \mathrm{M}$ after 12 hours of incubation. Canonical target genes (met, MMP7 and cyclin D1) as well as the co-activator Bcl-9 were down-regulated on the transcriptional level, whereas the non-canonical key player c-jun was clearly activated.

Therefore, Niclosamide treatment was associated with inhibitory effects on colorectal cancer and reduced Wnt activity. It may exert its effects by interfering with the nuclear $\beta$ catenin-Bcl-9-LEF/ TCF triple-complex and by up-regulation of c-jun representing the noncanonical Wnt/ JNK-signalling. Thus, our findings warrant further research of this drug as a treatment option for patients with advanced-stage colorectal cancer. 


\section{$7 \quad$ Literaturverzeichnis}

Aberle H, Bauer A, Stappart J, Kispert A, Kemler R (1997): $\beta$-catenin is a target for the ubiquitin-proteasome pathway. EMBO J 16, 3797-804

American Cancer Society (2011): Global Cancer Facts \& Figures $2^{\text {nd }}$ Edition. Atlanta: American Cancer Society

Amit S, Hatzubai A, Birman Y, Andersen JS, Ben-Shushan EB, Mann M, Ben-Neriah Y, Alkalay I (2002): Axinmediated CKI phosphorylation of $\beta$-catenin at Ser 45: a molecular switch for the wnt pathway. Genes Dev $\underline{16}, 1066-76$

Andres A, Toso C, Adam R, Baaroso E, Hubert C, Capussotti L, Gerstel E, Roth A, Majno PE, Mentha G (2012): A survival analysis of the liver-first reversed management of advanced simultaneuos colorectal liver metastases: a LiverMetSurvey-based study. Ann Surg $\underline{256}$, 772-8

Arend RC, Londoño-Joshi AI, Samant RS, Li Y, Conner M, Hidalgo B, Alvarez RD, Landen CN, Straughn JM, Buchsbaum DJ (2014): Inhibition of wnt/ $\beta$-catenin pathway by niclosamide: a therapeutic target for ovarian cancer. Gynecol Oncol $\underline{134}, 112-20$

Ashburn TT, Thor KB (2004): Drug repositioning: identifying and developing new uses for existing drugs. Nat Rev Drug Discov $\underline{3}, 673-82$

S3-Leitlinie Kolorektales Karzinom. Version 1.1 - August 2014. http://www.awmf.org/uploads/tx szleitlinien/021-0070Ll S3 KRK 2014-08.pdf (Zugriff: 13.02.2015)

Balgi AD, Fonseca BD, Donohue E, Tsang TCF, Lajoie P, Proud CG, Nabi IR, Roberge M (2009): Screen for chemical modulators of autophagy reveals novel therapeutic inhibitors of mTORC1 signaling. PLoS One $\underline{4}$ e 7124

Barker N, Clevers H (2006): Mining the wnt pathway for cancer therapeutics. Nat Rev Drug Disc $\underline{5}$, 997-1015

Barth H: 36.23 Antihelminthika. In: Allgemeine und spezielle Pharmakologie und Tokikologie; hrsg. v. Aktories K, Förstermann U, Hofmann F, Starke K. 10. Auflage; Elsevier GmbH, Urban \& Fischer Verlag, München 2009, 916-21

Behrens J, von Kries JP, Kühl M, Bruhn L, Wedlich D, Grosschedl R, Birchmeier W (1996): Functional interaction of $\beta$-catenin wit the transcription factor LEF-1. Nature $\underline{382}, 638-42$

Bhanot P, Brink M, Samos CH, Hsieh JC, Wang Y, Macke JP, Andrew D, Nathans J, Nusse R (1996): A new member of the frizzled family from drosophila functions as a wingless receptor. Nature $\underline{382,225-30}$

Boon EMJ, van der Neut R, van de Wetering M, Clevers H, Pals ST (2002): Wnt signaling regulates expression of the recptor tyrosine kinase Met in colorectal cancer. Cancer Res $62,5126-28$

Boutros M, Paricio N (1998): Dishevelled activates JNK and discriminates between JNK pathways in planar polarity and wingless signaling. Cell $\underline{4}, 109-18$

Brabletz T, Jung A, Dag S, Hlubek F, Kirchner T (1999): $\beta$-catenin regulates the expression of the matrix metalloproteinase-7 in human colorectal cancer. Am J Pathol 155, 1033-8 
Brannon M, Gomperts M, Sumoy L, Moon RT, Kimelman D (1997): A $\beta$-catenin/ XTcf-3 complex binds to the siamois promoter to regulate dorsal axis specification in xenopus. Genes Dev $\underline{11}, 2359-70$

Brembeck F, Schwarz-Romond T, Bakkers J, Wilhelm S, Hammerschmidt M, Birchmeier W (2004): Essential role of BCL9-2 in the swith between $\beta$-catenin's adhesive and transcriptional functions. Genes Dev $\underline{18}$, 2225-30

Cancer Genome Atlas Network (2012): Comprehensive molecular characterization of human colon and rectal cancer. Nature $\underline{487}, 330-7$

Cardona K, Mastrodomenico P, D’Amico F, Shia J, Gönen M, Weiser MR, Paty PB, Kingham TP, Allen PJ, De Matteo RP et al. (2013): Detailed pathological characteristics of the primary colorectal tumor independently predict outcome after hepatectomy for metastases. Ann Surg Oncol 20, 148-54

Cavallo RA, Cox RT, Moline MM, Roose J, Polevoy GA, Clevers H, Peifer M, Bejsovec A (1998): Drosophila Tcf and groucho interact to repress wingless signalling activity. Nature $\underline{395}, 604-8$

Chang YW, Yeh TK, Lin KT, Chen WC, Yao HAT, Lan SJ, Wu YS, Hsieh HP, Chen CM, Chen CT (2006): Pharmacokinetics of anti-SARS-CoV agent niclosamide and its analogs in rats. JFDA $\underline{14}$, 329-333

Chen M, Wang J, Lu J, Bond MC, Ren XR, Lyerly HK, Barak LS, Chen W (2009): The anti-helminthic niclosamide inhibits wnt/frizzled1 signaling. Biochemistry $\underline{48}, 10267-74$

Chiannadurai G (2002): CtBP, an unconventional transcriptional corepressor in development and oncogenesis. Mol Cell $\underline{9}$, 213-24

Chong CR, Sullivan Jr. DJ (2007): New uses for old drugs. Nature $\underline{448}$, 645-6

Cidón EU (2010): The challenge of metastatic colorectal cancer. Clin Med Insights Oncol $\underline{4}$, 55-60

Clevers H (2006): Wnt/ $\beta$-catenin signaling in development and disease. Cell $\underline{127}$ 469-80

Cliffe A, Hamada F, Bienz M (2003): A role of dishevelled in relocating axin to the plasma membrane during wingless signaling. Curr Biol $\underline{13}$, 960-6

Crawford HC, Fingleton BM, Rudolph-Owen LA, Heppner Goss KJ, Rubinfeld B, Polakis P, Matrisian LM (1999): The metalloproteinase matrilysin is a target of $\beta$-catenin transactivation in intestinal tumors. Oncogene 18, 28383-91

Cummings LC, Payes JD, Cooper GS (2007): Survival after hepatic resection in metastatic colorectal cancer. Cancer 109, 718-26

Da Violante G, Zerrouk N, Richard I, Provot G, Chaumeil JC, Arnaud P (2002): Evaluation of the cytoxicity effect of dimethyl sulfoxide (DMSO) on Caco2/TC7 colon tumor cell cultures. Biol Pharm Bull 25, 1600-3

Dahmani R, Just PA, Perret C (2011): The wnt/ $\beta$-catenin pathway as a therapeutic target in human hepatocellular carcinoma. Clin Res Hepatol Gastroenterol 35, 709-13

Dajani R, Fraser E, Roe SM, Yeo M, Good VM, Thompson V, Dale TC, Pearl LH (2003): Structural basis for recruitment of glycogen synthase kinase $3 \beta$ to the axin-APC scaffold complex. EMBO J 22 , 494-501

Daniels DL, Weis WI (2005): $\beta$-catenin directly displaces groucho/ TLE repressors from Tcf/Lef in Wntmediated transcription activation. Nat Struct Mol Biol 12, 364-71 
Davidson G, Wu W, Shen J, Bilic J, Fenger U, Stannek P, Glinka A, Niehrs C (2005): Casein kinase $1 \gamma$ couples wnt receptor activation to cytoplasmic signal transduction. Nature $\underline{438}, 867-72$

Devarakonda B, Hill RA, Liebenberg W, Brits M, de Villiers MM (2005): Comparison of the aqueous solubilization of practically insoluble niclosamide by polyamidoamine (PAMAM) dendrimers andy cyclodextrins. Int J Pharm $\underline{304}$ 193-209

Dihlmann S, Gebert J, Siermann A, Herfarth C, von Knebel Doeberitz M (1999): Dominant negative effect of the APC $^{1309}$ mutation: a possible explantation for genotype-phenotype correlations in familial adenomatous polyposis. Cancer Res $\underline{59}$, 1857-60

Du SJ, Purcell SM, Christian JL, McGrew L, Moon RT (1995): Identification of distinct classes and functional domains of wnts through expression of wild-type chimeric proteins in xenopus embryos. Mol Cell Biol $15,2625-34$

Eklof Spink K, Fridman SG, Weis WI (2001): Molecular mechanisms of $\beta$-catenin recognition by adenomatous polyposis coli revealed by the structure of an APC- $\beta$-catenin complex. EMBO J 22, 6203-12

Fadok VA, Voelker DR, Campbell PA, Cohen JJ, Bratton DL, Henson PM (1992a): Exposure of phosphatidylserine on the surface of apoptotic lymphocytes triggers specific recognition and removal by macrophages. J Immunol 148, 2207-16

Fadok VA, Savill JS, Haslett C, Bratton DL, Doherty DE, Campbell PA, Henson PM (1992b): Different populations of macrophages use either the vitronectin or the phosphatidylserine receptor to recognize and remove apoptotic cells. J Immunol 149 4029-35

Fearon EB (2011): Molecular genetics of colorectal cancer. Annu Rev Pathol $\underline{6}, 470-507$

Fearon ER, Vogelstein B (1990): A genetic model for colorectal tumorigenesis. Cell 61, 759-67

Fong Y, Cohen AM, Fortner JG, Enker WE, Turnbull AD, Coit DG, Marrero AM, Prasad M, Blumgart LH, Brennan MF (1997): Liver resection of colorectal metastases. J Clin Oncol 15, 938-946

Gentle A, Anastasopoulos F, McBrien NA (2001): High-resolution semi-quantitative real-time PCR without use of a standard curve. Biotechniques $\underline{31}, 502,504-6,508$

Germann A, Dihlmann S, Hergenhahn M, Von Knebel Doeberitz M, Koesters R (2003): Expression profiling of CC531 colon carcinoma cells reveals similar regulation of $\beta$-catenin target genes by both butyrate and aspirin. Int J Cancer 106, 187-197

Groß U: 17 Parasitosen. In: Kurzlehrbuch Medizinische Mikrobiologie und Infektiologie. 2. Auflage; Georg Thieme Verlag, Stuttgart 2006, 463

Ha NC, Tonozuka T, Stamos JL, Choi HJ, Weis WI (2004): Mechanism of phosphorylation-dependent binding of APC to $\beta$-catenin and its role in $\beta$-catenin degradation. Mol Cell $\underline{15}$, 511-21

Habas R, Kato Y, He X (2001): Wnt/ frizzled activation of Rho regulates vertebrate gastrulation and requires a novel formin homology protein Daam1. Cell $\underline{107}$, 843-54

Hart M, Concordet JP, Lassot I, Albert I, de los Santos R, Durand H, Perret C, Rubinfeld B, Margottin F, Benarous $\mathrm{R}$ et al. (1999): The F-box protein $ß$ - $\operatorname{TrCP}$ associates with phosphorylated $\beta$-catenin and regulates its activity in the cell. Curr Biol 9 , 207-10 
He X, Axelrod JD (2006): A WNTer wonderland in Snowbird. Development 133, 2597-603

Hsieh JC, Kodjabachian L, Rebbert ML, Rattner A, Smallwood PM, Samos CH, Nusse R, Dawid IB, Nathans J (1999): A new secreted protein that binds wnt proteins and inhibits their activity. Nature $\underline{398}$, 431-6

Huber O, Korn R, McLaughlin J, Ohsugi M, Herrmann B, Kemler R (1996): Nuclear localization of $\beta$-catenin by interaction with transcription factor LEF-1. Mech Dev $\underline{59}$, 3-10

Ikeda S, Kishida S, Yamamoto H, Murai H, Koyama, Kikuchi A (1998): Axin, a negative regulator of the wnt signaling pathway, forms a complex with GSK- $3 \beta$ and $\beta$-catenin and promotes GSK-3 $\beta$-dependent phophorylation of $\beta$-catenin. EMBO J 17 1371-84

Imperi F, Maasai F, Pillai CR, Longo F, Zennaro E, Rampioni G, Visca P, Leoni L (2013): New life for an old drug: the antihelminthic drug niclosamide inhibits pseudomonas aeruginose quorum sensing. Antimicrob Agents Chemother 57, 996-1005

Itoh K, Antipova A, Ratcliffe MJ, Sokol S (2000): Interaction of dishevelled and xenopus axin-related protein is required for wnt signal transduction. Mol Cell Biol 20, 2228-38

Jackman RJ, Mayo CW (1951): The adenoma-carcinoma sequence in cancer of the colon. Surg Gynecol Ostet 93, 327-30

Jen J, Powell SM, Papadopoulos N, Smith KJ, Hamilton SR, Vogelstein B, Kinzler KW (1994): Molecular determinants of dysplasia in colorectal lesions. Cancer Research $\underline{54}$ 5523-6

Jin Y, Lu Z, Ding K, Li J, Du X, Chen C, Sun X, Wu Y, Zhou J, Pan J (2010): Antineoplastic mechanisms of niclosamide in acute myelogenous leukemia stem cells: inactivation of the NF- $\kappa B$ pathway and generation of reactive oxygen species. Cancer Res $\underline{70}$, 2516-27

Kestler HA, Kühl M (2008): From individual wnt pathways towards a wnt signaling network. Phil Trans R Soc B $\underline{363}, 1333-47$

Ketola K, Hilvo M, Hyötyläinen T, Vuoristo A, Ruskeepää AL, Orešič M, Kallioniemi O, Iljin K (2012): Salinomycin inhibits prostate cancer growth and migration via induction of oxidative stress. Br J Cancer 106, $99-106$

Khanim FL, Merrick BAME, Giles HV, Jankute M, Jackson JB, Giles LJ, Birtwistle J, Bunce CM, Drayson MT (2011): Redeployment-based drug screening identifies the anti-helminthic niclosamide as antimyeloma therapy that also reduces free light chain production. Blood Cancer J 1 , e39

Kiesslich T, Berr F, Alinger B, Kemmerling R, Pichler M, Ocker M, Neureiter D (2012): Current status of therapeutic targeting of developmental signalling pathways in oncology. Curr Pharm Biotechnol $\underline{13}$, 2184-220

Kim SY, Kang JW, Song X, Kim BK, Yoo YD, Kwon YT, Lee JL (2013): Role of the IL-6-JAK1-STAT3-OCT-4 pathway in the conversion of non-stem cancer cells into cancer stem-like cells. Cell Signal $\underline{25}, 961-9$

Kimelman D, Xu W (2006): $\beta$-catenin destruction complex: insights and questions from structural perspective. Oncogene 25 , 7482-91

Kinzler KE, Vogelstein B (1996): Lessons from hereditary colorectal cancer. Cell $\underline{87}$ 159-70 
Kinzler KW, Nilbert MC, Su LK, Vogelstein B, Bryan TM, Levy DB, Smith KJ, Preisinger AC, Hedge P, MaKechnie D et al. (1991): Identification of FAP locus genes from chromosome 5q21. Science $\underline{253}, 661-5$

Kishida S, Yamamoto H, Hino SI, Ikeda S, Kishida M, Kikuchu A (1999): DIX domains of dvl and axin are necessary for protein interactions and their ability to regulate $\beta$-catenin stability. Mol Cell Biol $\underline{19}$, 4414-22

Kitagawa M, Hatakeyama S, Shirane M, Matsumoto M, Ishida N, Hattori K, Nakamichi I, Kikuchi A, Nakayama KI, Nakayama K (1999): A F-box protein, FWD1, mediates ubiquitin-dependent proteolysis of $\beta$-catenin. EMBO J 18, 2401-10

Korinek V, Barker N, Morin PJ, van Wichen D, de Weger R, Kinzler KW, Vogelstein B, Clevers H (1997): Constitutive transcriptional activation by a $\beta$-catenin-tcf complex in $\mathrm{APC}-/$ colon carcinoma. Science $\underline{275}, 1784-7$

Kramps T, Peter O, Brunner E, Nellen D, Froesch B, Chatterjee S, Murone M, Züllig S, Basler K (2002): Wnt/ wingless signaling requires BCL9/ legless-mediated recruitment of pygopus to the nuclear $\beta$-cateninTCF complex. Cell 109, 47-60

Krause P, Flikweert H, Monin M, Seif AAH, Helms G, Cantanhede G, Ghadimi M, Koenig S (2013): Increased growth of colorectal liver metastasis following partial hepatectomy. Clin Exp Metastasis $\underline{30}$ 681-93

Lammi L, Arte S, Somer M, Järvinen H, Lahermo P, Thesleff I, Pirinen S, Nieminen P (2004): Mutations in AXIN2 cause familial tooth agenesis and predispose to colorectal cancer. Am J Hum Genet $\underline{74}$, 1043-50

Latres E, Chiaur DS, Pagano M (1999): The human F box protein B-Trcp associates with the Cul1/ SKP1 complex and regulates the stability of $\beta$-catenin. Oncogene $\underline{18}$, 849-54

Lee E, Salic A, Krüger R, Heinrich R, Kirschner MW (2003):The roles of APC and axin derived from experimental and theoretical analysis of the wnt pathway. PLoS One $1,116-32$

Lee S, Son AR, Ahn J, Song JY (2014): Niclosamide enhances ROS-mediated cell death through c-jun activation. Biomed Pharmacother $\underline{68}$, 619-24

Leporrier J, Maurel J, Chiche L, Bara S, Segol P, Launoy G (2006): A population-based study of the incidence, management and prognosis of hepatic metastases from colorectal cancer. Br J Surg $\underline{93}$, 465-74

Li L, Yuan H, Xie W, Mao J, Caruso AM, McMahon A, Sussman DJ, Wu D (1999): Dishevelled proteins lead to two signaling pathways. J Biol Chem $\underline{274}, 129-34$

Li R, You S, Hu Z, Chen ZG, Sica GL, Khuri FR, Curran WJ, Shin DM, Deng X (2013a): Inhibition of STAT3 by niclosamide synergizes with erlotinib against head and neck cancer. PLoS One $\underline{8}$, e64760

Li R, Hu Z, Sun SY, Chen ZG, Owonikoko TK, Sica GL, Ramalingam SS, Curran WJ, Khuri FR, Deng X (2013b): Niclosamide overcomes acquired resistance to erlotinib through suppression of STAT3 in non-small cell lung cancer. Mol Cancer Ther $\underline{12}$, 2200-12

Li Y, Li PK, Roberts MJ, Arend RC, Samant RS, Buchsbaum DJ (2014): Multi-targeted therapy of cancer by niclosamide. A new application for an old drug. Cancer Lett 349: 8-14 
Liao G, Tao Q, Kofron M, Chen JS, Schloemer A, Davis RJ, Hsieh JC, Wylie C, Heasman J, Kuan CY (2006): Jun $\mathrm{NH}_{2}$-terminal kinase (JNK) prevents nuclear $\beta$-catenin accumulation and regulates axis formation in xenopus embryos. Proc Natl Acad Sci USA 103 , 16313-8

Lin K, Wang S, Julius MA, Kitajewski J, Moos Jr. M, Luyten FP (1997): The cysteine-rich frizzled domain of Frzb1 is required and sufficient for modulation of wnt signaling. Proc Natl Acad Sci USA 94, 11196-200

Liu C, Li Y, Semenov M, Han C, Baeg GH, Tan Y, Zhang Z, Lin X, He X (2002): Control of $\beta$-catenin phosphorylation/ degradation by a dual-kinase mechanism. Cell $\underline{108}$, 837-47

Liu C, Lou W, Zhu Y, Nadiminty N, Schwartz CT, Evans CP, Gao AC (2014): Niclosamide inhibits androgen receptor variants expression and overcomes enzalutamide resistance in castration-restistant prostate cancer. Clin Cancer Res 20, 3198-210

Liu W, Dong X, Mai M, Seelan RS, Taniguchi K, Krishnadath KK, Hallin KC, Cunningham JM, Qian C, Christensen E et al. (2000): Mutations in AXIN2 cause colorectal cancer with defective mismatch repair by activating $\beta$-catenin/ TCF signaling. Nat Genet $\underline{26}, 146-7$

Livak KJ, Schmittgen TD (2001): Analysis of relative gene expression data using real-time quantitative PCR and the 2(-Delta-Delta C(T)) Method. Methods 25, 402-8

Logan CY, Nusse R (2004): The wnt signaling pathway in development and disease. Annu Rev Cell Dev Biol $\underline{20}$, 781-810

Londoño-Joshi AI, Arend RC, Aristizabal L, Lu W, Samant RS, Metge BJ, Hidalgo B, Grizzle WE, Conner M, Forero-Torres A, LoBuglio A et al. (2014): Effect of niclosamide on basal-like breast cancers. Mol Cancer Ther $13,800-11$

Lu W, Lin C, Roberts MJ, Waud WR, Piazza GA, Li Y (2011): Niclosamide suppresses cancer cell growth by inducing wnt c-receptor LRP6 degradation and inhibiting the wnt/ $\beta$-catenin pathway. PLoS One $\underline{6}$, e29290

Mao B, Wu W, Li Y, Hoppe D, Stannek P, Glinka A, Niehrs C (2001): LDL-receptor-related protein6 is a receptor for Dickkopf proteins. Nature $\underline{411}, 321-5$

Mao J, Wang J, Liu B, Pan W, Farr GH, Flynn C, Yuan H, Takada S, Kimelman D, Li L et al. (2001): Low-density lipoprotein receptor-related protein-5 binds to axin and regulates the canonical wnt signaling pathway. Mol Cell 7 801-9

McDonald SL, Silver A (2009): The opposing roles of Wnt-5a in cancer. Br J Cancer 101, 209-14

McDonald SL, Silver AR (2011): On target? Strategies and progress in the development of therapies for colorectal cancer targeted against wnt signalling. Colorectal Dis 14, 360-9

Merschjohann K, Steverding D (2008): In vitro trypanocidal activity of the antihelminthic drug niclosamide. Exp Parasitol 118, 637-640

Mikels AJ, Nusse R (2006): Purified Wnt5a protein activates or inhibits beta-catenin- TCF signaling depending on receptor context. PLoS Biol $\underline{4}, 570-582$ 
Molenar M, van de Wetering M, Oosterwegel M, Peterson-Maduro J, Godsave S, Korinek V, Roosen J, Destrée O, Clevers H (1996): XTcf-3 trascription factor mediates $\beta$-catenin-induced axis formation in xenopus embryos. Cell 86 , 391-9

Mook Jr. RA, Chen M, Lu J, Barak LS, Lyerly HK, Chen W (2013): Small molecule modulators of Wnt/ $\beta$-catenin signaling. Bioorg Med Lett

Moriguchi T, Kawachi K, Kamakurat S, Masuyama N, Yamanaka H, Matsumoto K, Kikuchi A, Nishida E (1999): Distinct domains of mouse dishevelled are responsible for the c-Jun N-terminal kinase/ stress-activated protein kinase activation and the axis formation in vertebrates. J Biol Chem 274, 30957-62

Morin PJ, Sparks AB, Korinek V, Barker N, Clevers H, Vogelstein B, Kinzler KW (1997): Activation of $\beta$-catenintcf signaling in colon cancer by mutation in $\beta$-catenin or APC. Science $275,1787-90$

Munemitsu S, Albert I, Souza B, Rubinfeld B, Polakis P (1995). Regulation of intracellular $\beta$-catenin levels by the adenomatous polyposis coli (APC) tumor-suppressor protein. Proc Natl Acad Sci USA 92, 3046-50

Muto T, Bussey HJ, Morson BC (1975): The evolution of cancer of the colon and rectum. Cancer $\underline{36}, 2251-70$ Nishisho I, Nakamura Y, Miyoshi Y, Miki Y, Ando H, Horii A, Koyama K, Utsunomiya J, Baba S, Hedge P et al. (1991): Mutations of chromosome 5q21 in FAP and colorectal cancer patients. Science 253, 665-9

Nusse R (2005): Wnt signaling in disease and in development. Cell Res $\underline{15}$, 28-32

Oishi I, Suzuki H, Onishi N, Takada R, Kani S, Ohkawara B, Koshida I, Suzuki K, Yamada G, Schwabe GC et al. (2003): The receptor tyrosine kinase Ror2 is involved in non-canonical Wnt5a/ JNK signaling pathway. Genes Cells $\underline{8}$, 645-54.

Olson DJ, Gibo DM (1998): Antisense wnt5a mimics wnt-1-mediated C57MG mammary epithelial cell transformation. Exp Cell Res 241, 134-41

O'Neil BH, Goldberg RM (2008): Innovations in chemotherapy for metastatic colorectal cancer: an update of recent clinical trials. Oncologist $\underline{13}, 1074-83$

Onkopedia Leitlinie Kolonkarzinom. Empfehlungen der Fachgesellschaft zur Diagnostik und Therapie hämatologischer und onkologischer Erkrankungen. Hrsg. v. DGHO Deutsche Gesellschaft für Hämatologie und Medizinische Onkologie e.V. Stand September 2012. https://www.dghoonkopedia.de/de/onkopedia/leitlinien/kolonkarzinom (Zugriff: 13.03.2015)

Onkopedia Leitlinie Rektumkarzinom. Empfehlungen der Fachgesellschaft zur Diagnostik und Therapie hämatologischer und onkologischer Erkrankungen. Hrsg. v. DGHO Deutsche Gesellschaft für Hämatologie und Medizinische Onkologie e.V. Stand September 2012. https://www.dghoonkopedia.de/de/onkopedia/leitlinien/rektumkarzinom (Zugriff: 13.03.2015)

Ono M, Yin P, Navarro A, Moravek MB, Coon JS, Druschitz SA, Gottardi CJ, Bulun SE (2014): Inhibition of canonical wnt signaling attenuates human leiomyoma cell growth. Fertil Steril $\underline{101}$ 1441-49

Osada T, Chen M, Yang XY, Spasojevic I, Vandeusen JB, Hsu D, Clary BM, Clay TM, Chen W, Morse MA et al. (2011): Antihelminth compound niclosamide downregulates Wnt signaling and elicts antitumor responses in tumors with activating APC mutations. Cancer Res $\underline{71}$, 4172-82 
Palmer HG, Gonzáles-Sancho JM, Espada J, Berciano MT, Puig I, Baulida J, Quintanilla M, Cano A, de Herreros AG, Lafarga M et al. (2001): Vitamin D(3) promotes the differentiation of colon carcinoma cells by induction of e-cadherin and the inhibition of beta-catenin signaling. J Cell Biol 154, 369-87

Pan JX, Ding K, Wang CY (2012): Niclosamide, an old antihelminthic agent, demonstrates antitumor activity by blocking multiple signaling pathways of cancer stem cells. Chin J Cancer $\underline{31}$ 178-84

Pinson KI, Brennan J, Monkley S, Avery BJ, Skarnes WC (2000): A LDL-receptor-related protein mediates wnt signaling in mice. Nature 407, 535-9

Powell SM, Zils N, Beazer-Barclay Y, Bryan TA, Hamilton SR, Thibodeau SN, Vogelstein B, Kinzler KW (1992): APC mutations occur early during colorectal tumorgenesis. Nature $\underline{359}$, 235-7

Powell SM, Petersen G, Krush AJ, Booker S, Jen J, Giardielle FM, Hamilton SR, Vogelstein B, Kinzler KW (1993): Molecular diagnosis of familial adenomatous polyposis. N Engl J Med 329, 1982-7

Pukrop T, Binder C (2008): The complex pathways of wnt 5a in cancer progression. J Mol Med 86, 259-66 Rao TP, Kühl M (2011): An update overview on wnt signaling pathways: a prelude for more. Circ Res $\underline{106}$, 1798-806

Rattner A, Hsieh JC, Smallwood PM, Gilbert DJ, Copeland NG, Jenkins NA, Nathans J (1997): A family of secreted proteins contains homology to the cysteine-rich ligand-binding domain of frizzled receptors. Proc Natl Acad Sce USA 94, 2859-63

Ren X, Duan L, He Q, Zhang Z, Zhou Y, Wu D, Pan J, Pei D, Ding K (2010): Identification of niclosamide as a new small-molecule inhibitor of the STAT3 signaling pathway. ACS Med Chem Lett $\underline{1}$, 454-459

Robert Koch-Institut (Hrsg.) und die Gesellschaft für epidemiologische Krebsregister in Deutschland e.V. (Hrsg.): Krebs in Deutschland 2007/ 2008. 8. Ausgabe. Berlin 2012, 12-13, 36-39

RÖMPP: https://roempp.thieme.de/roempp4.0/do/data/RD-14-01132 (Zugriff: 13.03.2015)

Roose J, Molenar M, Peterson J, Jurenkamp J, Brantjes H, Moerer P, van de Wetering M, Destrée O, Clevers H (1998): The xenopus wnt effector CTcf-3 interacts with groucho-related transcriptional repressors. Nature $395,608-12$

Rubinfeld B, Souza B, Albert I, Müller O, Chamberlain SH, Masiarz FR, Munemitsu S, Polakis P (1993): Association of the APC gene product with $\beta$-catenin. Science $\underline{262}, 1731-4$

Sack U, Walther W, Scudiero M, Kobelt D, Lemm M, Fichtner I, Schlag PM, Shoemaker RH, Stein U (2011): Novel effect of antihelminthic niclosamide on S100A4-mediated metastatic progression in colon cancer. J Natl Cancer Inst 103, 1018-36

Sampietro J, Dahlberg CL, Cho US, Hinds TR, Kimelman D, Xu W (2006): Crystal structure of a betacatenin/BCL9/Tcf4 complex. Mol Cell 24, 293-300

Sansom OJ, Reed KR, van de Wetering M, Muncan V, Winton DJ, Clevers H, Clarke AR (2005): Cyclin D1 is not an immediate target of $\beta$-catenin following Apc loss in the intestine. J Viol Chem 280, 28463-7

Sato A, Yamamoto H, Sakane H, Koyama H, Kikuchi A (2010): Wnt5a regulates distinct signalling pathways by binding to frizzled2. EMBO J 29, 41-54 
Schmittgen TD, Zakrajsek BA (2000): Effect of experimental treatment on housekeeping gene expression: validation by real-time, quantitative RT-PCR. J Biochem Biophys Methods $\underline{46}, 69-81$

Sebio A, Kahn M, Lenz HJ (2014): The potential of targeting wnt/ $\beta$-catenin in colon cancer. Expert Opin Ther Targets $\underline{18}, 1-5$

Seifert JRK, Mlodzik M (2007): Frizzled/ PCP signalling: a conversed mechanism regulating cell polarity and directed motility. Nature $\underline{8}, 126-38$

Shtutman M, Zhurinsky J, Simcha I, Albanese C, D’Amico M, Pestell R, Ben-Ze'ev A (1999): The cyclin D1 gene is a target of the $\beta$-catenin/ LEF-1 pathway. Proc Natl Acad Sci USA $\underline{96}$, 5522-27

Smith KJ, Johnson KA, Bryan TM, Hill DE, Markowitz S, Willson JKV, Paraskeva C, Petersen GM, Hamilton SR, Vogelstein B et al. (1992): The APC gene product in normal and tumor cells. Proc Natl Acad Sci USA 90, 2846-50

Stamos JL, Weis EI (2012): The $\beta$-catenin destruction complex. Cold Spring Harb Perspect Biol $\underline{5}$, a007898

Strutt D (2003): Frizzled signalling and cell polarisation in drosophila and vertebrates. Development $\underline{130}$, 4501-13

Su LK, Vogelstein B, Kinzler KW (1993): Association of the APC tumor suppressor protein with catenins. Science 262 , 1734-7

Su Y, Simmen RC (2009): Soy isoflavone genistein upregulates epithelial adhesion molecule E-cadherin expression and attenuates beta-catenin signaling in mammary epithelial cells. Carcinogenesis $\underline{30}, 331-9$

Tamai K, Semenov M, Kato Y, Spokony R, Liu C, Katsuyama Y, Hess F, Saint-Jeannet JP, He X (2000): LDLreceptor-related proteins in wnt signaling transduction. Nature 407, 530-6

Tamai K, Zeng X, Liu C, Zhang X, Harada Y, Chang Z, He X (2004): A mechanism for wnt coreceptor activation. Mol Cell $13,149-56$

Tetsu O, McCormick F (1999): $\beta$-catenin regulates expression of cyclin D1 in colon carcinoma cells. Nature $\underline{398}, 422-6$

The Wnt Homepage:

- $\quad$ http://www.stanford.edu/group/nusselab/cgi-bin/wnt/human (Zugriff: 13.03.2015)

- $\quad$ http://www.stanford.edu/group/nusselab/cgi-bin/wnt/Frizzled vertebrate (Zugriff: 13.03.2015)

- $\quad$ http://www.stanford.edu/group/nusselab/cgi-bin/wnt/target genes (Zugriff: 13.03.2015)

Thompson B, Townsley F, Rosin-Arbesfeld R, Musisi H, Bienz M (2002): A new nuclear component of the wnt signalling pathway. Nature Cell Biol $\underline{4}$, 367-73

Tichopad A, Dilger M, Schwarz G, Pfaffl MW (2003): Standardized determination of real-time PCR efficiency from single reaction set-up. Nucleic Acids Res $\underline{31}$, e122

Tolwinski NS, Wieschaus (2004): Rethinking WNT signaling. Trends genet 20, 177-81

Topol L, Jiang X, Choi H, Garrett-Beal L, Carolan PJ, Yang Y (2003); Wnt-5a inhibits the canonical wnt pathway by promoting GSK-3-independent $\beta$-catenin degradation. J Cell Biol $\underline{162}$ 899-908 
Torres MA, Yang-Snyder JA, Purcell SM, DeMarais AA, McGrew LL, Moon RT (1996): Activities of the wnt-1 class of secreted signaling factors are antagonized by the wnt-5a class and by dominant negative cadherine in early xenopus development. J Cell Biol $\underline{133}$, 1123-37

Umbauer M, Djiane A, Goisset C, Penzo-Méndez A, Riou JF, Boucaut JC, Shi DL (2000): The C-terminal cytoplasmic Lys-Thr-X-X-X-Trp motif in frizzled receptors mediates wnt/ $\beta$-catenin signalling. EMBO J 19 , 4944-54

van de Wetering M, Cavallo R, Dooijes D, van Beest M, van Es J, Loureiro J, Ypma A, Hursh D, Jones T, Bejsovec A et al. (1997): Armadillo coactivates transcription driven by the product of the drosophila segment polarity gene dTCF. Cell $\underline{88}, 789-99$

van Es JH, Clevers H (2005): Notch and wnt inhibitors as potential new drugs for intestinal neoplastic disease. Trends Mol Med 11, 496-502

van Noort M, Meeldijk J, van der Zee R, Destree O, Clevers H (2002): Wnt signaling controls the phophorylation status of $\beta$-catenin. J Biol Chem 277, 17901-5

Vermes I, Haanen C, Steffens-Nakken H, Reutelingsperger C (1995): A novel assay for apoptosis. Flow cytometric detection of phosphatidylserine expression on early apoptotic cells using fluorescin lablled Annexin V. J Immunol Methods 184, 39-51

Vogelstein B, Fearon ER, Hamilton SR, Kern SE, Preisinger AC, Leppert M, Nakamura Y, White R, Smits AM, Bos JL (1988): Genetic alterations during colorectal-tumor development. N Engl J Med 319, 525-532

Wang AM, Ku HH, Liang YC, Chen YC, Hwu YM, Yeh TS (2009): The autonomous noth signal pathway is activated by baicalin and baicalein but is supressed be niclosamide in K562 cells. J Cell Biochem $\underline{106}$, $682-692$

Wang YC, Chao TK, Chang CC, Yo YT, Yu MH, Lai HC (2013): Drug screening identifies niclosamide as an inhibitor of breast cancer stem-like cells. PLoS One $\underline{8}$ e74538

Watanabe T, Noritake J, Kaibuchi K (2005): Regulation of microtubules in cell migration. Trends Cell Biol $\underline{15}$, $76-83$

Weber U, Paricio N, Mlodzik M (2000): Jun mediates frizzled-induced R3/ R4 cell fate distinction and planar polarity determination in the drosophila eye. Development 127, 3619-29

Wehrle-Haller B, Imhof BA (2003): Actin, microtubules and focal adhesion dynamics during cell migration. Int J Biochem Cell Biol $\underline{35}$ 39-50

Wehrli M, Dougan ST, Caldwell K, O’Keefe L, Schwartz S, Vaizel-Ohnyon D, Schejter E, Tomlinson A, DiNardo S (2000): Arrow encodes a LDL-recptor-related protein essential for wingless signalling. Nature $\underline{407}$, $527-30$

Weinbach EC, Garbus J (1969): Mechanism of action of reagents that uncouple oxidative phosphorylation. Nature 221, 1016-1018

Weitz J, Knaebel HP, Büchler MW (2003): Sporadisches und hereditäres Karzinom von Kolon und Rektum. Chirurg $\underline{74}, 717-725$ 
Wieland A, Trageser D, Gogolok S, Reinartz R, Höfer H, Keller M, Leinhass A, Schelle R, Normann S, Klaas L et al. (2013): Anticancer effects of niclosamide in human glioblastoma. Clin Cancer Res $\underline{19}$, 4124-36

Winston JT, Strack P, Beer-Romero P, Chu CY, Elledge SJ, Harper JW (1999): The SCFß-TRCP-ubiquitin ligase complex associates specifically with phosphorylated destruction motifs in IкB $\alpha$ and $\beta$-catenin and stimulates IкB $\alpha$ ubiquitination in vitro. Genes Dev $\underline{13}, 270-83$

Winter CG, Wang B, Ballew A, Royou A, Karess R, Axelrod JD, Luo L (2001): Drosophila Rho-associated kinase (Drok) links frizzled-mediated planar cell polarity signaling to the actin cytoskeleton. Cell $\underline{105}$, 81-91

Wittekind C: Tumoren des Verdauungstraktes. In: TNM-Klassifikation maligner Tumoren. hrsg. v. Wittekind C, Bootz F; 7. Auflage; Wiley-Liss, Heidelberg/ Berlin 2010, 61-122

Wong GT, Gavin BJ, McMahon AP (1994): Differential transformation of mammary epithelial cells by wnt genes. Mol Cell Biol 14, 6278-6286

Wong HC, Bourdelas A, Kruass A, Lee HJ, Shao Y, Wu D, Mlodzik M, Shi DL, Zheng J (2003): Direct binding of the PDZ domain of dishevelled to a conserved internal sequence in the C-terminal region of frizzled. Mol Cell $\underline{12}, 1251-60$

Wong ML, Medrano JF (2005): Real-time PCR form RNA quantitation. Biotechniques $\underline{39}$, 75-85

Wu CJ, Jan JT, Chen CM, Hsieh HP, Hwang DR, Liu HW, Liu CY, Huang HW, Chen SC, Hong CF et al. (2004): Inhibition of severe acute respiratory syndrome coronavirus replication by niclosamide. Antimicrob Agents Chemother $\underline{48}$, 2693-6

Wu CS, Li YR, Chen JJW, Chen YC, Chu CL, Pan ICH, Wu YS, Lin CC (2014): Antihelminthic niclosamide modulates dendritic cell activation and function. Cell Immunol 288, 15-23

Wu G, Xu G, Schulamn BA, Jeffrey PD, Harper JW, Pavletich NP (2003): Structure of a ß-TrCP-Skp1- $\beta$-catenin complex: destruction motif binding and lysine specificity of the $\operatorname{SCF}^{\beta-T r C P 1}$ ubiquitin ligase. Mol Cell $\underline{11,1445-56}$

Xiao JH, Ghosn C, Hinchman C, Forbes C, Wang J, Snider N, Cordrey A, Zhao Y, Chandraratna RA (2003): Adenomatous polyposis coli (APC)- independent regulation of beta-catenin degradation via a retinoid $\mathrm{X}$ receptor-mediated pathway. J Biol Chem $\underline{278}$, 29954-62

Xing Y, Clements WK, Trong IL, Hinds TR, Stenkamp R, Kimelman D, Xu W (2004): Crystal structure of a $\beta$ catenin/ APC complex reveals a critical role for APC phosphorylation in APC function. Mol Cell 15 , 52333

Yanagawa SI, van Leeuwen F, Wodarz A, Klingensmith J, Nusse R (1995): The dishevelled protein is modified by wingless signaling in drosophila. Genes $\operatorname{Dev} \underline{9}$ 1087-97

Yanagawa SI, Matsuda Y, Lee JS, Matsubayashi H, Sese S, Kadowaki T, Ishimoto A (2002): Casein kinase I phosphorylates armadillo protein and induces its degradation in drosophila. EMBO J 21, 1733-42

Yang J, Zhang W, Evans PM, Chen X, Liu C (2006): Adenomatous polyposis coli (APC) differentially regulates $\beta$ catenin phosphorylation and ubiquitination in colon cancer cells. J Bio Chem $\underline{281}$ 17751-7

Yao H, Ashihara E, Maekawa T (2011): Targeting the wnt/ $\beta$-catenin signaling pathway in human cancers. Expert Opin Ther Targets 15, 873-87 
Ye T, Xiong Y, Xia Y, Song X, Liu L, Li D, Wang N, Zhang L, Zhu Y, Zeng J, Wie Y et al. (2014): The antihelminthic drug niclosamide induces apoptosis, impairs metastasis and reduces immunsuppressive cells in breast cancer model. PLoS One 9 e e85887

Yo YT, Lin YW, Wang YC, Balch C, Huang RL, Chan MWY, Sytwu HK, Chen CK, Chang CC, Nephew KP et al. (2012): Growth inhibition of ovarian tumor-initiating cells by niclosamide. Mol Cancer Ther $\underline{11}$, 170312

Yost C, Torres M, Miller JR, Huang E, Kimelman D, Moon RT (1996): The axis-inducing activity, stability, and subcellular distribution of $\beta$-catenin is regulated in xenopus embryos by glycogen synthase 3 . Genes Dev 10, 1443-54

You S, Li R, Park D, Xie M, Sica GL, Cao Y, Xiao ZQ, Deng X (2013): Disruption of STAT3 by niclosamide reverses radioresistance of human lung cancer. Mol Cancer Ther $13,606-16$

Zeng X, Tamai K, Doble B, Li S, Huang H, Habas R, Okamura H, Woodgett J, He X (2005): A dual-kinase mechanism for wnt co-recptor phosphorylation and activation. Nature $\underline{438}, 873-7$ 


\section{Veröffentlichungen}

Teile dieser Arbeit habe ich als Vortrag bei den 15. Chirurgischen Forschungstagen im September 2011 in Dresden und als Poster auf der 28. Jahrestagung der German Association of the Study of the Liver (Deutsche Arbeitsgemeinschaft zum Studium der Leber) im Januar 2012 in Hamburg präsentiert. Die Abstracts sind an folgenden Stellen veröffentlicht worden:

Monin MB, Flikweert H, Wolfgramm S, Kendziorra E, Grade M, Krause P, Ghadimi BM, König S (2011): Niclosamide down-regulates Wnt-signalling and inhibts proliferation of CRC cell lines. Langenbecks Arch Surg $\underline{396}$, 898-9

Monin MB, Krause P, Flikweert H, Seif A, Wolfgramm S, Streich R, Kendziorra E, Ghadimi M, Becker H, König S (2012): Niclosamid inhibiert das Wachstum kolorektaler Lebermetastasen durch Reduktion der Wnt-Aktivität. Z Gastroentol 50 150 


\section{Danksagung}

Ich möchte mich abschließend bei allen bedanken, die mich bei der Erstellung dieser Dissertationsarbeit unterstützt haben.

Für die Möglichkeit, meine Dissertation in der Klinik für Allgemein-, Viszeral- und Kinderchirurgie zu verfassen, gilt mein Dank dem Direktor der Klinik, Herrn Prof. Dr. med. B. Michael Ghadimi.

Im Team der Projektgruppe Liver regeneration and treatment strategies habe ich mich sehr wohl gefühlt.

Als erstes bedanke ich mich bei Frau Prof. Dr. med. Sarah König und Frau PD Dr. rer. nat. Petra Krause für das Überlassen eines klinisch relevanten Forschungsthemas. Durch einen konstruktiven Austausch haben sie meine Arbeit kontinuierlich begleitet. Besonders gefreut habe ich mich, dass sie ein offenes Ohr für meine eigenen Anregungen zu den Versuchen hatten und mir die Möglichkeit gaben, diese umzusetzen.

Bei der Einarbeitung in die Labormethoden haben mich Sabine Wolfgramm, Roswitha Streich, Caroline Breysach, Sabine Buth, Dr. rer. nat. Sabine Niebert und Derya Bocuk hilfsbereit und geduldig unterstützt. Sie wussten mich immer wieder zu motivieren.

Robin Stelling hat sich bei der Verfassung seiner Dissertationsarbeit parallel mit der Wirkung des Niclosamids auf humane Pankreaskarzinomzelllinien beschäftigt. Wir konnten uns ergänzen, standen uns bei und haben uns immer wieder Mut zugesprochen.

Das persönliche und freundschaftliche Miteinander schaffte eine unverwechselbare Arbeitsatmosphäre im Team.

Zum Schluss bedanke ich mich bei all meinen Freunden und natürlich bei meiner Familie. Explizit möchte ich meine Eltern Ursel und Manfred Monin sowie meine Großmutter Hanna Redicker nennen. Ohne sie wäre mein bisheriger Lebensweg wohl gänzlich anders verlaufen. Insbesondere mein Humanmedizinstudium sowie die Anfertigung der Arbeit in dieser Form wären ohne ihre vielschichtigen Unterstützungen nicht möglich gewesen. 


\section{Lebenslauf}

Mein Name ist Malte Benedikt Monin. Ich wurde am 15. August 1987 als Sohn von Ursel-Elisabeth Monin, geb. Redicker, und Manfred Monin in Detmold geboren.

Meine Grundschulzeit verbrachte ich von 1994 bis 1998 an der Kusselberg-Grundschule in Detmold. Anschließend besuchte ich das Stadtgymnasium Detmold. Meine Schulausbildung schloss ich dort 2007 mit dem Erwerb der Allgemeinen Hochschulreife (Gesamtnote 1,6) ab.

Nach Absolvierung meines Wehrersatzdienstes in der Rose Klinik für onkologische Rehabilitation in Horn-Bad Meinberg nahm ich zum Sommersemester 2008 mein Studium der Humanmedizin an der Georg-August-Universität in Göttingen auf. 2010 legte ich den Ersten Abschnitt der Ärztlichen Prüfung mit der Gesamtnote - gut - ab. Das Praktische Jahr führte mich zunächst an die University of Winnipeg in Kanada (Fachbereiche: Allgemeine Innere Medizin, Pulmonologie, Nephrologie, Kardiologie). Danach wechselte ich an die Universitätsmedizin Göttingen in die Klinik für Hämatologie und Onkologie. Einblicke in die Allgemein-, Viszeral- und Thoraxchirurgie sowie Unfallchirurgie und Orthopädie bekam ich am Klinikum Lüneburg. Schließlich belegte ich mein Wahltertial Neurologie am Sankt Bernward Krankenhaus in Hildesheim. Mit dem Zweiten Abschnitt der Ärztlichen Prüfung (Gesamtnote: sehr gut) schloss ich mein Studium im Dezember 2014 erfolgreich ab.

2011 begann ich in der Abteilung für Allgemein-, Viszeral- und Kinderchirurgie der Universitätsmedizin Göttingen in der Arbeitsgruppe von Frau Prof. Dr. med. Sarah König mit der Datenerhebung für diese Dissertation. Die Wahl des Dissertationsthemas ist in meinem Interesse an onkologischen Fragestellungen begründet. Gerade die kolorektale Karzinogenese stellt für mich aufgrund der mittlerweile weitgehend entschlüsselten histologischen und molekularen Veränderungsprozesse ein Modell dar, aus dem man Rückschlüsse für die Entwicklung anderer Neoplasien ziehen kann. Verbunden damit ist die Hoffnung, hierdurch neue Therapiestrategien entwickeln zu können. Einen Ansatz in diese Richtung liefert die vorliegende Arbeit.

Seit April 2015 lebe ich in Hannover und arbeite im Sankt Bernward Krankenhaus in Hildesheim als Assistenzarzt in der Klinik für Neurologie und klinische Neurophysiologie. 